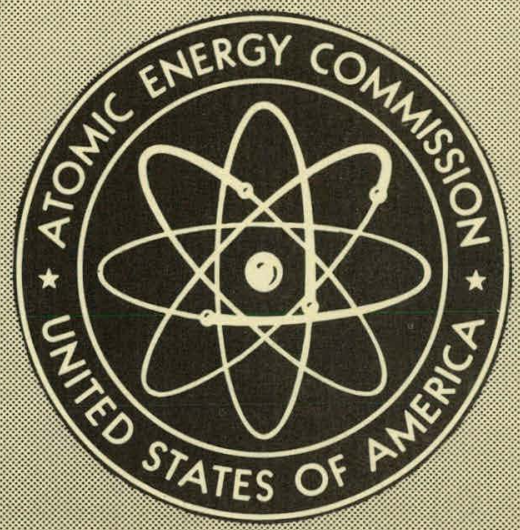

IS-300

CHEMISTRY

SOME PHYSICAL AND CHEMICAL PROPERTIES OF SCANDIUM AND THE RARE EARTHS

By

Maynard Allyn Hiller

J. E. Powell

July 1959

Ames Laboratory

Iowa State University

Ames, Iowa 


\section{DISCLAIMER}

This report was prepared as an account of work sponsored by an agency of the United States Government. Neither the United States Government nor any agency Thereof, nor any of their employees, makes any warranty, express or implied, or assumes any legal liability or responsibility for the accuracy, completeness, or usefulness of any information, apparatus, product, or process disclosed, or represents that its use would not infringe privately owned rights. Reference herein to any specific commercial product, process, or service by trade name, trademark, manufacturer, or otherwise does not necessarily constitute or imply its endorsement, recommendation, or favoring by the United States Government or any agency thereof. The views and opinions of authors expressed herein do not necessarily state or reflect those of the United States Government or any agency thereof. 


\section{DISCLAIMER}

Portions of this document may be illegible in electronic image products. Images are produced from the best available original document. 
F. H. Spedding, Director, Ames Laboratory.

Work performed under Contract No. W-7405-Eng-82.

\section{LEGAL NOTICE}

This report was prepared as an account of Government sponsored work. Neither the United States, nor the Commission, nor any person acting on behalf of the Commission:

A. Makes any warranty or representation, expressed or implied, with respect to the accuracy, completeness, or usefulness of the information contained in this report, or that the use of any information, apparatus, method, $\mathrm{or}$ process disclosed in this report may not infringe privately owned rights; or

B. Assumes any liabilities with respect to the use of, or for damages resulting from the use of any intormation, apparatus, method, or process disclused in this 1 epurt.

As used in the above, "person aelling un belalf of the Cummission" includes any $\mathrm{cm}$ ployee or contractor of the Commission, or employee of such contractor, to the extent that such employee or contractor of the Commission, or employee of such contractor prepares, disseminates, or provides access to, any information pursuant to his employment or contract with the Commission, or his employment with such contractor.

Printed in USA. Price $\$ 1.75$. Available from the Office of Technical Services, Department of Commerce, Washington 25, D. C. 


\section{PAGES 1 to 2 WERE INTENTIONALLY LEFT BLANK}




\title{
SOME PHYSICAL AND CHEMICAL PROPERTIES OF SCANDIUM AND THE RARE EARTHS*
}

\author{
Maynard Allyn Hiller and J. E. Powell
}

\begin{abstract}
Conductances, densities, partial molal volumes, solubilities, and transference numbers were measured for scandium chloride, nitrate, and perchlorate.

The stability constants of the chelates formed by the rare earths and scandium with $\operatorname{ME}\left(1,2\right.$-bis-[2-di(carboxymethyl)-aminoethoxy]ethane) and $\mathrm{DE}\left(2,2^{\prime}\right.$-bis-[di (carboxymethyl) amino]diethyl ether) were measured polarographically. In addition, the stability constants of the scandium chelates of HEDTA ( $\mathrm{N}^{\prime}$-hydroxyethyl)-ethylenediamine- $\mathrm{N}, \mathrm{N}, \mathrm{N}^{\prime}$-triacetic acid), EDTA-(ethylenediamine-N, N, $\mathrm{N}^{\prime}, \mathrm{N}^{\prime}$-tetraacetic acid), DCTA (1,2-diaminocyclohexane-N, N, $\mathrm{N}^{\prime}, \mathrm{N}^{\prime}$-tetraacetic acid), and DETPA ((carboxymethyl)-bis-[2-di-(carboxymethyl)aminoethyl] amine) were also measured.

Due to hydrolysis and formation of polymeric hydroxycomplexes, the conductance data could not be used to obtain an answer for the ionic conductance of scandium(III) at infinite dilution. As was expected, the equivalent conductances of the scandium solutions were higher than the rare-earth series.

The transference number data did not suffer so badly from hydrolysis errors as did the conductances since the transference number determinations were limited to higher concentrations in order to get a visible boundary by the moving boundary method. However, even so, there was an appreciable amount of hydrolysis even in the most concentrated solutions.

Formation constants need to be known accurately for every possible. species in solution before the cortribution of individual species to the conductance and transference data can be determined.

When the data were corrected for the conductance due to hydrogen ion, the equivalent conductance was observed to decrease in very dilute solutions. This was to be expected since the $\mathrm{Sc}(\mathrm{OH})^{++}, \mathrm{Sc}(\mathrm{OH})_{2}^{+}$, and $\mathrm{Sc}\left[(\mathrm{OH})_{2} \mathrm{Sc}\right]_{n}(3+\mathrm{n})^{+}$species would certainly make a smaller contribution to the total conductance than scandium(III) due to their greater size and lesser charge unit weight.

The stability constant data indicate that separation of the rare earths in the middle of the series would be quite poor with either ME or DE as ion-exchange eluants. With all six chelating agents measured, scandium would precede the rare earths in the elution sequence as evidenced by the stability constant values.
\end{abstract}

* This report is based on a $\mathrm{Ph}$. D. thesis by Maynard Allyn Hiller submitted July, 1959, to lowa State University, Ames, Iowa. This work was done under contract with the Atomic Energy Commission: 


\section{THIS PAGE}

\section{WAS INTENTIONALLY LEFT BLANK}


GENERAL INTRODUCTION

EVOLUTION OF, AND INTRODUCTION TO, THE IONIC INTERACTION THEORY 2

CONDUCTANCES $\quad 3$

Introduction and Theory .

History of the Method $\quad 5$

Experimental $\quad 7$

Preparation of materials

Apparatus $\quad \cdot \quad \cdot \quad 9$

Procedure $\quad 11$

Results $\quad 12$

Discussion of Data $\quad 21$

DENSITIES AND PARTIAL MOLAL VOLUMES $\quad 26$

Introduction $\quad 26$

Experimental $\quad 26$

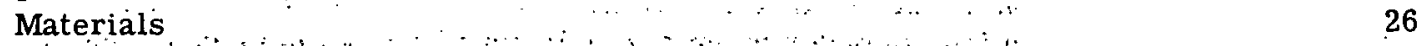

Apparatus $\quad 26$

$\begin{array}{ll}\text { Procedure and results } & 26\end{array}$

TRANSFERENCE NUMBERS 29

Introduction $\quad \cdot \quad 29$

History of Transference Number Measurements $\quad 32$

Experimental $\quad \cdots \cdots \cdots$

Materials $\quad 35$

Apparatus $\quad \cdot \quad \cdot 35$

Procedure $\quad 38$

Results $\quad$. 39

Discussion of Results $\quad 44$

SOLUBILITIES

$\begin{array}{ll}\text { Introduction } & 44\end{array}$

Experimental $\quad$ - 44

Apparatus $\quad$. $\quad 44$

Materials $\quad$. 44

Procedure $\quad . \quad . \quad 44$

$\begin{array}{lll}\text { Results } & 45\end{array}$

$\begin{array}{ll}\text { Discussion } & 45\end{array}$ 
STABILITY CONSTTANTS

Introduction $\quad 45$

Experimental $\quad 49$

Materials $\quad \cdot \quad 49$

Apparatus. $\quad 49$

Procedure $\quad 50$

Discussion $\quad 57$

LITERATURE CITED 


\section{GENERAL INTRODUCTION}

The Debye-Hückel concept of electrolytic solutions has been successful in explaining the deviations from ideal behavior of extremely dilute solution. (1). Simplifying assumptions in both the model and the mathematics employed in the theory limit applicability of the equations to solutions of relatively low concentration.

There is a need for experimental evidence derived from electrochemical measurements such as conductance, and transference, in order to correlate the various properties of solutions with their dependence on concentration. For several years, the personnel of the Ames Laboratory have been engaged in such measurements on the rare-earth salts.

Spedding, Porter and Wright $(2,3,4)$ started the investigations by measuring conductances, transference numbers, and activity coefficients by means of e.m.f.'s of concentration cells with transference for some of the rare-earth chlorides. Continuing the study, Yaffe (5) measured the same three properties for some of the bromides; Dye (6) measured more of the chlorides; Jaffe (7) determined the solubilities, conductances, and densities for some of the sulfates, as well as conductances and transference numbers for some of the perchlorates and nitrates (8). The most recent investigators in the field were Heiser (9) who worked on conductances, transference numbers, and activity coefficients from isopiestic comparisons for more of the nitrates and Saeger (10) who currently is engaged in conductance measurements on very concentrated solutions of several of the chlorides.

As a part of the over-all program, Ayers (11) obtained densities and partial molal volumes by a magnetic float method. Atkinson (12) measured molal compressibilities by ultrasonic interferometry and obtained an idea of the degree of hydration from these data.

Calorimetric measurements of heats of solution of rare-earth metals and salts in water and hydrochloric acid were carried out by Miller $(13,14)$, F'lynn $(15,16)$, Naumann (17), and Eberts (18).

The rare earths are ideally suited for electrochemical measurements since they are moderately basic and show little tendency to hydrolyze or to form complexes with strongly acid anions.

The rare-earth elements together with yttrium are particularly valuable for studies of electrolytic solutions for another reason. In the rare-earth series, the inner $4 \mathrm{f}$ shell of electrons is being filled while the outer electron shells are, for the most part, filled to the same degree for the entire series. The inclusion of yttrium allows one to observe the effect of removing whole shells of electrons, thus changing the effective nuclear field strength.

Scandium shares the distinction with the rare earths and yttrium of being another member of the group having completed outer shells while also possessing incomplete inner shells. The three valency electrons, commun to all, are tied up with the negative ions when the salts ionize. It is the leading element in the first transition series. However, electrochemical data for aqueous scandium solutions are not as easy to interpret as rare-earth data since scandium is weakly basic and its solutions exhibit extensive hydrolysis.

When a supply of very pure scandium oxide became available as a result of methods developed at the Ames Laboratory (19), it was decided to add to the collection of thermodynamic and electrochemical data which had been accumulated for the rare earths and yttrium by measuring some of the same properties for scandium.

It was the intent of this report, then, to measure the conductance of some nf the simple scandium salts, the transference numbers with the necessary accompanying partial molal vol- 
umes and densities, the stability constants with several organic chelating agents, and the solubility of some of the simple salts. It was known that the hydrolysis and subsequent polymerization of scandium would complicate any attempt to interpret electrochemical data quantitatively. Primarily then, the work included in this report on conductance and transference measurements was intended to be mainly a preliminary survey of the field.

The measurement of the stability constants of scandium chelates led to the measurement of constants for the rare-earth complexes formed with two new chelating agents. This work was performed as an alternate route to the determination of the scandium stability constants, as well as to allow a comparison of the behavior of scandium with that of the rare earths.

Thus, this report includes work which is, at present, only a preliminary investigation in the electrochemical field (conductances and transference numbers of aqueous scandium solutions) as well as other work which is of fundamental importance in the separation of the rare earths (measurement of the stability constants of complexes of scandium, yttrium, and the rare earths with 1,2-bis-[2-di (carboxymethyl)aminoethoxy]ethane and 2,2' -bis-[di(carboxymethyl) amino] diethyl ether. The stability constants for the scandium complexes with ethylenediamine$N, N, N^{\prime}, N^{\prime}$-tetraacetic acid, $N^{\prime}$-(hydroxyethyl)-ethylenediamine- $N, N, N^{\prime}$-triacetic acid, 1,2diaminocyclohexane-N,N, $N^{\prime}, N^{\prime}$-tetraacetic acid, and (carboxymethyl)-bis -[2-di -(carboxymethyl) aminoethyl| amine were also measured.

\section{EVOLUTION OF, AND INTRODUCTION TO, THE IONIC INTERACTION THEORY}

It was recognized by the early workers in solution chemistry that measurement of colligative properties of electrolytes such as boiling point elevation, freezing point depression, and osmotic pressure showed a definite deviation from ideal behavior. The number of particles in solution was greater than indicated by the molecular formula of the solute.

Modern electrolytic solution theory assumes solutions of electrolytes contain charged entities, commonly referred to as ions, which are in exact electrical balance. Arrhenius first advanced such an idea in 1887 (20). He assumed that the concentration dependence of such properties as equivalent conductance was due to incomplete dissociation and proposed that $\alpha$, the degree of dissociation, was given by

$$
\alpha=\frac{\Lambda}{\Lambda_{0}}
$$

where $\Lambda_{n}$ is the equivalent conductance at infinite dilution. Ionic mobility was assumed to be independent of concentration.

Some parts of the Arrhenius' theory began to be disproved after 1900. Much data pointed toward the idea of complete dissociation and the observed variation of the transference number with concentration cast doubts on the assumption of mobility being independent of concentration.

Modern thinking advances the idea that little association occurs in solutions of strong electrolytes. This concept is proved correct by the striking success of the Debye-Hückel llieory in predicting behavior of strong electrolytes in dilute aqueous solutions.

van't Hoff (21) introduced in empirical factor, i, into the gas law equation when applied to the osmotic pressure of electrolytic solutions. This enabled him to fit the equation to the data exactly. The van't Hoff factor was found to be equal to the ratio of the number of molecular particles actually present to the number which would have been in solution had no dissociation occurred. The degree of disšociation as calculated from van't Hoff's factur and the Arrherius theory agreed very well for weak electrolytes. This supported the idea of ionic dissociation.

The concept of incomplete dissociation did not, however, explain the behavior of strong electrolytes. The proposal naturally followed, then, that strong electrolytes were completely dissociated in aqueous solutions. If the solution of a strong electrolyte were looked upon as a collection of small charged spheres in a medium of given dielectric constant, the deviations from ideal behavior could be looked upon as due to the interactions of these charged spheres.

The effect of coulombic forces on the ions in solution was recognized by Van Laar (22) who pointed out that coulombic forces between the ions should produce anomalous effects in osmotic pressure, conductance, and other properties. 
In 1904, Noyes (23) studied the spectra of solutions of colored strong electrolytes. His conclusions were that the salts were completely dissociated even in concentrated solutions.

Sutherland (24), in 1907, made an attempt as calculating the magnitude of the effect of the coulombic forces on the properties of an ionic solution. His calculations were only approximate but did show that coulombic forces between ions could produce the observed decrease in conductance with concentration.

Hertz (25) and Ghosh (26) attempted the mathematical treatment of interionic attraction, but the basis of their treatments proved to be inadequate. Milner (27), however, developed a mathematical theory which was essentially correct. He treated the problem by statistical methods and graphical solutions, but the mathematics proved to be too cumbersome to be practical. He was able to show, however, that at low concentrations, the deviations from ideal behavior should be proportional to the square root of the concentration.

In 1923, Debye and Hückel (1) developed a method for the integration of Milner's equations which resulted in simplification of the method and led to very successful interpretations of conductances, activity coefficients, transference numbers, and various partial molar quantities. The basic assumption for their work had been previously proposed by Bjerrum in 1909 (28). He suggested that typical strong electrolytes are completely dissociated in dilute aqueous solutions and deviation of the properties of such solutions from ideality is due to the electrostatic field of force due to the ionic charges. The magnitude of such deviations is determined primarily by concentrations and charges of the ions.

Some of the people who have concerned themselves with the statistical basis of the DebyeHuckel theory are Kramers (29), Fowler (30), Fowler and Guggenheim (31), Onsager (32), Kirkwood (33), and Halpern (34).

The important assumptions of the Debye-Huckel theory were:

1. All deviations from ideal behavior in moderately dilute solutions of electrolytes may be attributed to the coulombic interactions of the charged ions. Because electrical charges of unlike sign attract and those of like sign repel, a given ion will be surrounded by an ionic atmosphere in which there are, on the average, more ions of an opposite sign than those of like sign.

2. The solvent medium is assumed to be continuous with a constant dielectric constant.

3. The time-average charge distribution is such that the Boltzmann distribution factor is applicable to the ions.

4. The Poisson equation is valid for systems of ions in a solvent.

5. The solution of the potential equation is effected by expansion of the Boltzmann exponential expression and, since the net electrostatic potential in the atmosphere of any ion is small, the series converges rapidly and higher terms may be neglected. The solution of the equation gives the electrostatic potential in the neighborhood of the reference ion.

The development of the theory will not be included hére since Glasstone (35) and Harned and Owen (36) develop the theory in great detail in their monumental texts.

Suffice it to say that expressions for the activity coefficient, conductance, and transference number arise from the theory and have been shown on numerous occasions in the past to render a true picture of the experimental data at infinite dilutions.

\section{CONDUCTANCES}

Introduction and Theory

Conductance of electrolytic solutions is due to movement of the ions under the influence of an impressed electric field. Each individual ion carries a characteristic portion of the current.

A few fundamental definitions of quantities dealing with conductance measurements are:

1. The resistance, $R$, of a conductor is that property which converts electrical energy to heat. The resistance of a homogeneous medium of uniform cross-sectional area is:

$$
R=\Gamma \frac{1}{A}
$$


where $A$ is the cross-sectional area, $l$ is the length, and $\Gamma$ is the specific resistance. The specific resistance is the resistance between two opposite sides of a unit cube of the substance.

2. The conductance, $K$, of a conductor is equal to the reciprocal of the resistance, $R$.

3. The specific conductance, $L$, is equal to the reciprocal of the specific resistance, $l / \Gamma$, and is a characteristic property of the conductor.

4. The equivalent conductance, $\Lambda$, is related to the specific conductance, $L$, by

$$
\Lambda=\frac{1000 \mathrm{~L}}{\mathrm{C}}
$$

where $\mathrm{C}$ is the concentration in equivalents per liter. The equivalent conductance is the conductance of a solution containing one gram equivalent per liter when measured with parallel electrodes one centimeter apart. The equivalent conductance is made up of contributions from each ion such that

$$
\Lambda=\sum_{j=1}^{S} \lambda_{j} .
$$

$\lambda_{j}$ is related to the mobility of the ion, $u_{j}$, by the relidlunshly

$$
\lambda_{\mathrm{j}}=96,500 \mathrm{u}_{\underline{j}}
$$
meter.

The mobility of an ion, $\mathfrak{u}_{j}$, is its velocity under a potential gradient of one volt per centi-

An isolated ion has a definite mobility, $u_{j}^{0}$, in the absence of all other ions which is characteristic of the ion at constant temperature, pressure, and solvent, and depends on the ionic size and the tendency of the ion to carry solvent molecules with it through the solution.

Theoretical treatments of conductances allow the mobility at infinite dilution to be an empirical constant which can be determined from experimental data at infinite dilution.

Experimentally the mobility of an ion is found to be a function of concentration. Onsager (37) treated this phenomenon by applying an extension of the interionic attraction theory to conductance and obtained an expression for the equivalent conductance of an ionic constituent in a binary electrolyte.

$$
\lambda=\lambda_{0}-\left[\frac{0.9834 \times 10^{6}}{(\mathrm{DT})^{3 / 2}} \omega \lambda_{0}+\frac{28.94 \mathrm{Z}_{\mathrm{i}}}{\eta(\mathrm{DT})^{1 / 2}}\right]\left[\left(\mathrm{Z}_{+}+\mathrm{Z}_{-}\right) \mathrm{C}\right]^{1 / 2}
$$

where $\mathrm{C}$ is the concentration in equivalents of solute per liter, $\mathrm{D}$ is the dielectric constant, $\eta$ is the viscosity of the solvent, and $\mathrm{T}$ is the absolute temperature.

$$
\omega=Z_{+} Z_{-} \frac{2 q}{1+(q)^{1 / 2}}
$$

and

$$
u-\frac{\mathrm{Z}_{+} \mathrm{Z}_{-}\left(\lambda_{0}^{+}+\lambda_{0}^{-}\right)}{\left(\mathrm{Z}_{+}+\mathrm{Z}_{-}\right)\left(\mathrm{Z}_{+} \lambda_{0}^{-}+\mathrm{Z}_{-} \lambda_{0}^{+}\right)}
$$

where $\lambda_{0}^{+}$and $\lambda_{0}^{-}$are the limiting equivalent conductances, and $z_{+}$and $z_{-}$are the valences of the positive and negative ions, respectively.

The first bracketed term of the equation for the equivalent conductance of an ionic constituent in a binary electrolyte accounts for the time of relaxation effect and the second for the electrophoretic effect. Onsager postulated these two effects to account for the influence of the ionic atmosphere on the motion of the central ion. The basic ideas behind the two effects are:

1. The time of relaxation effect occurs since, around a selected ion, the atmosphere has spherical symmetry. When the ion is suddenly moved, the ionic atmosphere tends to move with it but is not able to adjust to the new position instantaneously. This results in an asymmetrical atmosphere, or dipole, with the central ion, which will exert an electrostatic attraction in the opposite direction to which the ion is moving. This, of course, results in a partial cancellation of the field, and hence, a slowing down of the ion's movement. For a steadily moving ion, a permanent distortion is effected. 
2. The electrophoretic effect arises as a consequence of the ionic atmosphere that surrounds the ion. When a potential gradient is impressed across a solution, a given ion tends to move with a certain velocity in the direction of the field, superimposed on the thermal motion. This velocity is related to the ion's limiting mobility. However, the ionic atmosphere, being of opposite charge, will tend to move in a direction opposite to that taken by the ion. This motion imparts energy to the solvent molecules through which the central ion is moving and the net velocity of the central ion is less than would be expected if the solvent molecules were stationary.

History of the Method

Several reviews of the history of conductance measurements $(38,39,40)$ are available in the literature.

Kohlrausch (41) made what were probably the first accurate measurements of electrolytic conductances in 1868.

Measurements of conductance were made prior to Kohlrausch's work but they employed D. C. methods such as were used to measure the resistance of solids $(42,43,44)$. Such methods allowed the formation of concentration gradients in the neighborhood of the electrodes which resulted in polarization and non-reproducibility, and, as a result, these early experiments gave erratic data.

Kohlrausch used an alternating current of 1000 cycles per second and measured the resistances on a modified Wheatstone bridge, using a telephone received as a null indicator. He viewed the reaction at the electrodes as the adsorption of oxygen and hydrogen which would redissolve in the solution if the polarity were reversed $(45,46)$. The effective capacitance of the cell was compensated by connecting a condenser in parallel with the resistance on the other arm of the bridge (47). To aid the reversible adsorption of hydrogen and oxygen at the electrodes, he plated the platinum electrodes with platinum black (48) in order to increase their surface. In addition, the cell was designed so that the measured resistance would be high since Kohlrausch and Holborn $(49$, p. 10) found polarization effects were negligible if the resistance was greater than fifty divided by the area of the electrodes. The cell constant was obtained by actual measurement of the cell dimensions (50). After determining the cell constant, seven standard reference solutions were prepared as secondary standards and their conductances measured. He also realized the importance of temperature control to accurate conductance measurements (51). The work was so carefully done that the data on potassium chloride are accepted as standard even today.

Improvements in conductance measurements since Kohlrausch's first work have been limited to better design of equipment rather than basic changes in methods of measurement. In 1913, Washburn and Bell (52) used a high-frequency generator as a current source and Washburn (53), in 1912, investigated the design of cells and characteristics of telephone receivers and other null indicators.

Taylor and Acree (54) made a study of alternating current sources in 1916 . They found that a pure sine wave current was desirable to prevent unsymmetrical electrolysis at the electrodes and to annul the influence of harmonics in the detector. They also found that the resistance of solutions is independent of the voltage providing the voltage is low enough to avoid heating effects in the.cells.

In 19.19, Hall and Adams (55) were the first to use an electronic oscillator as a current sourco and alco an amplificr to increase the sensitivity of lie medsurements.

Some of the people who concerned themselves with conductivity bridge design were Washburn and Bell (52), Taylor and Acree (54), Jones and Josephs. (56), Jones and Bollinger (57, 58, $59)$, Shedlovsky $(60,61)$, and Jones and Christian (62).

A description of the conductance equipment available from Leeds and Northrup Co. has been published by Dike (63).

Use of an amplifier between the bridge and detector was introduced by Hall and Adams in 1919 (55). In 1929, Jones and Bollinger (57) made a study of amplification problems.

The telephone receiver has been the classic null detector for several years. In 1917 Washburn and Parker (64) made some studies concerning the sensitivity of the telephone re-1. 
ceiver. In 1952 Spedding, Porter, and Wright (2) replaced the telephone receiver with an oscilloscope and thereby increased the sensitivity of the measurements immensely.

Taylor and Acree (54) experimented with the design of cells. They observed that the cell behaved as if it were a resistance in series with a condenser when used with alternating current. They found that the cell capacitance could be balanced out by use of a condenser in parallel or in series with the variable resistance arm of the bridge, or with an inductance in series with the cell. Resistance of solutions decreased slightly with an increase in frequency of the current used. Small, bright electrodes enhanced this effect and large, platinized ones inhibited it. Taylor and Acree reasoned that the ratio of resistances for any given solution in two cells, or of two solutions in any cell, must be constant. Experimentally they found this to be true for platinized electrodes. When they determined the ratio of resistances of two solutions in a cell with platinized electrodes and the ratio for the same two solutions in a cell with bright electrodes, they found a $2 \%$ discrepancy at 60 cycles. The discrepancy varied inversely with frequency and was least when results were extrapolated to infinite frequency by use of the formula

$$
R_{\text {infiuile fieyuency }}=\mathrm{R}-\frac{\mathbf{K}^{\prime}}{\mathfrak{I}}
$$

where $R$ is the measured resistance, $f$ is the frequency in cycles per second, and $K^{\prime}$ is a constant.

In 1916 Washburn (53) presented an extensive study on the theory and design of conductivity cells. He obtained formulas for the optimum area and separation of the electrodes as functions of bridge component resistances, specific conductance of the solution being measured, accuracy desired, and other factors. In general, the lower the specific conductance being measured, the larger the electrode areas should be.

Potassium chloride is probably the best known standard for the calibration of conductivity cells. Kohlrausch (50) measured his cell dimensions physically and then measured potassium chloride as a secondary standard. Parker and Parker (65) redetermined the specific conductance of potassium chloride solutions and eliminated an inconsistency in units by defining a demal (written $1 \mathrm{D}$ ) solution as one containing one gram molecule of salt dissolved in one cubic decimeter of solution at $0^{\circ}$. This defined the volume for the standard solution in the same units as the cell dimensions.

Jones and Bradshaw (66) made new absolute measurements of the specific conductivity on solutions of the same composition as used by Parker and Parker, and Jones and Prendergast (67) reinvestigated the solutions used by Kohlrausch. The values of Jones are currently accepted as the best standards available at $0^{\circ}, 18^{\circ}$, and $25^{\circ} \mathrm{C}$. but the values vary only very slightly from those of Kohlrausch and Parker and Parker. Jones and Prendergast (67) used pure mercury as a primary standard at $0^{\circ} \mathrm{C}$. The constants for several cells were obtained and the specific conductivity of concentrated sulfuric acid was measured so that it could be used as a secondary standard.

Complete cell calibration must provide for the Parker effect (68): which is the variation of the cell constant with the measured resistance. Parker believed this effect was due to adsorption at the electrodes. Shedlovsky (69) and Jones and Bollinger (58) correctly attributed this effect to capacitance between the cell leads.

For temperature control, any arrangement which would hold the temperature to $\pm 0.01^{\circ} \mathrm{C}$. was found to be suitable. Jones and Josephs (56) point out that water is a conductor, in cumlparison to mineral oil, and since the glass cell walls can act as a dielectric in a condenser, current may be permitted to flow in the water outside the cell. This, of course, would introduce an error and, hence, mineral oil is recommended as a bath medium.

Thus, for accurate measurement of conductivities one should observe the following precautions:

1. Use a fairly high frequency (preferably above 500 cycles per second) since data at low resistances (high concentrations) were found to be effected mainly by polarization phenomena and use of high frequencies lowers polarization capacitance (58).

2. Use cells having horizontal solution compartments with vertical filling tubes and vertical cell lead compartments placed as far apart as possible to minimize cell capacitive effects. 
The cell should also be as long as possible since a shorter cell will have a relatively greater polarization error with the same solution than a longer one (58).

3. The electrodes should be heavily platinized to lower cell capacitance and minimize variation of resistance with frequency (54). The electrode areas should also be as large as is practical since, again, polarization capacitance is minimized by increasing electrode areas and, in general, the lower the specific conductance being measured, the larger the electrode areas should be for greatest accuracy $(53,58)$.

4. Use a capacitance in parallel or in series with the variable resistance arm of the bridge or an inductance in series with the cell to nullify cell capacitive effects.

5. Use a low-voltage alternating current source to avoid electrolysis at the electrodes and to avoid heating in the cell.

6. The bridge should be shielded from stray magnetic fields and the oscillator should be situated a respectable distance from the bridge and cells.

7. An oil bath fitted with a temperature control capable of $\pm 0.01^{\circ} \mathrm{C}$. is desirable.

8. The cells should be calibrated taking the Parker effect into account and then should be used only in the region where their calibration was most accurate.

9. Use of an amplifier between the bridge and the detector is recommended as well as an oscilloscope as a null indicator.

\section{EXPERIMENTAL}

\section{Preparation of Materials}

The scandium used in this research was prepared as the oxide by applying the techniques of solvent extraction and ion exchange as developed at the Ames Laboratory (70) in the treatment of thortveitite ore.

The thortveitite ore, ( $\mathrm{Sc}$, rare earths) $)_{2}-\mathrm{Si}_{2} \mathrm{O}_{7}$, was ground to a powder, ball-milied, mixed with excess ammonium bifluoride, and heated overnight at $375-400^{\circ} \mathrm{C}$. in a platinum boat. A slow stream of air removed the gaseous products. The reaction may be represented as

$$
\mathrm{M}_{2} \mathrm{O}_{3} \cdot \mathrm{SiO}_{2}+10 \mathrm{NH}_{4} \mathrm{HF}_{2}-2 \mathrm{MF}_{3}+\mathrm{SiF}_{4}+10 \mathrm{HF}+10 \mathrm{NH}_{3}+5 \mathrm{H}_{2} \mathrm{O}
$$

The resulting fluoride mixture was mixed with excess calcium metal and reduced by heating in a tantalum crucible in an inert atmospherc at $1400^{\circ} \mathrm{C}$. The reaction was

$$
2 \mathrm{MF}_{3}+3 \mathrm{Ca} \rightarrow 3 \mathrm{CaF}_{2}+2 \mathrm{M}
$$

The scandium-rare earth metal buttons prepared as just outlined were dissolved in hydrochloric acid, the solution swamned with ammunium thiocyanate, and extracted with diethyl ether according to the procedure of Fischer and Bock (71). After evaporating the ether, the residues were ignited at $800^{\circ} \mathrm{C}$. The resulting oxide was then converted to the chloride, loaded on Dowex $50-\mathrm{X} 8$ hydrogen form cation-exchange columns, and eluted with $0.018 \mathrm{M} \mathrm{N}^{\prime}$-(hydroxyethyl) ethylenediamine- $\mathrm{N}, \mathrm{N}, \mathrm{N}^{\prime}$-triacetic acid buffered to a $\mathrm{pH}$ of $7.4-7.6$ with $\mathrm{NH}_{4} \mathrm{OH}$. The material was recovered in consecutive samples as the oxide by boiling the solution dry, destroying the organic matter with nitric acid, and igniting at $800^{\circ} \mathrm{C}$.

The oxide was further purified by one or two precipltations as the oxalate. This insured remuval of iron which interferes in the solvent extraction and ion-exchange purifications probably because of poor kinetics. The purity of the resulting oxide as used in preparing the nitrate, chloride, and perchlorate was as listed in Table 1.

The salt solutions were prepared by dissolving the oxide, with heating, in the respective reagent-grade acids. Because scandium oxide is not very basic, the $\mathrm{pH}$ of the solutions resulting from the dissolution was usually about one or below. For this reason, a procedure for elevating the $\mathrm{pH}$ without introducing extraneous cations or anions was used (72). The solution that 
Table 1 - Purity of the Scandium Oxide

\begin{tabular}{|c|c|c|c|}
\hline Impurity* & Analysis & Impurity* & Analysis $\uparrow$ \\
\hline $\mathrm{Lu}$ & $₹ 0.005$ & $\mathrm{Cu}$ & Very faint trace \\
\hline $\mathrm{Yb}$ & $\approx 0.005$ & $\mathrm{Hf}$ & Very faint trace \\
\hline $\mathrm{Tm}$ & $₹ 0.005$ & $\mathrm{Sn}$ & Very faint trace \\
\hline $\operatorname{Er}$ & $\neq 0.005$ & $\mathrm{Mg}$ & Very faint trace \\
\hline $\mathrm{Y}$ & d. $<0.01$ & $\mathrm{Zn}$ & Not detected \\
\hline $\mathrm{Ca}$ & Very weak & $\mathrm{Ti}$ & Not detected \\
\hline $\mathrm{Na}$ & Very weak & $\mathrm{Zr}$ & Not detected \\
\hline $\mathrm{Be}$ & Very weak & $\mathrm{Pb}$ & Not detected \\
\hline $\mathrm{Si}$ & Trace & $\mathrm{Al}$ & Not detceted \\
\hline $\mathrm{Fe}$ & Very faint trace & & \\
\hline
\end{tabular}

\footnotetext{
* The spectrum was examined for thirty-one other common elements a.s well as the other rare earths, but none were detected. Tho onor listed abovè are thuse mest oommunly asanciated with suandium.

† All analyses were made by emission spectrography. ¿ the element if present was below the 0.005 limit and $\mathrm{d}<$ means detected but less than.
}

was desired was onc that would result if a pure sample of the anhydrous salt were placed in water and allowed to come to equilibrium

$$
\mathrm{Sc}^{+3}+\mathrm{H}_{2} \mathrm{O} \rightleftharpoons \mathrm{Sc}(\mathrm{OH})^{+2}+\mathrm{H}^{+} .
$$

While in the case of the chloride, the anhydrous salt could have been prepared and then dissolved, it is simpler to titrate the solution to the equivalence point. To obtain such a titration curve, the $\mathrm{pH}$ must be above the equivalence $\mathrm{pH}$ at the start of the titration.

Hydroxide form Dowex 1-X8 anion resin was prepared by passage of carbonate-free base over a column of the resin until no more chloride was detected in the effluent solution. The carhnnate-free base was prepared by the procedure of Powell and Hiller (73). Addition of this hydroxide-torm resiln lo the ocandium silulluis raiboc the $\mathrm{pH}$ since the equilibrium for the reactions

$$
\begin{aligned}
& \overline{\mathrm{ROH}}+\mathrm{A}^{-} \rightleftharpoons \overline{\mathrm{R}} \mathrm{A}+\mathrm{OH}^{-} \\
& \mathrm{M}^{+\mathrm{n}}+\mathrm{OH}^{-} \rightleftharpoons \mathrm{MOH}^{(\mathrm{n}-1)+}
\end{aligned}
$$

favors the right hand side where $\bar{R}$ is the insoluble resin cation, $M$ is (lie anlt cation, and $A$ is the anion of the desired bull. Titration of an aliquot with the acid corresponding to the anion of the salt then gives

$$
\mathrm{MOH}^{(\mathrm{n}-1)^{+}}+(\mathrm{n}-1) \mathrm{A}^{-} \rightleftharpoons \mathrm{M}^{+\mathrm{n}}+\mathrm{nA} \mathrm{A}^{-}+\mathrm{H}_{2} \mathrm{O} \text {. }
$$

A Beckman, model $\mathrm{G}, \mathrm{pH}$ meter was used and the equivalence $\mathrm{pH}$ read from a graph of $\Delta \mathrm{ph} / \Delta$ milliliter vs. the average number of milliliters of acid used. The aliquot was returned to the stock solution which was then adjusted to the indicated equivalence $\mathrm{pH}$ and boiled to help break up any collnidal material suspended in solution. The nitrate, however, could not be boiled since the basic nitrate would precipitate upon boiling. Thereforc, it was heated for two days with heat lamps while keeping below the boiling point. The solutions were then cooled and, after redilution to the same total volume they occupied before boiling, their $\mathrm{pH}$ was checked. If it had changed, the titration procedure was repeated until the $\mathrm{pH}$ remained constant after boiling. Solutions prepared in this manner were stable indefinitely. 
The resulting stock solution was then analyzed by evaporating aliquots under a heat lamp and treating the solid chloride and perchlorate residues with a few drops of concentrated nitric acid to avoid formation of oxy-compounds which might not ignite easily to the oxide. Weighing as the oxide, $\mathrm{Sc}_{2} \mathrm{O}_{3}$, followed ignition at $800^{\circ} \mathrm{C}$.

The scandium chloride stock solution was analyzed for chloride ion gravimetrically by precipitating the silver salt, filtering on sintered glass filters, drying at $120^{\circ} \mathrm{C}$, and weighing as silver chloride. The results showed an empirical formula of $\mathrm{ScCl}_{3.008}$. Thus, it was felt that the titration-curve method was adequate for the preparation of equivalent solutions.

An average of fifteen dilutions was made from each stock solution using Normax or calibrated glassware and conductivity water. The conductivity water was made by redistilling ordinary distilled water over potassium permanganate and sodium hydroxide in a block tin Barnsted conductivity still.

The potassium chloride solutions for determination of the cell constants of the conductance cells were made up by weight from twice-recrystallized reagent grade potassium chloride which was fused in a platinum boat in a nitrogen atmosphere according to the method of Pinching and Bates (74). The data of Parker and Parker (65) were used in this research since, even though their data are not recognized as the most precise, they did their work over a much wider temperature range. A value for the specific conductance of potassium chloride at $35^{\circ} \mathrm{C}$. was needed and, since the data of Parker and Parker covered the range $0^{\circ}$ to $30^{\circ}$ in $5^{\circ}$ intervals, and the plot was nearly linear, an extrapolation was made to obtain a value at $35^{\circ} \mathrm{C}$.

\section{Apparatus}

The bridge used in this research was obtained from the Leeds and Northrup Company, Philadelphia, Pennsylvania. It was a research model conductivity bridge, catalog number 4666 , as described by Dike (63).

Alternating current of 500,1000 , and 2000 cycles per second was provided by a Leeds and Northrup audio-frequency electronic oscillator, catalog number 9842 .

The signal from the bridge was amplified by a Leeds and Northrup audio-frequency, narrow-band amplifier, catalog number 9847 , which could be tuned to the same frequency as the oscillator.

A cathode-ray oscillograph, type 274-A, manufactured by the Allen B. DuMont Laboratories, Inc. was used as a detector. The horizontal section of the oscilloscope was blocked out so a vertical line was produced when the conductance bridge was out of balance and a spot when the bridge was balanced. The electronic circuit diagram is shown in Figure 1 and the block diagram of the equipment in Figure 2.

The conductance cells used in this research were of the general form recommended by Jones and Bollinger (58) from their cell design studies. A set of three cells having widely different cell constants were used so that the specific conductance of a solution could be cross checked with at least two cells and so that appropriate cells could be used to keep the measured resistance within the optimum range of the bridge. The cells were also obtained from Leeds and Northrup (catalog numbers 4911, 4914, and 4915). The electrodes of all cells were adequately platinized as shown by agreement of measurements at 1000 and 2000 cycles per second. The so-called low cell had a cylindrical vertical chamber about $3 \mathrm{~cm}$. in diameter by $6 \mathrm{~cm}$. in height with rectangular electrodes hugging opposite sides and having about a 12 square $\mathrm{cm}$. area. The medium cell had a cylindrical horizontal chamber about $2 \frac{1}{2} \mathrm{~cm}$. in diameter by $7 \mathrm{~cm}$. long with circular electrodes about $13 / 4 \mathrm{~cm}$. in diameter sealed in opposite ends. The high cell had three separate, circular, bubble-like compartments about $2 \frac{1}{4} \mathrm{~cm}$. in diameter by $1 \mathrm{~cm}$. thick, the center one opening to the filler tube, the two end ones containing the electrodes which were about $1 \frac{3}{4} \mathrm{~cm}$. in diameter as well as air escape tubes to facilitate filling. The three compartments were joined by a tube about $3 \mathrm{~cm}$. long with an inside diameter of about $1 / 2 \mathrm{~cm}$. The cell was thus about $9 \mathrm{~cm}$. long.

The constant temperature baths were controlled by microset mercury thermoregulators coupled with electronic relays made by Precision Scientific Company, Chicago, nlinois (cata$\log$ numbers 62541 and 62690 ). The relays operated 250 watt infrared heat lamps which provided heat to the baths, and the coolant pump in the case of the $15^{\circ} \mathrm{C}$. bath. The $35^{\circ} \mathrm{C}$. bath required no cooling facilities, the $25^{\circ} \mathrm{C}$. bath was cooled by a cold finger having tap water 

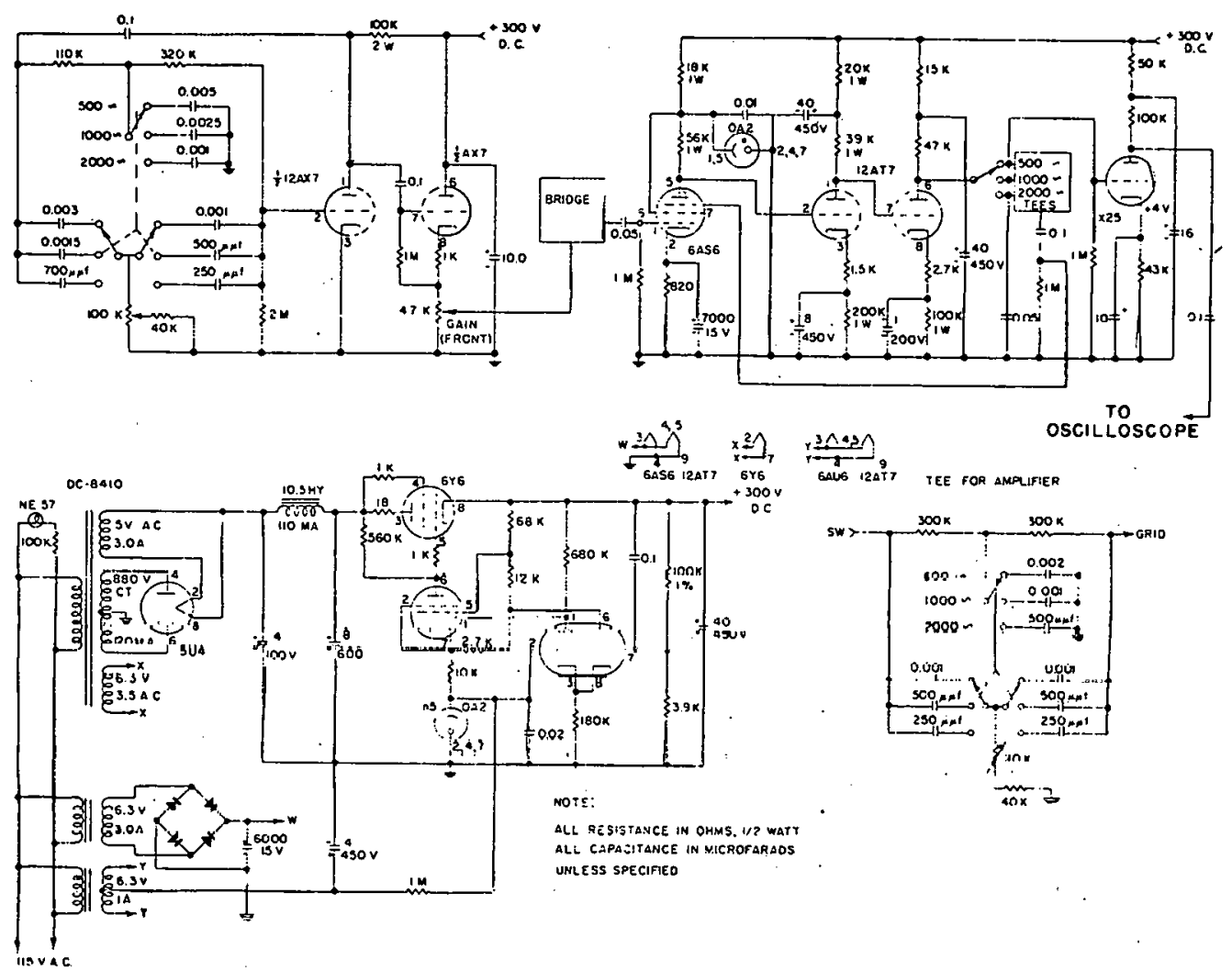

Fig. 1-The electronic circuit for the oscillator and amplifier used in the conductance measurements.

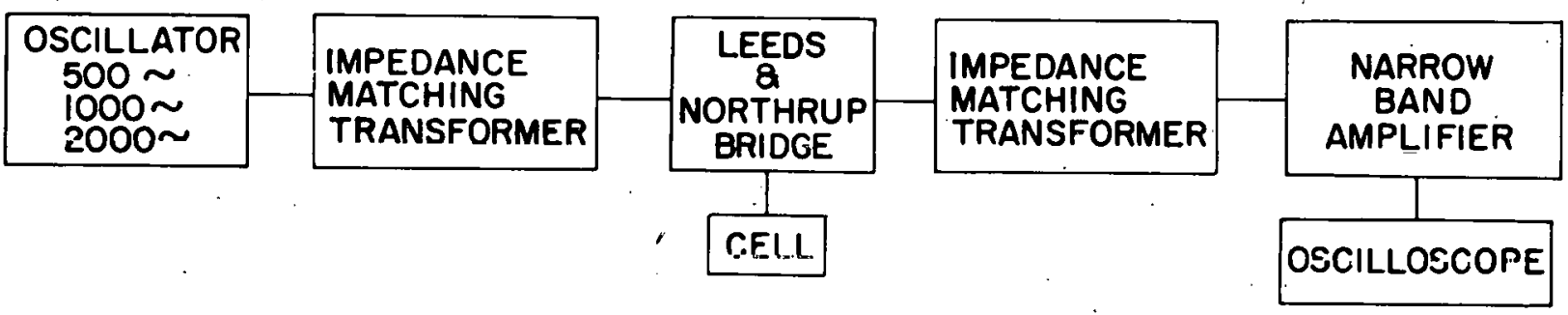

Fig. 2-Block diagram of the equipment used in conductance measurements.

circulated through it, and the $15^{\circ} \mathrm{C}$. bath was cooled by pumping $5^{\circ} \mathrm{C}$. water through a copper cooling coil buried in the bath. A second relay between the thermoregulator relay and the centrifugal coolant pump caused the operation of the pump and the infrared bulb to alternate. The $5^{\circ} \mathrm{C}$ cooling water was supplied by a refrigeration unit manufactured by the Lehigh Manufacturing Company, Lancaster, Pennsylvania. The cells, when immersed in the baths, were shielded from the infrared lamps by a metal plate, blackened on the side toward the lamp, and immersed across the center of the bath. The bath temperatures were checked periodically against a narrow-range thermometer which was calibrated by the National Bureau of Standards. The temperatures were held to within $\pm 0.02^{\circ} \mathrm{C}$.

All the baths were stirred with laboratory stirrers and were filled with mineral oil to minimize capacitance effects.

Connection of the cells to the bridge was made by means of platinum wire leads dipping into mercury compartments which were, in turn, in contact with the electrode leads. This arrangement facilitated connection and disconnection. 


\section{Procedure}

The conductivity cells were thoroughly cleaned with sulfuric acid-potassium dichromate cleaning solution and then very thoroughly rinsed with distilled water and soaked in several changes of conductivity water. Their cell constants were determined at several concentrations of standard potassium chloride solutions. The cell constant was plotted versus the measured resistance for each cell at each temperature as shown in Figure 3. When measuring the scandium solutions the appropriate cell constant was read from the plot and used at each resistance.
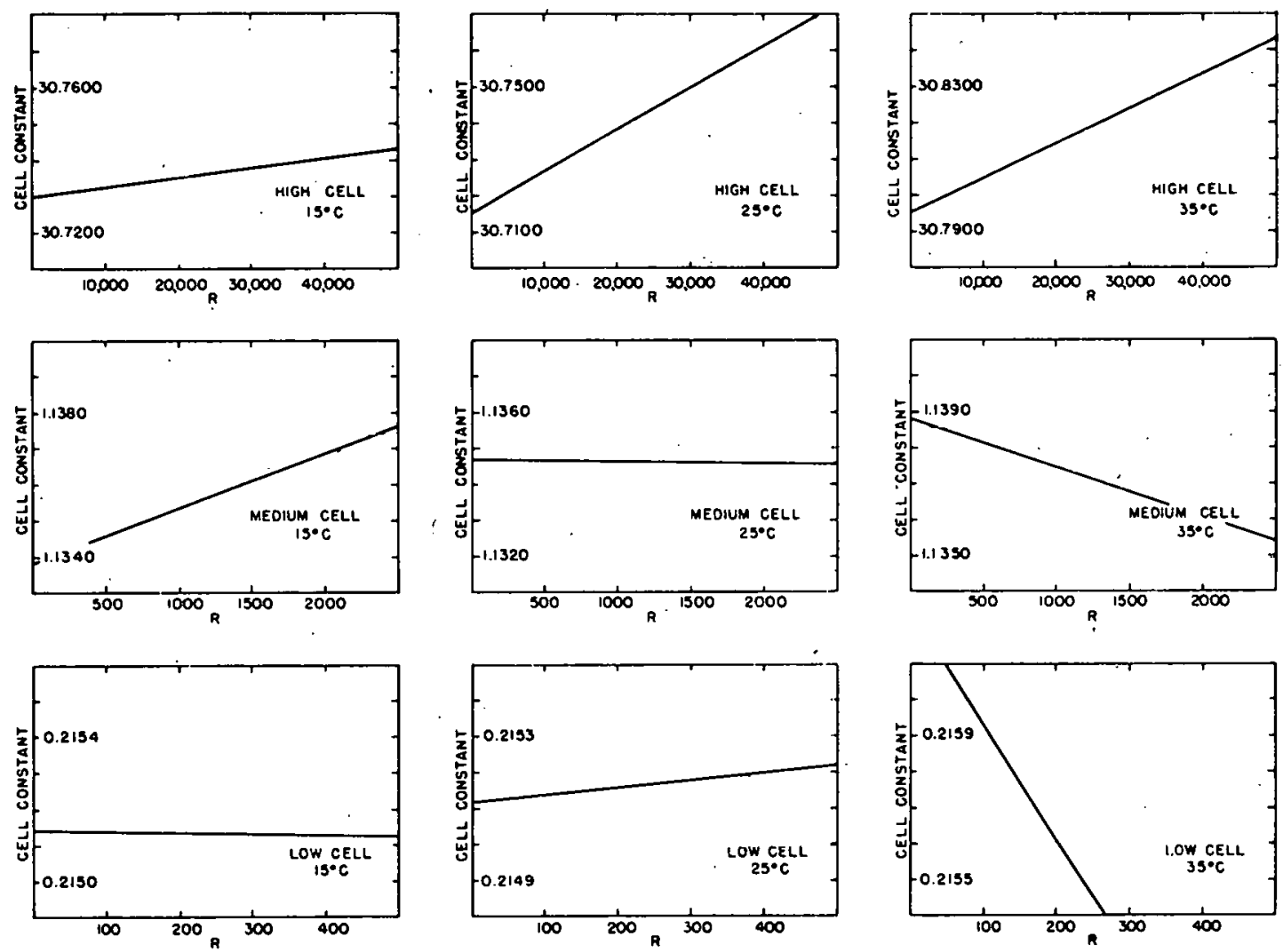

Fig. 3-Variation of cell constant with measured resistance for the high, medium, and low cells at $15^{\circ}, 25^{\circ}$, and $35^{\circ} \mathrm{C}$.

The resistance of the conductivity water used in making up the samples was also measured using the low and medium cells by shunting $30,000 \mathrm{ohms}$ in parallel with the cell. Since the true specific conductivity, $\mathrm{L}_{\mathrm{T}}$, is found by

$$
\mathrm{L}_{\mathrm{T}}=\frac{\mathbf{k}}{\mathrm{R}}-\mathrm{L}_{\mathrm{H}_{2} \mathrm{O}}=\mathrm{L}_{\mathrm{m}}-\mathrm{L}_{\mathrm{H}_{2} \mathrm{O}}
$$

where $\mathrm{L}_{\mathrm{m}}$ is lite uledsured spectfic conductivity, the conductivity of the water must be known to get, $\mathrm{k}$; the cell constant but $\mathrm{L}_{m}$ cannot be obtained without knowing the cell constant. Thus, the cell constants were obtained by successive approximations.

Readings on the potassium chloride standards as well as the scandium solutions were taken at 1000 and 2000 cycles per second and with two cells for each concentration. It was found to be unnecessary to correct the data to infinite frequency. The Taylor and Acree ratio (54) was also checked and the consistency of the cells found to be within experimental error and the limit of accuracy of dilution of the solutions. 
To avoid errors due to soaking out of salt absorbed at the electrodes, the lowest concentration solution was measured first, followed by ones of higher concentration. The cell was always rinsed at least four times with the solution to be measured.

The cells and their contents were found to come to temperature equilibrium in about 30 to 45 minutes after immersion in the bath. At least 45 minutes was allowed before readings were taken. Completeness of temperature equilibration could be followed by observation of the drift in resistance readings. An effort was made in all cases to read the resistance as soon as possible after throwing the switch to connect the cell into the circuit. In this way, heating effects in the cell were negligible.

Results

The data obtained from the measurements on the solutions were the resistances of the solutions, $R$. The calculations used to obtain the equivalent conductances of the solutions were

$$
L_{s} \equiv(k / R)-L_{I_{2} \mathrm{O}^{-}}-\mathrm{T}_{1 I^{+}}
$$

and

$$
\Lambda=\frac{1000 \mathrm{~L}_{S}}{C}
$$

where $L_{s}$ is the specific conductance of the solution due to the solute only, $k$ is the cell constant taking the Parker effect into account, $\mathrm{R}$ is the measured resistance in uhms, $\mathrm{L}_{\mathrm{H}_{2} \mathrm{O}}$ is the specific conductance of the water used in preparing the solutions, $\mathrm{L}_{\mathrm{H}^{+}}$is the specific conductance of the hydrogen ion in the solution minus the specific conductance of the hydrogen ion in the water used to prepare the solutions, and $C$ is the concentration of the solution in equivalents per liter.

The specific conductance of the hydrogen ion in the solution was calculated from its approximate concentration difference between solution and solvent as measured with a Beckman model G pH meter. The Onsager equation for the ionic specific conductivity

$$
\lambda=\lambda_{0}-\left[\frac{0.9834 \times 10^{6}}{(\mathrm{DT})^{3 / 2}} \omega \lambda_{0}+\frac{28.94 \mathrm{Z}_{\mathrm{i}}}{\eta(\mathrm{DT})^{1 / 2}}\right]\left[\left(\mathrm{Z}_{+}+\mathrm{Z}_{-}\right) \mathrm{C}\right]^{1 / 2}
$$

was used to calculate $\lambda_{H^{\prime}}$ wherc

$$
\omega=Z_{++} \cdot Z_{m} \frac{2 q}{1+(q)^{1 / 2}}
$$

and

$$
q=\frac{Z_{+} Z_{-}\left(\lambda_{0}^{+}+\lambda_{0}^{-}\right)}{\left(Z_{+}+Z_{-}\right)\left(Z_{+} \lambda_{0}^{-}+Z_{-} \lambda_{0}^{1}\right.}
$$

For uni-univalent salts or monobasic acids such as nitric, hydrochloric, and perchloric, $q=$ $1 / 2$ since $\mathrm{Z}_{+}$and $\mathrm{Z}_{-}$are both one. This in turn makes $\omega=0.5857$. Thus, the Onsager equation fur all leimperatures reduces to

$$
\lambda=\lambda_{0}-\left[\frac{0.57592 \times 10^{R} \lambda_{0}}{(\mathrm{DTT})^{3 / 2}}+\frac{28.94}{\eta(\mathrm{DT})^{1 / 2}}\right] \mathrm{C}^{1 / 2}
$$

where $C$ is the concentration in equivalents of solute per liter and $D, T, \eta$ and $\lambda_{0}$ vary with temperature. The values for $\mathrm{D}, \dot{\eta}$, and $\mathrm{T}$ are given in Table 2 .

The values for $\lambda_{0}^{+}$used in the Onsager equation were taken from Harned and Owen (36, p. 234). The values at each temperature for hydrogen ion were 300.73 at $15^{\circ} \mathrm{C}, 349.80$ at $25^{\circ} \mathrm{C}$, and 396.91 at $35^{\circ} \mathrm{C}$. Substitution of these values gave

$$
\begin{array}{ll}
\lambda_{\mathrm{H}^{+}}=300.73-31.6042 \mathrm{C} & \text { at } 15^{\circ} \mathrm{C}, \\
\lambda_{\mathrm{H}^{+}}=349.80-35.0827 \mathrm{C} & \text { at } 25^{\circ} \mathrm{C} \text {, and } \\
\lambda_{\mathrm{H}^{+}}=396.91-38.7345 \mathrm{C} & \text { at } 35^{\circ} \mathrm{C} \text { for monobasic acids. }
\end{array}
$$


Table 2-Values of the Dielectric Constant, Viscosity, and Temperature Used in the Onsager Equation

\begin{tabular}{cccc}
\hline Property & $15^{\circ} \mathrm{C}$. & $25^{\circ} \mathrm{C}$. & $35^{\circ} \mathrm{C}$. \\
\hline $\begin{array}{c}\text { Dielectric constant, } \\
\mathrm{D}, \text { in Debye units } \\
\begin{array}{c}\text { Viscosity, } \eta, \text { in } \\
\text { poise } \times 10^{3}\end{array}\end{array}$ & $82.23^{\mathrm{a}}$ & $78.54^{\mathrm{a}}$ & $75.04^{\mathrm{a}}$ \\
$\begin{array}{c}\text { Absolute temperature, } \\
\mathrm{T}^{\circ} \mathrm{K} .\end{array}$ & 288.16 & 298.16 & 308.16 \\
\hline
\end{tabular}

${ }^{\mathrm{a}}$ Reference 36, p. 161 .

${ }^{\mathrm{b}}$ Reference 75, p. 1632.

${ }^{\mathrm{c}}$ Reference 97, p. 57.

The $\lambda_{\mathrm{H}^{+}}$values calculated from the above were then converted to specific conductivities by

$$
\mathrm{L}_{\mathrm{H}^{+}}=\frac{\mathrm{C}_{\mathrm{H}^{+}} \lambda_{\mathrm{H}^{+}}}{1000}
$$

Subtraction of $\mathrm{L}_{\mathrm{H}^{+}}$and $\mathrm{L}_{\mathrm{H}_{2} \mathrm{O}}$ from the measured specific conductivities gave specific conductivities for the solute only, $L_{S}$, which were then converted to equivalent conductivities by

$$
\Lambda=\frac{1000 \mathrm{~L}_{\mathrm{S}}}{\mathrm{C}_{\mathrm{ScX}}}
$$

The corrected and uncorrected equivalent conductivity data for the three scandium salts are given in Tables 3-8 and the corresponding curves are included as. Figures 4-9. The curves in all cases immediately follow the table corresponding to them.

Table 3-Equivalent Conductances of Scandium Chloride Solutions,

\begin{tabular}{|c|c|c|c|c|c|c|}
\hline \multicolumn{3}{|c|}{ Normality $^{\mathrm{a}}$} & \multicolumn{4}{|c|}{ Equivalent conductance } \\
\hline $15^{\circ} \mathrm{C}:$ & $25^{\circ} \mathrm{C}$. & $35^{\circ} \mathrm{C}$. & & $15^{\circ} \mathrm{C}$ & $25^{\circ} \mathrm{C}$ & $35^{\circ} \mathrm{C}$. \\
\hline 0.0001165 & 0.0001163 & 0.0001159 & & 143.5 & 178.7 & 229.9 \\
\hline 0.0002331 & $0: 0002326$ & 0.0002318 & $\cdots$ & $136.9^{\prime}$ & 168.5 & 218.8 \\
\hline 0.0004663 & 0.0004653 & 0.0004637 & $\cdot$ & 129.4 & 161.8 & 205.9 \\
\hline 0.0009325 & 0.0009305 & 0.0009275 & & 121.3 & 154.3 & $195.6^{\circ}$ \\
\hline 0.001865 & 0.001861 & 0.001855 & & 114.9 & 148.6 & 186.1 \\
\hline $0: 003730$ & 0.003723 & 0.003710 & & 108.7 & 139.4 & 173.3 \\
\hline 0.007460 & 0.007445 & 0.007420 & & 102.6 & 131.1 & 162.5 \\
\hline 0.01492 & 0.01489 & $0.01484^{\circ}$ & & 96.08 & 120.7 & 150.9 \\
\hline 0.02984 & 0.02977 & 0.02969 & & 89.65 & 112.7 & 139.7 \\
\hline 0.05968 & 0.05955 & 0.05936 & & $83.49^{\circ}$ & 104.8 & 129.1 \\
\hline 0.1194 & 0.1191 & 0.1187 & & 77.29 & 96.91 & 118.7 \\
\hline 0.2388 & 0.2382 & 0.2375 & & 71.24 & 89.10 & 108.7 \\
\hline 0.4775 & ' $\quad 0.4784$ & $0.414 y$ & & 64.74 & 80.74 & 98.08 \\
\hline
\end{tabular}
Uncorrected for Hydrogen Ion Conductivity

${ }^{a}$ The densities used in calculating the normalities at other than $25^{\circ} \mathrm{C}$ can be found in the section of this report which deals with densities.

It will be noticed that the $\mathrm{pH}$ 's used in correcting the conductivity data were measured at $25^{\circ} \mathrm{C}$. The hydrogen ion concentrations from these $\mathrm{pH}$ 's were corrected for temperature and substituted in the Onsager equation to obtain the specific conductances. Essentially the equivalent conductance correction resulting from these specific conductances was the same whether 
Table 4-Equivalent Conductances of Scandium Chloride Solutions, Corrected for Hydrogen Ion Conductivity

\begin{tabular}{|c|c|c|c|c|c|c|}
\hline \multirow{2}{*}{$\mathrm{pH}^{\mathrm{a}}$} & \multicolumn{3}{|c|}{ Normality ${ }^{b}$} & \multicolumn{3}{|c|}{$\begin{array}{l}\text { Equivalent } \\
\text { conductivity }^{a}\end{array}$} \\
\hline & $15^{\circ} \mathrm{C}$. & $25^{\circ} \mathrm{C}$. & $35^{\circ} \mathrm{C}$. & $15^{\circ} \dot{C}$ & $25^{\circ} \mathrm{C}$ & $35^{\circ} \mathrm{C}$. \\
\hline 4.67 & 0.0001165 & 0.0001163 & 0.0001159 & 88.18 & 118.9 & 159.1 \\
\hline 4.52 & 0.0002331 & 0.0002326 & 0.0002318 & 98.64 & 131.5 & 168.5 \\
\hline 4.38 & 0.0004663 & 0.0004653 & 0.0004637 & 98.54 & 131.2 & 170.5 \\
\hline 4.11 & 0.0009325 & 0.0009305 & 0.0009275 & 96.53 & 127.7 & 163.2 \\
\hline 3.90 & 0.001865 & 0.001861 & 0.001855 & 94.69 & 125.0 & 158.0 \\
\hline 3.71 & 0.003730 & 0.003723 & 0.003710 & 92.95 & 121.1 & 152.4 \\
\hline 3.54 & 0.007460 & 0.007445 & 0.007420 & 90.30 & 117.7 & 147.3 \\
\hline 3.43 & U.U1घ்42 & 0.01489 & 0.01181 & 87.20 & 113.4 & 141,0 \\
\hline 3.17 & 0.02984 & 0.02977 & 0.02969 & 83.50 & 107.3 & 133.0 \\
\hline 3.00 & 0.06068 & ก.กรดิร̄ธิ & 0.05936 & 19.35 & 100.4 & I4ts.6 \\
\hline 2.78 & 0.1194 & 0.1191 & 0.1187 & 13.16 & 92.24 & 119.8 \\
\hline 2.60 & 0.2388 & 0.2382 & 0.2375 & 68.10 & 85.42 & 104.4 \\
\hline $2.3 \dot{y}$ & $\dot{0.4775}$ & $0.47 \mathrm{C} 1$ & 0.1719 & $6 \% 14$ & $1 \% 1.88$ & 94.74 \\
\hline
\end{tabular}

${ }^{a}$ Two batches of conductivity water were used on these samples, one had a pH of 6.75 , the other 6.05 . To obtain the correct $\mathrm{L}_{\mathrm{H}^{+}}$values and $\mathrm{L}_{\mathrm{H}_{2} \mathrm{O}}$ values, synthetic mixtures of the two hatches were made to exactly duplicate the composition found in the respective scandium samples but, of course, wilhout the scandium salt. Measurement of the $\mathrm{pH}$ and conductivities of these samples enabled true values of $\mathrm{L}_{\mathrm{H}_{2} \mathrm{O}}$ and $\mathrm{L}_{\mathrm{H}^{+}}$to be determined so they could be used in correcting the equivalent conductivity. A further comment regarding the $\mathrm{pH}$ measurement is to be found in the text immediately following the presentation of the tables and curves dealing with conductivities.

${ }^{\mathrm{b}}$ The densities used in calculating the normalilies at other than $25^{\circ} \mathrm{C}$. can be found in the section of this report which deals with densities.

Tahle 5-Equivalent Conductances of Scandium Nitrate Solutions, Uncorrected for Hydrogen Ion Conductivity

\begin{tabular}{|c|c|c|c|c|c|}
\hline \multicolumn{3}{|c|}{ Normalit $y^{a}$} & \multicolumn{3}{|c|}{ Equivalent conductivity } \\
\hline $15^{\circ} \mathrm{C}$. & $25^{\circ} \mathrm{C}$ & $35^{\circ} \mathrm{C}$ & $15^{\circ} \mathrm{C}$ & $25^{\circ} \mathrm{C}$. & $35^{\circ} \mathrm{C}$. \\
\hline 0.0002947 & 0.0002940 & 0.0002930 & 118.6 & 154.2 & 191.7 \\
\hline 0.0005895 & 0.0005880 & 0.0005860 & 113.7 & 146.5 & 182.8 \\
\hline 0.001179 & 0.001176 & 0.001172 & 108.6 & 139.4 & 175.1 \\
\hline 0.002359 & 0.002303 & 0.008344 & 103.2 & $1.31 . .9$ & .164 .7 \\
\hline 0.004718 & 0.004705 & 0.004688 & 97.04 & 123.3 & 152.9 \\
\hline 0.009435 & 0.009411 & 0.009375 & 90.90 & 115.4 & 142.7 \\
\hline 0.01887 & 0.01882 & 0.01875 & $84.55^{\prime}$ & 106.8 & 131.6 \\
\hline 0.03773 & 0.03764 & 0.03750 & 78.34 & 98.59 & 120.9 \\
\hline 0.07547 & 0.07528 & 0.07501 & 72.00 & 90.59 & 110.5 \\
\hline 0.1509 & 0.1506 & 0.1500 & 65.70 & 81.99 & 99.84 \\
\hline 0.3019 & 0.3011 & 0.3000 & .59 .14 & 73.50 & 88.85 \\
\hline 0.6037 & 0.6023 & 0.6001 & 51.67 & 63.94 & 76.94 \\
\hline
\end{tabular}

${ }^{a}$ The densities used in calculating the normalities at other than $25^{\circ} \mathrm{C}$. can be found in the section of this report which deals with densities. 
Table 6-Equivalent Conductances of Scandium Nitrate Solutions, Corrected for Hydrogen Ion Conductivity

\begin{tabular}{|c|c|c|c|c|c|c|}
\hline \multirow[b]{2}{*}{$\mathrm{pH}^{\mathrm{a}}$} & \multicolumn{3}{|c|}{ Normality $^{\mathrm{b}}$} & \multicolumn{3}{|c|}{$\begin{array}{l}\text { Equivalent } \\
\text { conductivity }\end{array}$} \\
\hline & $15^{\circ} \mathrm{C}$. & $25^{\circ} \mathrm{C}$. & $35^{\circ} \mathrm{C}$. & $15^{\circ} \mathrm{C}$. & $25^{\circ} \mathrm{C}$ & $35^{\circ} \mathrm{C}$. \\
\hline 4.33 & 0.0002947 & 0.0002940 & 0.0002930 & 72.58 & 100.2 & 130.5 \\
\hline 4.18 & 0.0005895 & 0.0005880 & 0.0005860 & 81.07 & 108.6 & 139.8 \\
\hline 3.99 & 0.001179 & 0.001176 & 0.001172 & 83.06 & 109.8 & 141.2 \\
\hline 3.81 . & 0.002359 & 0.002353 & 0.002344 & 83.60 & 109.2 & 138.8 \\
\hline $3.65^{\circ}$ & 0.004718 & 0.004705 & 0.004688 & 82.89 & 106.9 & 134.2 \\
\hline 3.48 & 0.009435 & 0.009411 & 0.009375 & 80.43 & 103.2 & 128.8 \\
\hline 3.30 & 0.01887 . & 0.01882 & 0.01875 & 76.61 & 97.55 & 121.1 \\
\hline 3.16 & 0.03773 & 0.03764 & 0.03750 & 72.85 & 92.19 & 113.6 \\
\hline 2.98 & 0.07547 & 0.07528 & 0.07501 & 67.84 & 85.75 & 105.0 \\
\hline 2.79 & 0.1509 & 0.1506 & 0.1500 & 62.49 & 78.25 & 95.57 \\
\hline $2.50^{\circ}$ & 0.3019 & 0.3011 & 0.3000 & 56.02 & 69.85 & 84.69 \\
\hline 2.23 & 0.6037 & 0.6023 & 0.6001 & 48.76 & 60.55 & 73.08 \\
\hline
\end{tabular}

${ }^{\mathrm{a}}$ The $\mathrm{pH}$ of the conductivity water used in these dilutions: was 5.69 .

${ }^{\mathrm{b}}$.The densities used in calculating the normalities at other than $25^{\circ} \mathrm{C}$. can be found in the section of this report which deals with densities.

Table 7 - Equivalent Conductances of Scandium Perchlorate Solutions, Uncorrected for Hydrogen Ion Conductivity

\begin{tabular}{|c|c|c|c|c|c|}
\hline \multicolumn{3}{|c|}{ Normality $^{\mathrm{a}}$} & \multicolumn{3}{|c|}{ Equivalent conductivity } \\
\hline $15^{\circ} \mathrm{C}:$ & $25^{\circ} \mathrm{C}$ & $35^{\circ} \mathrm{C}$ & $15^{\circ} \mathrm{C}$ & $25^{\circ} \mathrm{C}$ & $35^{\circ} \mathrm{C}$. \\
\hline 0.0001193 & 0.0001193 & 0.0001185 & 137.0 & 176.1 & 216.7 \\
\hline 0.0002386 & 0.0002385 & 0.0002371 & 129.3 & 166.6 & 207.3 . \\
\hline 0.0004773 & 0.0004770 & 0.0004743 & 123.4 & 159.4 & 198.7 \\
\hline 0.0009545 & 0.0009540 & 0.0009485 & 115.7 & 150.1 & 187.9 \\
\hline 0.001909 & 0.001908 & 0.001897 & 108.3 & 139.5 & 175.3 \\
\hline 0.003818 & 0.003807 & 0.003795 & 102.0 & 131.2 & 163.5 \\
\hline 0.007635 & 0.007613 & 0.007580 & 96.28 & 123.3 & 153.1 \\
\hline 0.01518 & 0.01523 & 0.01518 & 90.50 & 115.2 & 112.4 \\
\hline 0.03036 & 0.03045 & 0.03036 & 84.91 & 107.7 & 132.6 \\
\hline 0.06072 & 0.06091 & 0.06072 & 79.58 & 100.6 & 123.5 \\
\hline 0.1214 & 0.1218 & 0.1214 & 74.71 & 94.15 & 115.3 \\
\hline 0.2428 & 0.2436 & 0.2428 & 69.66 & 87.37 & 106.7 \\
\hline
\end{tabular}

${ }^{a}$ The densities used in calculating the normalities at othor than $23^{\wedge} \mathcal{C}$. can he found in the section of this report which deals with densities. 
Table 8- Equivalent Conductances of Scandium Perchlorate Solutions, Corrected for Hydrogen Ion Conductivity

\begin{tabular}{|c|c|c|c|c|c|c|}
\hline \multicolumn{2}{|c|}{. } & \multicolumn{2}{|l|}{ Normality ${ }^{b}$} & \multicolumn{3}{|c|}{$\begin{array}{l}\text { Equivalent } \\
\text { conductivity }\end{array}$} \\
\hline $\mathrm{pH}^{\mathrm{a}}$ & $15^{\circ} \mathrm{C}$. & $25^{\circ} \mathrm{C}$. & $35^{\circ} \mathrm{C}$. & $15^{\circ} \mathrm{C}$. & $25^{\circ} \mathrm{C}$. & $35^{\circ} \mathrm{C}$. \\
\hline 4.73 & 0.001193 & 0.0001193 & 0.0001185 & 94.07 & 126.1 & 160.0 \\
\hline 4.46 & 0.0002386 & 0.0002385 & 0.0002371 & 87.64 & 118.1 & 152.0 \\
\hline 4.21 & 0.0004773 & 0.0004770 & 0.0004743 & 85.48 & 115.3 & 148.6 \\
\hline 4.05 & 0.0009545 & 0.0009540 & 0.0009485 & 88.32 & 118.1 & 151.6 \\
\hline 3.88 & 0.001909 & 0.001908 & 0.001897 & 87.84 & 116.6 & 148.5 \\
\hline 3.73 & 0.003818 & 0.003807 & 0.003795 & 87.49 & 114.3 & 144.2 \\
\hline 3.58 & 0.007635 & 0.007613 & 0.007590 & 85.00 & 110.8 & 138.9 \\
\hline 3.38 & 0.01518 & 0.01523 & 0.01518 & 82.34 & 106.3 & 131.6 \\
\hline 3.23 & 0.03036 & 0.03045 & 0.09036 & 79.14 & 101.0 & 124.9 \\
\hline 3.07 & 0.06072 & 0.06091 & 0.06072 & 75.41 & 95.76 & 117.9 \\
\hline 2.88 & 0.1214 & 0.1218 & 0.1214 & 71.48 & 90.38 & 111.0 \\
\hline 2.61 & 0.2428 & 0.2436 & 0.2428 & $8 \theta .66$ & 83.87 & 102.7 \\
\hline
\end{tabular}

${ }^{\mathrm{a}}$ The $\mathrm{pH}$ of the conductivity water used in these dilutions was 5.77 .

${ }^{b}$ The densities used in calculating the normalities at other than $25^{\circ} \mathrm{C}$. can be found in the section of this report dealing with densities.

it was $15^{\circ}, 25^{\circ}$, or $35^{\circ} \mathrm{C}$. This is because the hydrogen ion concentralions were all below 0.004 $M$ and the densities of hydrochloric, nitric, or perchloric acid solutions at this molarity do not change very much with a $10^{\circ}$ temperature change.

The analysis for nitrate, done by reduction to ammonia with Devarda's alloy and subsequent titration, showed only 2.76 nitrates per scandium in the scandium solutions. It was also noted that the error in analysis was about $3 \%$. The solutions were, of course, prepared exactly as were the perchlorates and chlorides and should have been at their equivalence point as shown by the titration curves. Nevertheless, this discrepancy injects a degree of uncertainty regarding the validily of the nitrate data. Since the nitrate showed such a discrepancy, it was decided to check the perchlorate. An analysis was done gravimetrically using tetraphenylarsonium chloride and gave an empirical formula of $\mathrm{Sc}\left(\mathrm{ClO}_{4}\right)_{2.94}$.

As has been mentioned before, the calculation of the normalities at $15^{\circ} \mathrm{C}$ and $35^{\circ} \mathrm{C}$ from the nurmality ae measured at $25^{\circ} \mathrm{C}$ involves the use of density data for the scandium sulutiuns. Since normality is defined as

$$
\mathrm{N}_{25^{\circ} \mathrm{C}}=\mathrm{G} . \mathrm{E} . \mathrm{W} . / \text { liter of solution at } 25^{\circ} \mathrm{C}
$$

then division by the density ( $\mathrm{D}=$ grams of solution/milliliter) and by 1000 to change litera to milliliters gives the units

(G. E. W./liter of solution) $\left(\frac{\text { milliliter }}{\text { grams of solution }}\right)\left(\frac{1}{1000}\right)=$ G. E. W./gram of solution at $25^{\circ} \mathrm{C}$.

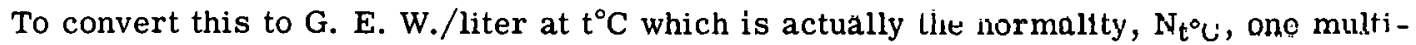
plies by the density at $t^{\circ} \mathrm{C}$ and by 1000 to reconvert to a liter basis. The final form is then

$$
\mathrm{N}_{25}{ }^{\circ} \mathrm{C}\left(\mathrm{D}_{\mathrm{t}{ }^{\circ} \mathrm{C}} / \mathrm{D}_{25{ }^{\circ} \mathrm{C}}\right)=\mathrm{N}_{\mathrm{t}}{ }^{\circ} \mathrm{C}
$$

Since the density data is also needed to calculate the partial molal volumes, which are needed as corrections on the transference numbers, the section on densities immediately follows the conductance section and precedes the transference number section of this report.

Bodlander's data on scandium chloride conductivities presented in Figure 4, actually agree fairly well with the data correcled for hydrogen ion conductivity gathered in this research. The 


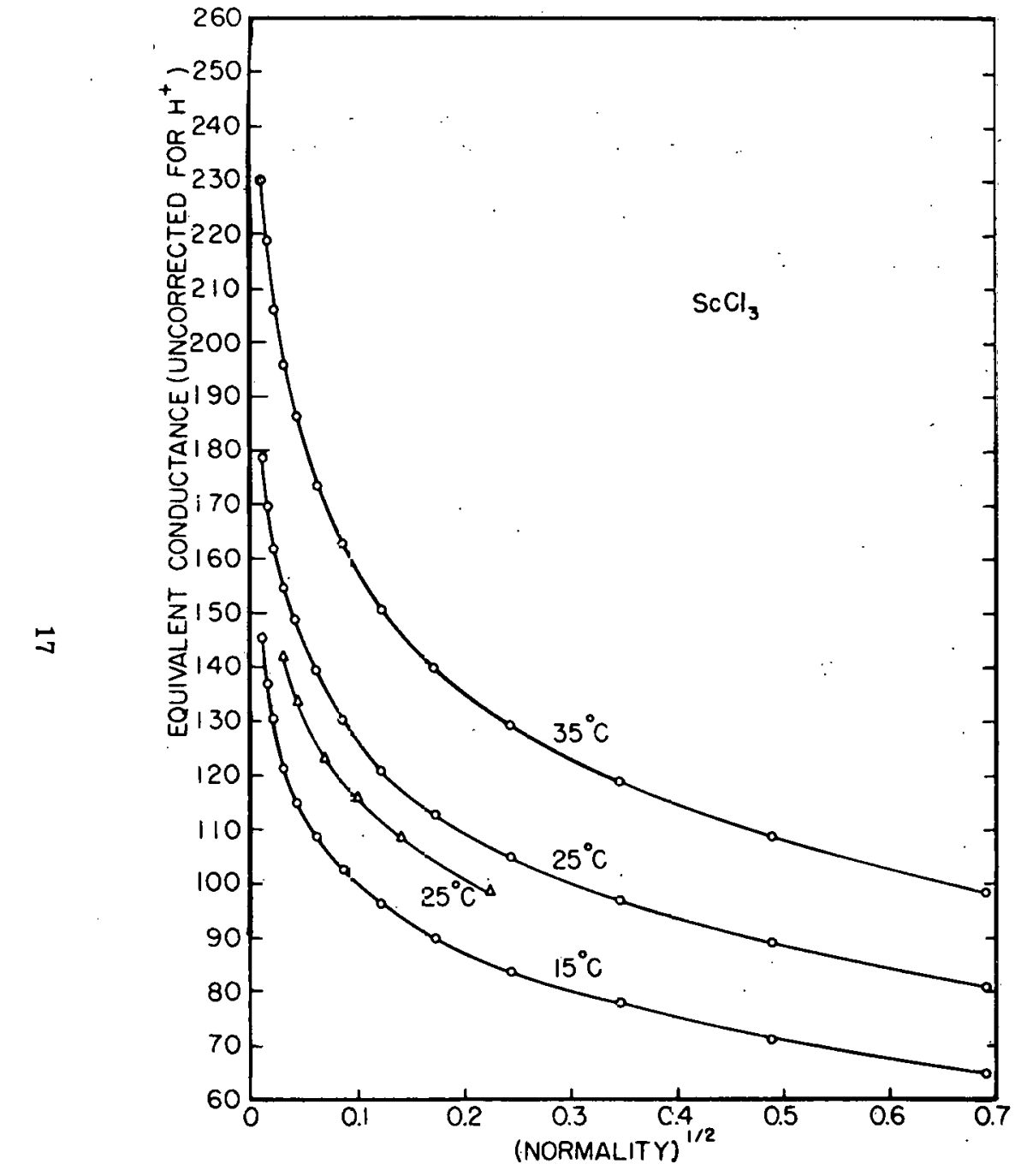

Fig. 4-Equivalent conductance of scandium chloride, uncorrected for hydrogen ion conductivity, at $15^{\circ}, 25^{\circ}$, anci $35^{\circ} \mathrm{C}$.

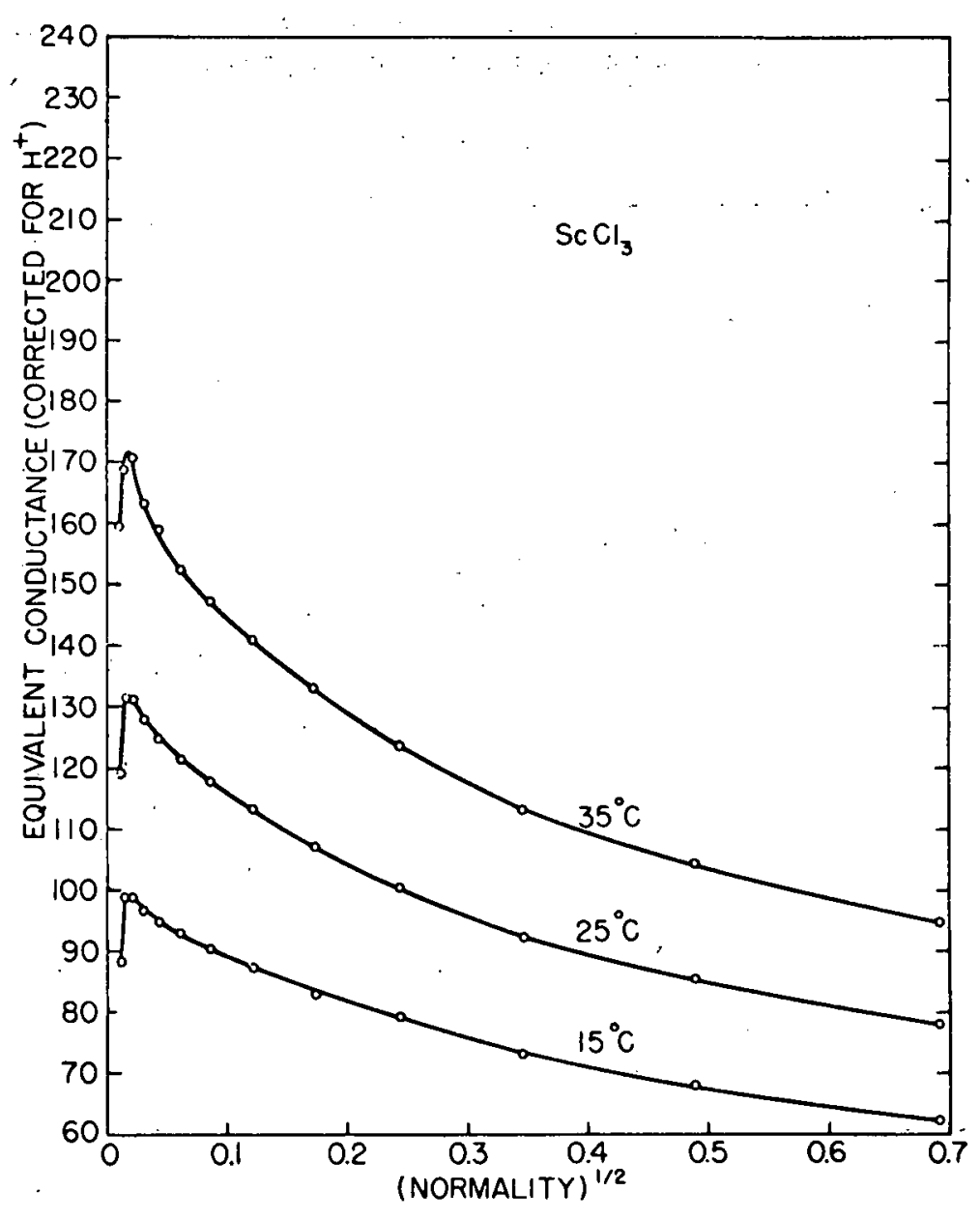

Fig. 5-Equivalent conductance of scandium chloride, corrected for hydrogen ion conductivity, at $15^{\circ}, 25^{\circ}$, and $35^{\circ} \mathrm{C}$. 


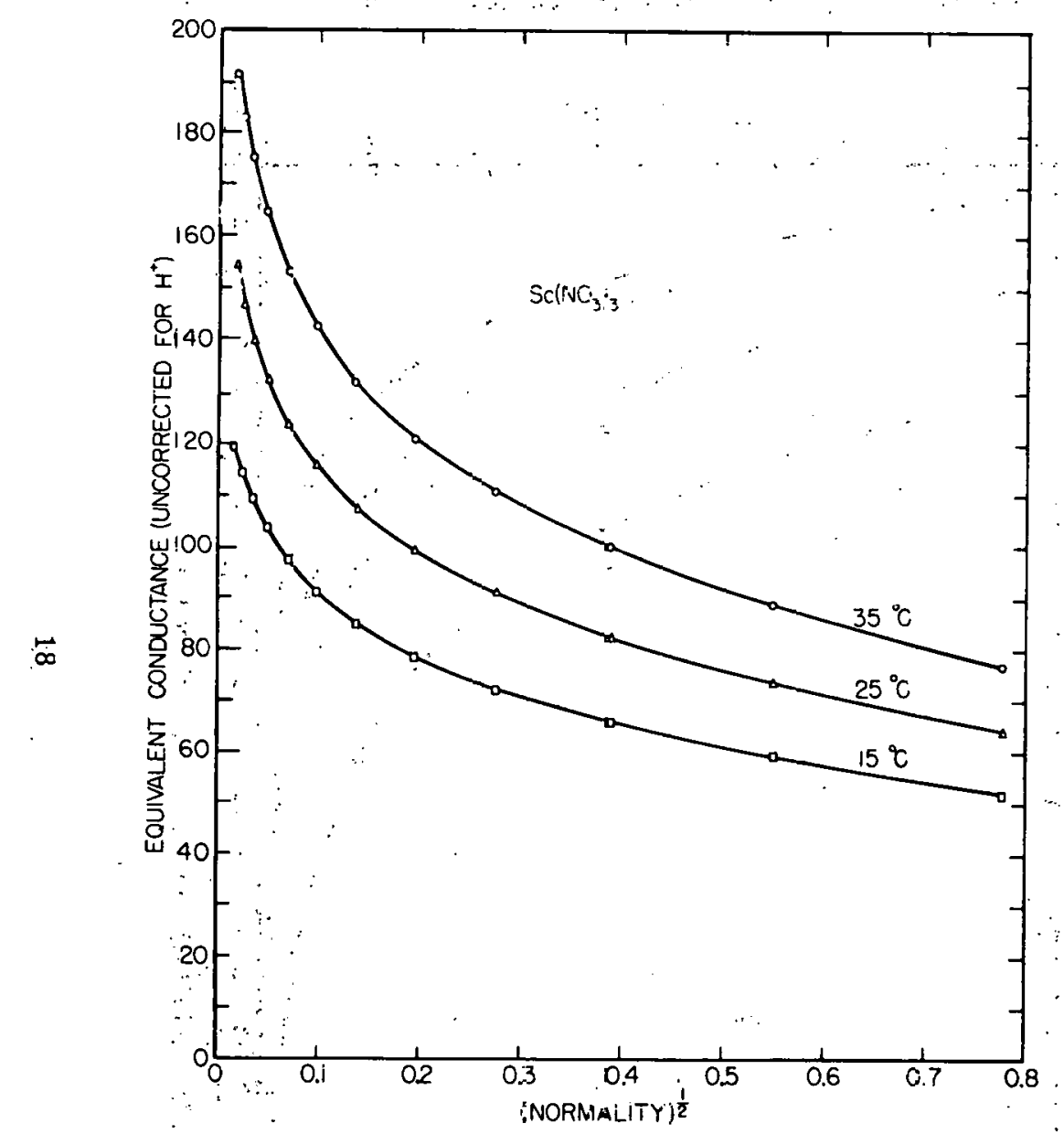

Fig. 6-Equivalent conductance of scandiura nitrate, uncorrected for-hydrogen ion conductivity, at $15^{\circ}, 25^{\circ}$, and $35^{\circ} \mathrm{C}$.

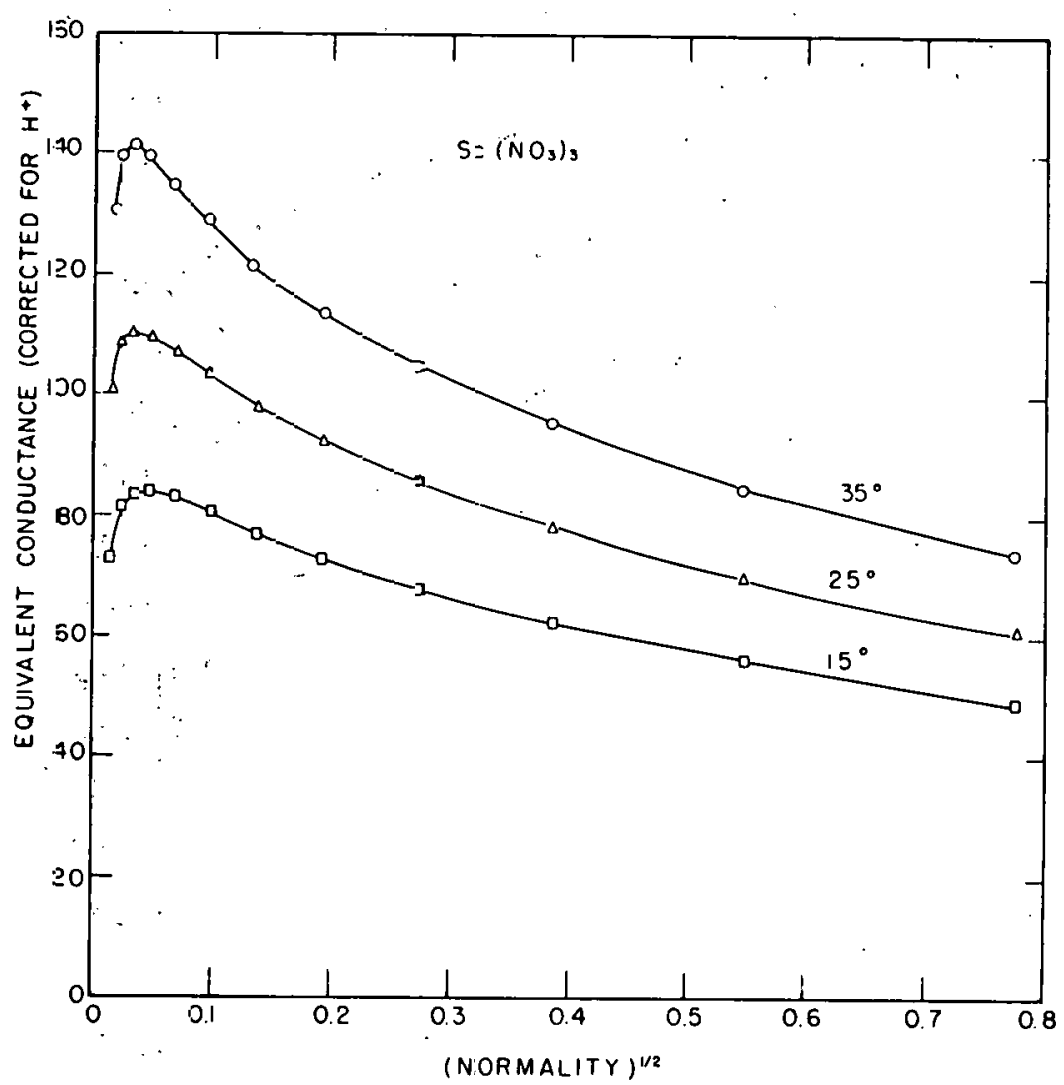

Fig. 7 - Equivalent conductance of scandium nitrate, uncorrected for tydrogen ion conductivity, at $15^{\circ}, 25^{\circ}$, and $35^{\circ} \mathrm{C}$. 
5

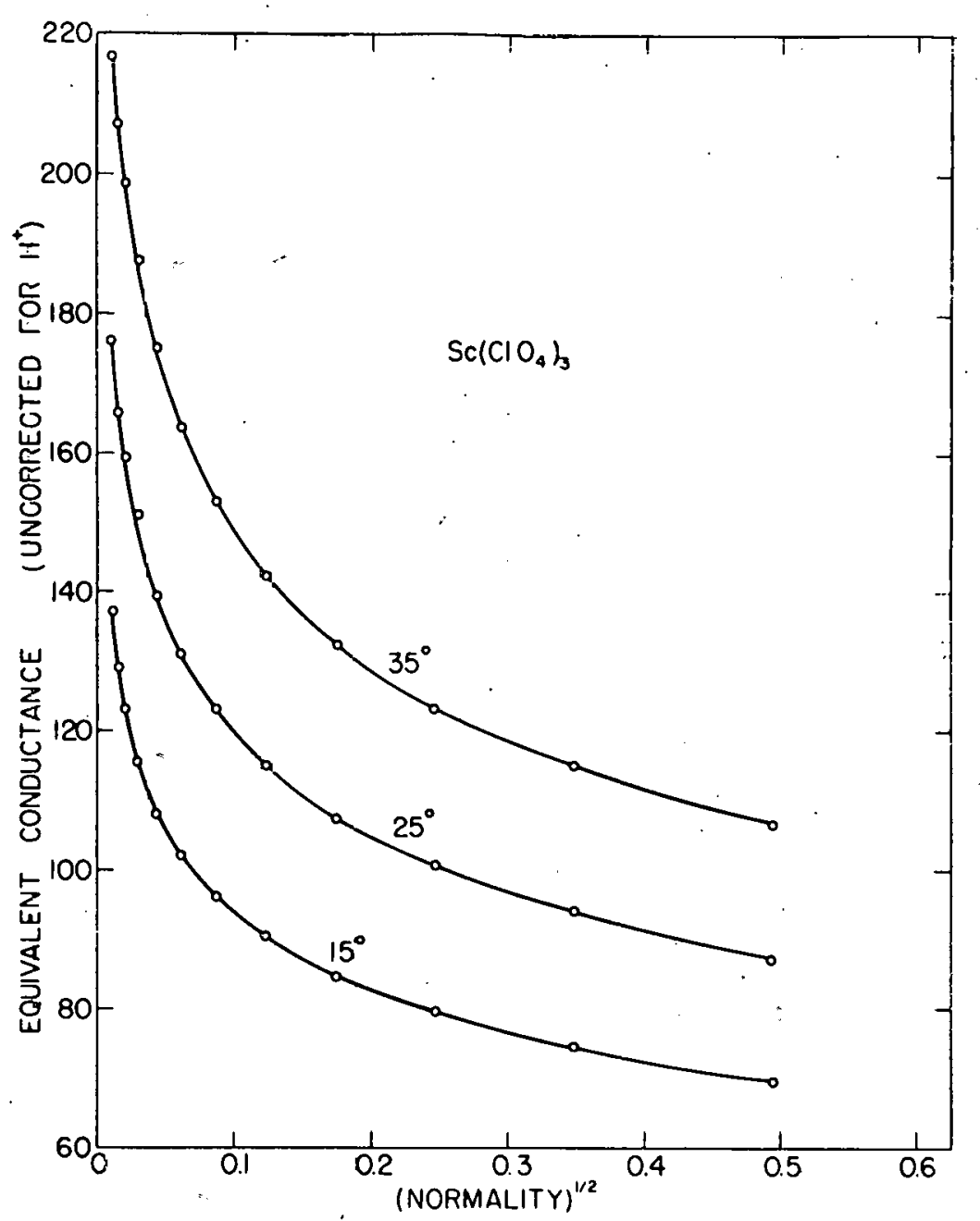

Fig. 8- Equivalent conductance of scandium perchlorate solutions, uncorrested for hydrogen ion conductivity, at $15^{\circ}$; $25^{\circ}$ : and $35^{\circ} \mathrm{C}$.

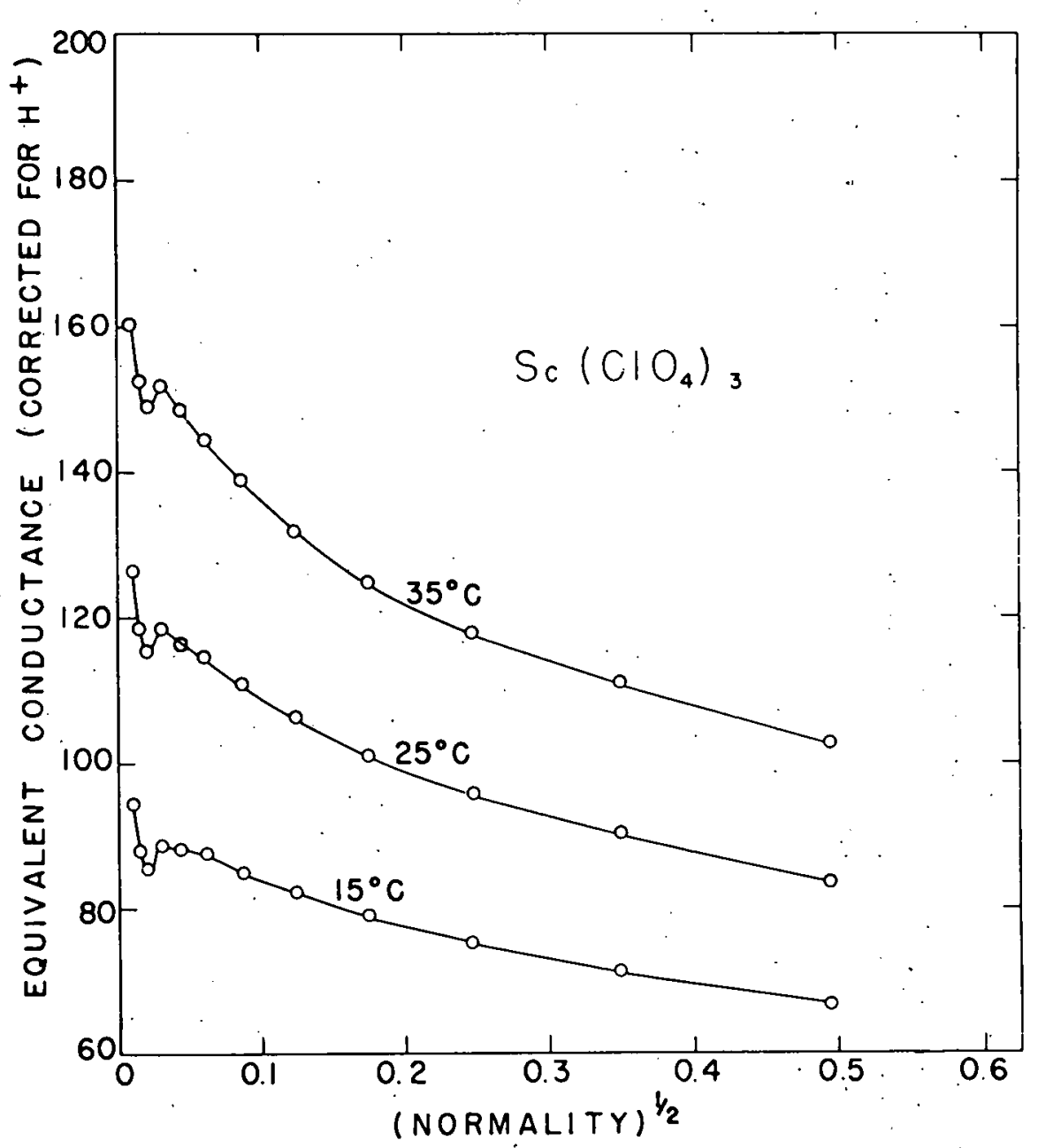

Fig. 9-Equivalent conductance of scandium perchlorate solutions, corrected for hydrogen ion conductivity, at $15^{\circ}, 25^{\circ}$, and $35^{\circ} \mathrm{C}$. 
discrepancy could arise from Bodlander not having pure scandium, not adjusting her solutions to the equivalence point, or from the measuring equipment, it being not so highly advanced in design in 1915 as it is today.

An attempt was made to extrapolate the conductivity data to infinite dilution by use of Onsager's limiting law for the case of a single electrolyte dissociating into two kinds of ions

$$
\Lambda=\lambda_{1}+\lambda_{2}=\Lambda_{0}-S_{(\Lambda)} \Gamma^{1 / 2}
$$

where $\Gamma$ is the ionic strength, $1 / 2 \Sigma C_{i}\left(Z_{+}+Z_{-}\right)^{1 / 2}$ and $\Lambda_{0}$ is the equivalent conductance at infinite dilution. $S_{(\Lambda)}$ is the limiting slope and can be expressed by

$$
S_{(\Lambda)}=A \Lambda_{0}+B
$$

which then gives

$$
\Lambda_{0}=\left[\mathrm{A} \Lambda_{0}+\mathrm{B}\right] \Gamma^{1 / 2}
$$

$A$ is equal to $\omega\left(1.981 \times 10^{6}\right) /\left(D^{\prime} I\right)^{3 / 2}$ where $\omega=\left(\left|z_{+}\right|\left|z_{-}\right|\right)(2 q) /\left(1+q^{1 / 2}\right)$ and

$\mathrm{B}$ is equal to $\frac{29.16\left(\left|\mathrm{z}_{+}\right|+\left|\mathrm{z}_{-}\right|\right)}{\eta(\mathrm{DT})^{1 / 2}}$.

$$
q=\left[\frac{\left|z_{+}\right|\left|z_{-}\right|}{\left(\left|\eta_{1}\right|+\left|\eta_{+}\right|\right)}\right]\left[\frac{\lambda_{+}+\lambda_{-}}{\left|\eta_{1}\right| \lambda_{+}+\left|\eta_{1}\right| \lambda_{1}}\right]
$$

Since $\Lambda_{0}=\lambda_{+}^{0}+\lambda_{-}^{0}$, if one now substitutes $\Lambda_{0}-\lambda_{-}^{0}$ for $\lambda_{+}^{0}$ and defines y as equal to $q /\left(1+q^{1 / 2}\right)$, then for $3-1$ electrolytes

$$
\left.y=\frac{0.75 \Lambda_{0} /\left(\Lambda_{0}+2 \lambda_{-}^{0}\right)}{1+\left[0.75 \Lambda_{0} /\left(\Lambda_{0}+2 \lambda_{-}^{0}\right)\right]}\right]^{1 / 2}
$$

and by use of the values of $\mathrm{D}, \mathrm{T}$, and $\eta$ given in Table 2 , and the $\lambda_{-}^{0}$ values given in Table 9 , equations relating $\Lambda$ and $\Lambda_{0}$ for the chloride, nitrate, and perchlorate salts at $15^{\circ}, 25^{\circ}$, and $35^{\circ} \mathrm{C}$

Table $9-$ Values of $\lambda_{-}^{\circ}$ for Chloride, Nitrate, and Perchlorate Ions at $15^{\circ}, 25^{\circ}$, and $35^{\circ} \mathrm{C}$.

\begin{tabular}{cccc}
\hline & \multicolumn{3}{c}{ Ion } \\
\cline { 2 - 4 } Temperature & Chloride & Nitrate & Perchlorate \\
& & & \\
15 & $61.41^{\mathrm{a}}$ & $58.60^{\mathrm{b}}$ & $55.00^{\mathrm{b}}$ \\
35 & $76.34^{\mathrm{c}}$ & $71.42^{\mathrm{d}}$ & $67.32^{\mathrm{e}}$ \\
\hline
\end{tabular}

\footnotetext{
${ }^{2}$ Reference 76, p. 454 .

b Those values wore oxtrapolated from data proconted in Referenne 7h, $\mathrm{p} 454$.

C Reference 78 , p. 40 .

"Reference 79. p. 79.

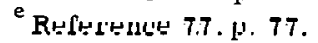

were developed. The resulting equation for aqueous solutions of $3-1$ electrolytes at $15^{\circ} \mathrm{C}$ has the form

$$
\Lambda_{0}=\Lambda+\left[132.719+3.2619 \text { y } \Lambda_{0}\right] C^{i / 2}
$$

At $25^{\circ} \mathrm{C}$

$$
\Lambda_{0}=\Lambda+\left[170.318+3.3138 \text { y } \Lambda_{0}\right] C^{1 / 2}
$$


and at $35^{\circ} \mathrm{C}$

$$
\Lambda_{0}=\Lambda+\left[213.130+3.3798 \text { y } \Lambda_{0}\right] C^{1 / 2}
$$

At each experimental concentration the measured values of $\Lambda$ were used to calculate $\Lambda_{0}$, the calculated values being given the symbol $\Lambda_{0}^{\prime}$. Since the expression could not be solved explicitly for $\Lambda_{0}^{\prime}$, values for $\Lambda_{0}^{\prime}$ at each approximation had to be obtained by successive approxi mations. The calculations were carried out by use of the I. B. M. 650 computer. The values of $\Lambda_{0}^{\prime}$ so derived are shown in Tables 10-13 with accompanying Figures 10-13.

Table 10-Equivalent Conductance at Infinite Dilution for Scandium Chloride at $15^{\circ}, 25^{\circ}$, and $35^{\circ} \mathrm{C}$., Uncorrected for Hydrogen in Conductivity

\begin{tabular}{llllll}
\hline & Normality & & \multicolumn{3}{c}{ Calculated $\Lambda_{0}^{\prime}$} \\
\hline \multicolumn{1}{c}{$15^{\circ} \mathrm{C}}$. & \multicolumn{1}{c}{$25^{\circ} \mathrm{C}}$. & $35^{\circ} \mathrm{C}$. & $15^{\circ} \mathrm{C}$. & $25^{\circ} \mathrm{C}$. & $35^{\circ} \mathrm{C}$. \\
\hline 0.00005806 & 0.00005806 & 0.00005806 & 157.7 & 195.3 & 243.4 \\
0.0001165 & 0.0001163 & 0.0001159 & 146.3 & 179.1 & 234.4 \\
0.0002331 & 0.0002326 & 0.0002318 & 140.6 & 173.2 & 224.9 \\
0.0004663 & 0.0004653 & 0.0004637 & 134.6 & 168.4 & 214.3 \\
0.0009325 & 0.009305 & 0.0009275 & 128.4 & 164.4 & 207.4 \\
0.001865 & 0.001861 & 0.001855 & 124.7 & 161.4 & 201.0 \\
0.003730 & 0.003723 & 0.003710 & 122.5 & 157.2 & 195.9 \\
0.007460 & 0.007445 & 0.007420 & 122.1 & 166.3 & 194.3 \\
0.01492 & 0.01489 & 0.01484 & 124.0 & 156.3 & 196.1 \\
0.02984 & 0.02977 & 0.02969 & 130.0 & 164.6 & 205.5 \\
\hline
\end{tabular}

Table 11 - Equivalent Conductance at Infinite Dilution for Scandium Chloride at $15^{\circ}, 25^{\circ}$, and $35^{\circ} \mathrm{C}$., Corrected for Hydrogen Ion Conductivity

\begin{tabular}{|c|c|c|c|c|c|}
\hline \multicolumn{3}{|c|}{ Normality } & \multicolumn{3}{|c|}{ Calculated $\Lambda_{0}^{\prime}$} \\
\hline $15^{\circ} \mathrm{C}$. & $25^{\circ} \mathrm{C}$. & $35^{\circ} \mathrm{C}$. & $15^{\circ} \mathrm{C}$. & $25^{\circ} \mathrm{C}$ & $35^{\circ} \mathrm{C}$. \\
\hline 0.00005825 & 0.00005815 & 0.00005795 & 85.07 & $\therefore 112.3$ & 147.4 \\
\hline 0.0001165 & 0.0001163 & 0.0001159 & 90.29 & 121.7 & 162.8 \\
\hline 0.0002331 & 0.0002326 & 0.0002318 & 101.7 & $135: 6$ & 173.8 \\
\hline 0.0004663 & 0.0004653 & 0.0004637 & 103.0 & 137.1 & 178.1 \\
\hline 0.0009325 & 0.0009305 & 0.0009275 & .102 .8 & 136.0 & 173.8 \\
\hline 0.007865 & 0.001861 & 0.001855 & 103.6 & 136.7 & 172.9 \\
\hline 0.003730 & 0.003723 & 0.003710 & 105.7 & 137.7 & 173.5 \\
\hline 0.007460 & 0.007440 & 0.007120 & 108.5 & 111.5 & 177.5 \\
\hline 0.01492 & 0.01489 & 0.01484 & 113.8 & 147.9 & 184.6 \\
\hline 0.02984 & 0.02977 & 0.02969 & 122.5 & 157.9 & 197.1 \\
\hline
\end{tabular}
(81).

The method of calculating $\Lambda_{0}^{\prime}$ used here is a modification of the method used by Shedlovsky

\section{Discussion of Data}

The troubles experienced in trying to get any quantitative ideas from the measured conductances'stem from the fact that scandium is drastically hydrolyzed in aqueous solution. In 1953 and 1954 Kilpatrick and Pokras (82), working with scandium perchlorate solutions, calculated the hydrolysis constants from their e.m.f. data. In 1956 Biedermann, Kilpatrick, Pok - 
Table 12 - Equivalent Conductance at Infinite-Dilution for Scandium Nitrate at $15^{\circ}, 25^{\circ}$, and $35^{\circ} \mathrm{C}$, , Corrected for Hydrogen Ion Conductivity

\begin{tabular}{|c|c|c|c|c|c|}
\hline \multicolumn{3}{|c|}{ Normality } & \multicolumn{3}{|c|}{ Calculated $\Lambda_{0}^{\prime}$} \\
\hline $15^{\circ} \mathrm{C}$ & $25^{\circ} \mathrm{C}$. & $35^{\circ} \mathrm{C}$. & $15^{\circ} \mathrm{C}$ & $25^{\circ} \mathrm{C}$ & $35^{\circ} \mathrm{C}$. \\
\hline 0.00003685 & 0.00003675 & 0.00003663 & 43.71 & 57.78 & 77.85 \\
\hline 0.00007370 & 0.00007350 & 0.00007325 & 61.17 & 82.68 & 107.1 \\
\hline 0.0001474 & 0.0001470 & 0.0001465 & 67.90 & 93.24 & 121.5 \\
\hline 0.0002947 & 0.002940 & 0.0002930 & 75.64 & 104.3 & 135.8 \\
\hline 0.0005895 & 0.0005880 & 0.0005860 & 85.67 & 114.7 & 147.7 \\
\hline 0.001179 & 0.001176 & 0.001172 & 89.70 & 118.5 & 152.4 \\
\hline 0.002359 & 0.002353 & 0.002344 & 93.14 & 121.7 & 154.8 \\
\hline 0.004718 & 0.004705 & 0.004688 & 96.63 & 124.8 & 157.0 \\
\hline 0.009435 & 0.009411 & 0.009375 & 100.2 & 128.9 & 161.5 \\
\hline
\end{tabular}

Table 13-Equivalent Conductance at Infinite Dilution for Scandium Perchlorate at $15^{\circ}, 25^{\circ}$, and $35^{\circ} \mathrm{C}$, Corrected for Hydrogen Ion Conductivity

\begin{tabular}{|c|c|c|c|c|c|}
\hline \multicolumn{3}{|c|}{ Normality } & \multicolumn{3}{|c|}{ Calculated $\Lambda_{0}^{\prime}$} \\
\hline $15^{\circ} \mathrm{C}$. & $25^{\circ} \mathrm{C}$ & $35^{\circ} \mathrm{C}$. & $15^{\circ} \mathrm{C}$. & $25^{\circ} \mathrm{C}$. & $35^{\circ} \mathrm{C}$. \\
\hline 0.00002985 & 0.00002975 & 0.00002965 & 79.46 & 114.4 & 143.3 \\
\hline 0.00005970 & 0.00005950 & 0.00005930 & 80.52 & 112.0 & 139.5 \\
\hline 0.0001194 & 0.0001190 & 0.0001186 & 96.27 & 129.1 & 163.8 \\
\hline 0.0002387 & 0.0002380 & 0.0002372 & 90.66 & 122.1 & 152.2 \\
\hline 0.0004773 & 0.0004760 & 0.0004743 & 89.75 & 121.0 & 155.9 \\
\hline 0.0009545 & 0.0009520 & 0.0009485 & 94.50 & 126.4 & 162.1 \\
\hline 0.001909 & 0.001904 & 0.001897 & 96.67 & 127.3 & 163.4 \\
\hline 0.003818 & 0.003808 & 0.003795 & 99.20 & 130.2 & 165.5 \\
\hline 0.007635 & 0.007615 & 0.007590 & 103.27 & 134.7 & 169.3 \\
\hline 0.01527 & 0.01523 & 0.01518 & 108.91 & 140.9 & 175.5 \\
\hline
\end{tabular}

ras, and Sillén (83) recalculated Kilpatrick's and Pokras' original data using general methods for polynuclear complexes.

The data showed that the following reactions take place

$$
\begin{gathered}
{\left[\mathrm{Sc}\left(\mathrm{H}_{2} \mathrm{O}\right)_{6}\right]^{+3}+\mathrm{H}_{2} \mathrm{O} \rightleftharpoons\left[\mathrm{Sc}\left(\mathrm{H}_{2} \mathrm{O}\right)_{5} \mathrm{OH}\right]^{+2}+\mathrm{H}_{3} \mathrm{O}^{+}} \\
{\left[\mathrm{Sc}\left(\mathrm{H}_{2} \mathrm{O}\right)_{5} \mathrm{OH}\right]^{+2}+\mathrm{H}_{2} \mathrm{O}=\left[\mathrm{Sc}\left(\mathrm{H}_{2} \mathrm{O}\right)_{4}(\mathrm{OH})_{2}\right]^{++}+\mathrm{H}_{3} \mathrm{O}^{+}}
\end{gathered}
$$

and

$$
2\left[\mathrm{Sc}\left(\mathrm{H}_{2} \mathrm{O}\right)_{5} \mathrm{OH}\right]^{+2} \rightleftharpoons\left[\mathrm{Sc}\left(\mathrm{H}_{2} \mathrm{O}\right)_{5} \mathrm{OH}\right]_{?}^{+4}
$$

The formation of the monohydroxy species and its polymerization seem to be the dominant reactions. The recalculation of the data assuming "core plus links" complexes of the general formula $\left[\mathrm{Sc}(\mathrm{OH})_{2} \mathrm{Sc}\right]_{n}^{+(3+\mathrm{n})}$ showed that at least the complexes with $\mathrm{n}$ equal to 1 and $2, \mathrm{Sc}_{2}(\mathrm{OH})_{2}^{+4}$ and $\mathrm{Sc}_{3}(\mathrm{OH})_{4}^{+5}$, must exist. Existence of higher complexes was also indicated.

The formation of the monohydroxy species would not take place to any great extent if it were not for the subsequent formation of the polymeric species since the single acid dissociation constant is on the order of $1.17 \times 10^{-5}$ followed by a dimerization constant of $7.38 \times 10^{5}$ as found by Kilpatrick and Pokras (82). The dimerization process is strongly temperature dependent, the formation of polynuclear complexes being favored by an increase in temperature and hindered by an increase in ionic strength. 


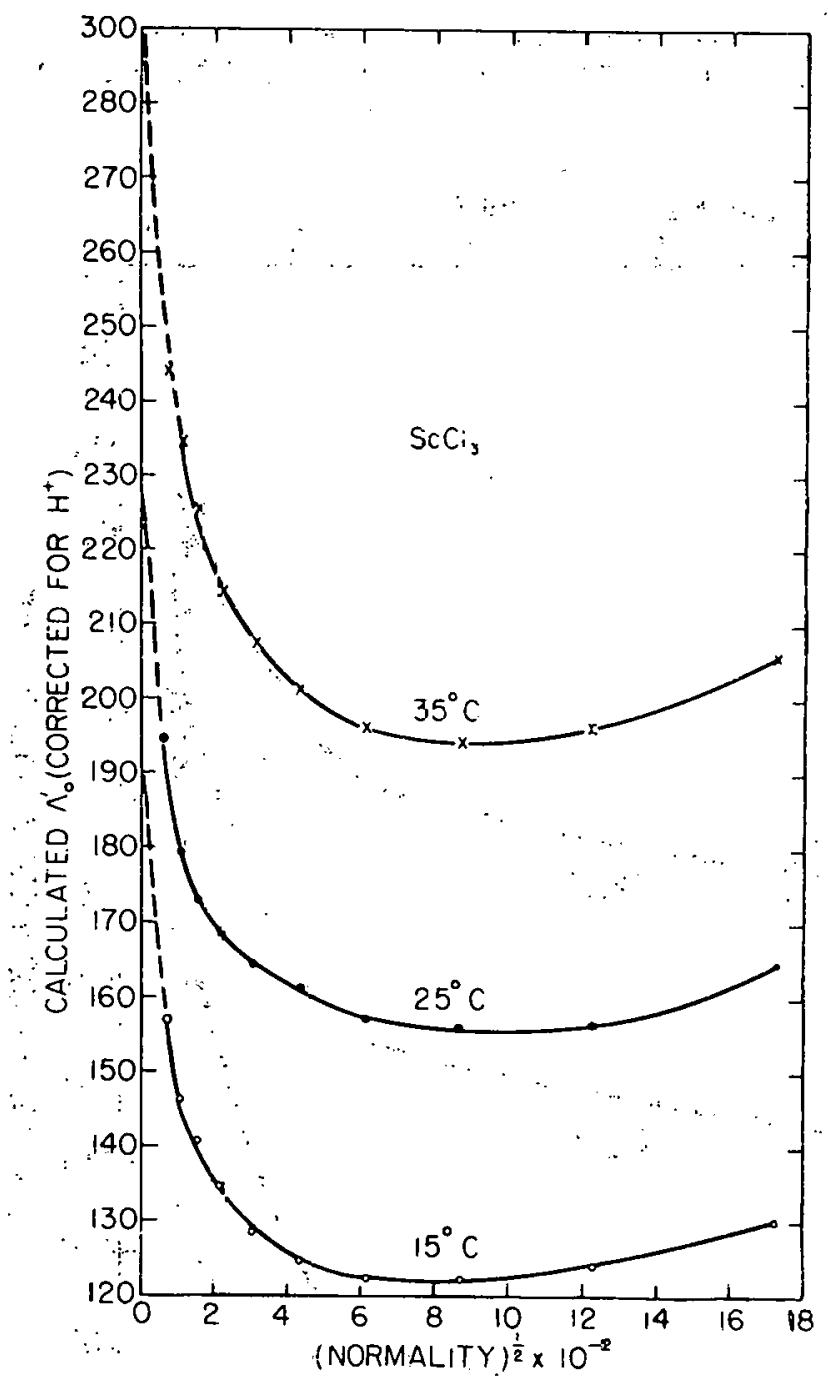

Fig. $10-$ Equivalent conductance at iñinite dilution for scandium chloride at $15^{\circ}, 25^{\circ}$, and $35^{\circ} \mathrm{C}$., uncorrected for hydrogen ion conductivity.

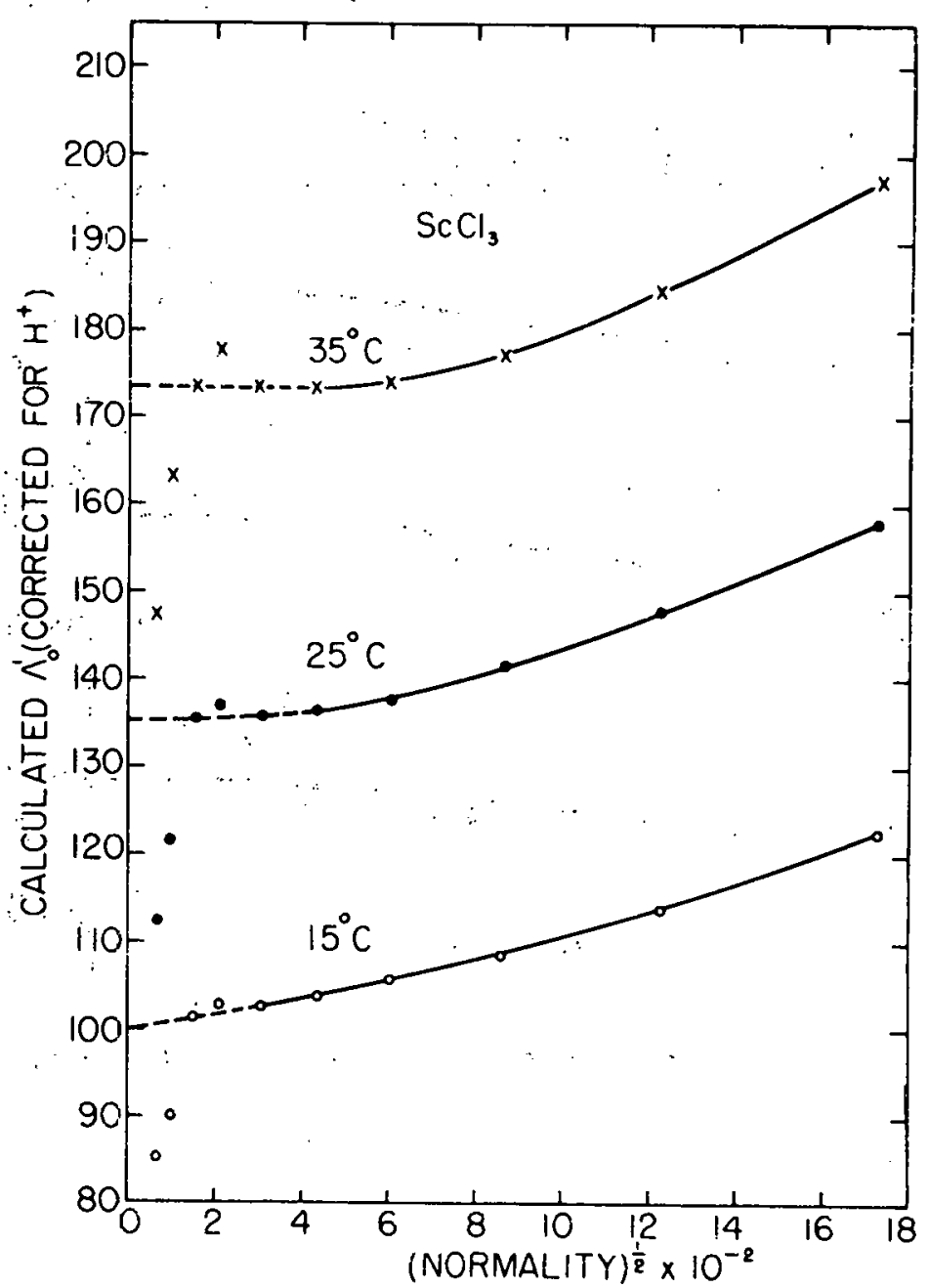

Fig. 11- Equivalent conductance at infinite dilution for scandium chloride at $15^{\circ}, 25^{\circ}$, and $35^{\circ} \mathrm{C}$., corrected for hydrogen ion conductivity. 


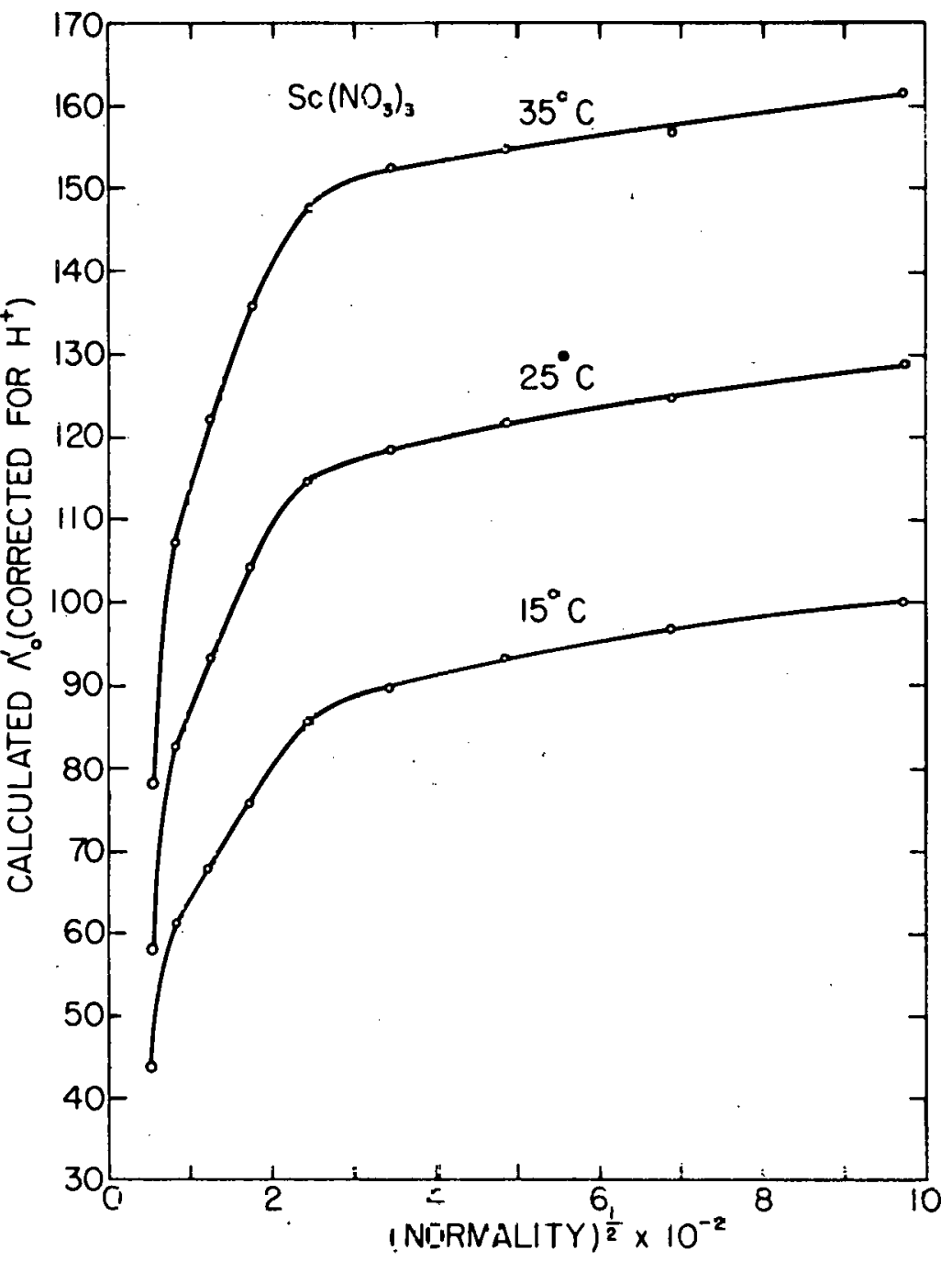

Fig. $1 \bar{c}$ - Equivalent eonductan $x$ at infirite dilution for scandiun nitrate at $15^{\circ}, 25^{\circ}$, ar: $35^{\circ} \mathrm{C}$, corrected for hydrogen ion conductivity.

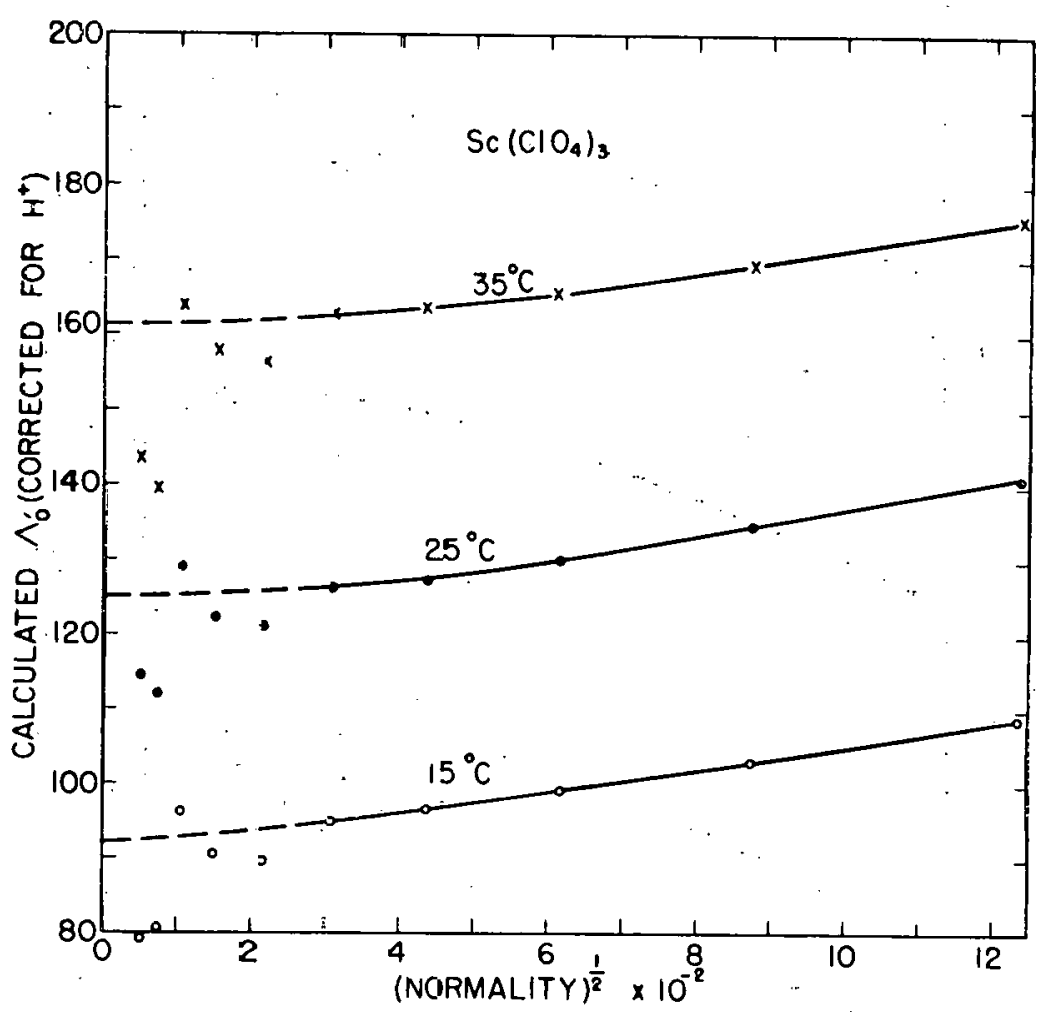

Fig. 13- Equiralent conductance at infinite dilution for scandium perchlorate at $15^{\circ} 25^{\circ}$, ar: $35^{\circ} \mathrm{C}$., corrected for hycrogen ion conductivity. 
Thus, because species other than $\mathrm{Sc}^{+3}$ are present, the use of Onsager's limiting conductance equation for the calculation of $\Lambda_{0}^{\prime}$ is not quite correct since it is derived for the case of a single electrolyte dissociating into two kinds of ions only. Because of this, no value for the conductivity of the $\mathrm{Sc}^{+3}$ ion at infinite dilution can be obtained.

If one could work with more concentrated solutions, the polymerization and hydrolysis would be suppressed. However, Onsager's law would not be valid for concentrated solutions. If the transference numbers were known as well as conductivity, then

$$
\mathrm{T}_{+} \Lambda=\lambda_{+}
$$

and plots of $\lambda_{+}$vs. concentration could be extrapolated to zero concentration to obtain $\lambda_{+}^{0}$ values. In such concentrated solutions, the moving boundary method of determining transference numbers would be useless because a visible boundary probably could not be set up. A Hittorftype experiment might be possible but the extrapolation of the $\lambda_{+}$values to zero concentration would require a long, inaccurate extrapolation. Thus, the value of $\lambda_{+}^{0}$ for the scandium ion, $\mathrm{Sc}^{+3}$, will not be known until someone solves the conductance data for the relative contribution of each possible ionic species; a monumental mathematical manipulation.

The entire situation is very much more complex in the presence of anions, other than perchlorate, which may themselves form complexes with the metal ions, since then there is a competition between the anions, water, and $\mathrm{OH}^{-}$for the available coordination positions. This could be the case with the nitrate since, at low concentrations, it showed a reversal, in the trend of increasing equivalent conductance with decreasing concentration even with the uncorrected data.

The equivalent conductances of the scandium salts are higher than their rare-earth counterparts. Such should be the case since the unhydrated scandium ion has a smaller radius than any of the unhydrated rare earths and, therefore, its mobility should be higher. Even so, the conductance is not as high as it would be if one were measuring the conductivity of the $\mathrm{Sc}^{+3}$ ion itself.

The turnover of the corrected equivalent conductance curves at low concentrations can be explained if one considers that the conductivity of the hydrogen ion is a large value as ionic conductivities go and when this contribution is subtracted from the total measured conductivity, the contributions from species such as Sc $(\mathrm{OH})^{+2}$ and $\mathrm{Sc}\left[(\mathrm{OH})_{2} \mathrm{Sc}\right]^{+(3+n)}$ become increasingly important. Since the conductivity of such species would be expected to be much smaller than the $\mathrm{Sc}^{+3}$ ion because of size effects and charge effects, the conductivity reverses its original trend and falls. The cusp in the perchlorate curve which had been corrected for hydrogen ion was checked by making fresh dilutions from the stock solutions and it reappeared. The author finds it extremely difficult to reconcile the fact that the equivalent conductivity increases again after falling unless, for some reason, the hydroxy polymers dissociate again upon further dilution.

The uncorrected $\Lambda_{0}^{\prime}$ data for scandium when plotted vs. $\sqrt{\mathrm{N}}$ gave curves very reminiscent of those obtained by Jaffe (84) for the rare-earth sulfates. The large minimum in the curves (Figure 10) is a result of inserting the incorrect charge types and incorrect concentrations in the Onsager equation. Only the representative chloride curves are presented as a figure.

The downward trend of the corrected $\Lambda_{0}^{\prime}$ vs. $\sqrt{\mathrm{N}}$ curves for the nitrate is probably only another demonstration of the odd behavior exhibited by the nitrate such as the equivalent conductance curve turning over on itself at low concentrations even before correction for $\mathrm{H}^{+}$contribution. This in turn is probably a reflection of the unfortunate circumstance that the nitrate failed tu show three nitrates per scandium even though the titration curve looked correct. Apparently, quite stable hydroxy-nitrate species formed which were soluble but not titratable. If one ignores the points at low concentration where scattering starts, the $\Lambda_{0}^{\prime}$ vs. $\sqrt{\mathrm{N}}$ curves for the chloride and perchlorate show behavior typical of what was experienced with the rare earths $(9,78,84)$ and, for this reason, the curves (corrected for hydrogen ion conductivity) are included in their entirety.

If one ignores the dotted-line portion of the $\Lambda_{0}^{\prime}$ vs. $\sqrt{\mathrm{N}}$ curves for chloride (Figure 11) and perchlorate (Figure 13) and observes the actual dip in the curves followed by a definite dropping off, it is evident such behavior starts at about the point the $\Lambda$ vs. $\sqrt{\mathrm{N}}$ curves correrted for hydrogen ion (Figures 5 and 9, respectively) start to fall. The larger, more noticeable devia- 
tion in the perchlorate case is a consequence of the dip actually observed in the $\Lambda$ vs. $\sqrt{\mathrm{N}}$ corrected perchlorate curves. Again, it is certain the correct charge types and concentrations were not applied in the Onsager equation so the odd behavior was not wholly unexpected. It is quite evident why the literature is devoid of electrolytic measurements on hydrolyzable cations.

The errors involved in measuring the resistances of the solutions were negligible compared to uncertainties in the concentrations of about $\pm 0.1 \%$. An additional error of about $0.1 \%$ due to $\mathrm{pH}$ measurement errors may have been introduced into the data which had been corrected for hydrogen ion conductivity.

\section{DENSITIES AND PARTIAL MOLAL VOLUMES}

Introduction

Several means of measuring the mass per unit volume; or density have been devised over the years. The methods vary from the most simple type of pycnometer or specific gravity bottle with a precision of about \pm 0.001 , to dilatometric and magnetic float methods with an accuracy of about $\pm 1 \times 10^{-7}$. 'Ihe various methóds are reviewed by Bauer (85). The partial inulal volumes are derived from the densities and are used to correct the transference numbers: 'The densities are also used to calculate normalities at $15^{\circ}$ and $35^{\circ} \mathrm{C}$.

\section{Experimental}

\section{Materials}

The solutions used in this study were the more concentrated of the solutions prepared for use in conductance measurements.

\section{Apparatus}

The densities were determined by use of thermometer-fitted pycnometers. Water baths were set up at $34^{\circ}, 24^{\circ}$, and $14^{\circ} \mathrm{C}$. in which to equilibrate the solutions. All weighings were done on an Ainsworth Chain-o-matic balance.

\section{Procedure and results}

The pycnometers were calibrated with conductivity water. All weights were corrected to vacuum weights and a second pycnometer was used as a tare to cancel buoyancy effects. The solutions, previously equilibrated in the thermostated baths were loaded in the pycnometers and the thermometer inserted. Very gradual warming to the desired temperature as indicated by the pycnometer thermometers was accomplished by waving the pycnometer under an infrared lamp. The pycnometer thermometers were checked against the Bureau of Standards:calibrated thermometer. When the desired temperature was reached, the overflow tube was relieved of its bubble of solution, capped, and the entire assembly weighed after the temperature returned to that of the room $\left(25^{\circ} \mathrm{C}\right.$.). The resultant data is included here as Figures. $14-16$.

Treatment of the data by least.squares methods gave the following equations to fit the curves.

For the chloride at $15^{\circ} \mathrm{C}, \quad \rho=0.0439 \mathrm{~N}+0.9991$, at $25^{\circ} \mathrm{C} ., \quad \rho=0.0434 \mathrm{~N}+0.9970$, and at $35^{\circ} \mathrm{C} ., \quad \rho=0.0429 \mathrm{~N}+0.9941$. For the nitrate at $15^{\circ} \mathrm{C} ., \rho=0.0563 \mathrm{~N}+0.9992$, al. $25^{\circ} \mathrm{C} ., \quad \rho=0.0556 \mathrm{~N}+0.0072$, and at $35^{\circ} \mathrm{C} ., \rho=0.0549 \mathrm{~N}+0.9943$. For the per $=$ chlorate at $15^{\circ} \mathrm{C} ., \quad \rho=0.0836 \mathrm{~N}+0.9991$, at $25^{\circ} \mathrm{C} ., \quad \rho=0.0812 \mathrm{~N}+0.9970$, and at $35^{\circ}$. C., $\rho=0.0805 \mathrm{~N}+0.9940$.

where $\mathrm{N}$ in all cases is the normality. The density was used to calculate the normalities at $15^{\circ} \mathrm{C}$. and $35^{\circ} \mathrm{C}$. from data at $25^{\circ} \mathrm{C}$. 


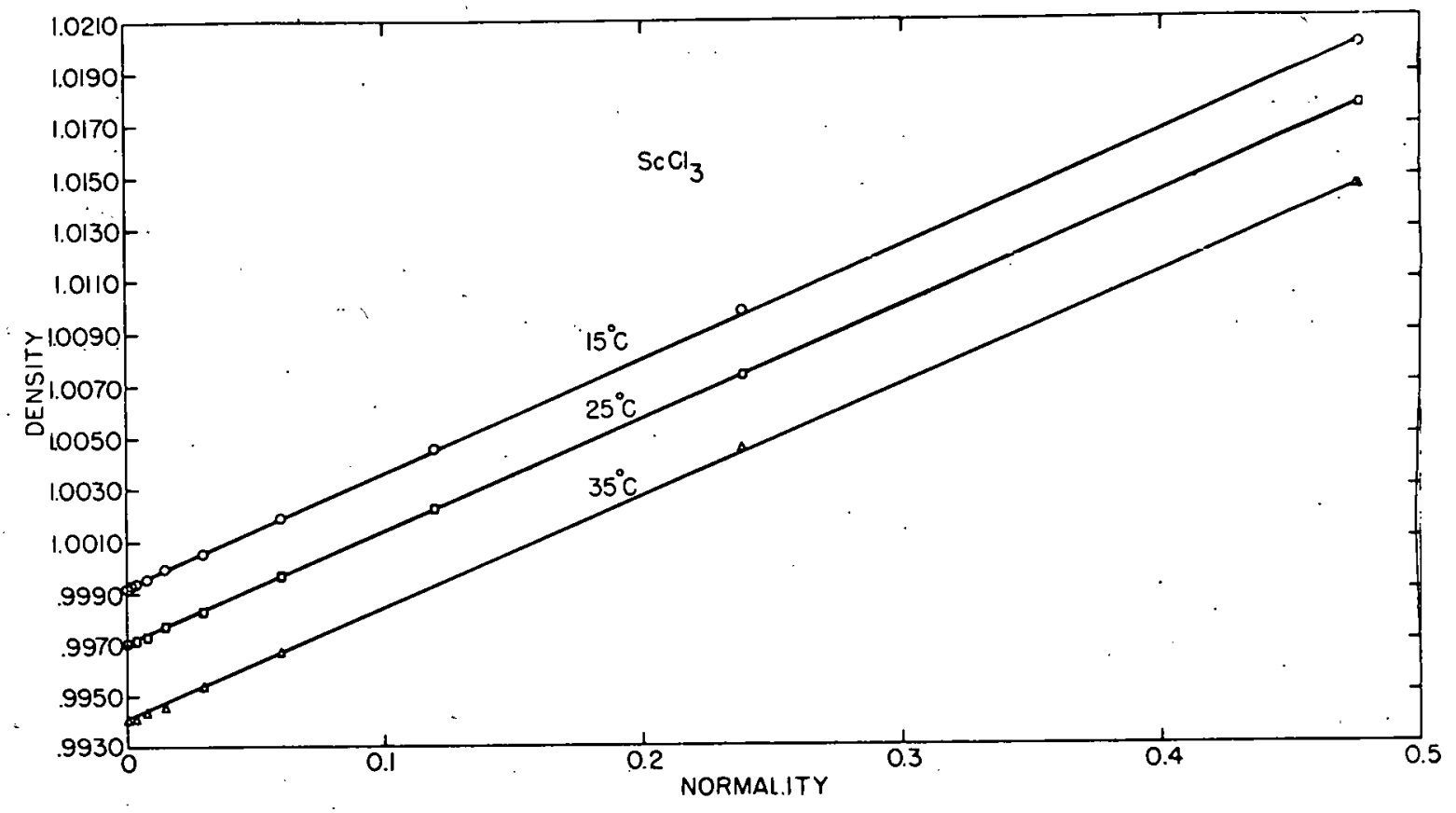

Fig. 14-Densities of aqueous scandium chloride solutions as a function of concentration.

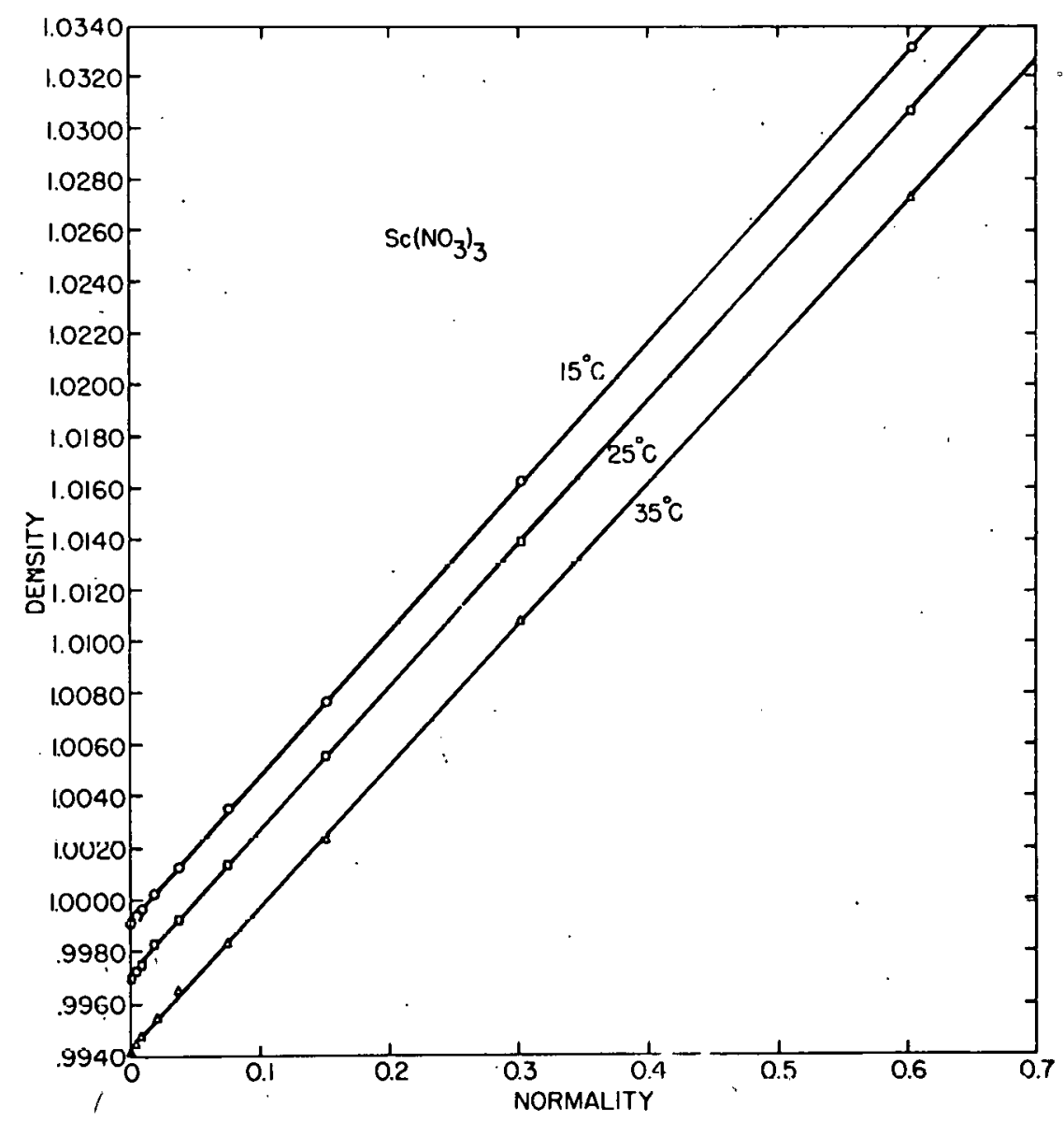

Fig. $15=$ Densities of aquooud ocandium nitrate sulüliüns as a function of concentration. 


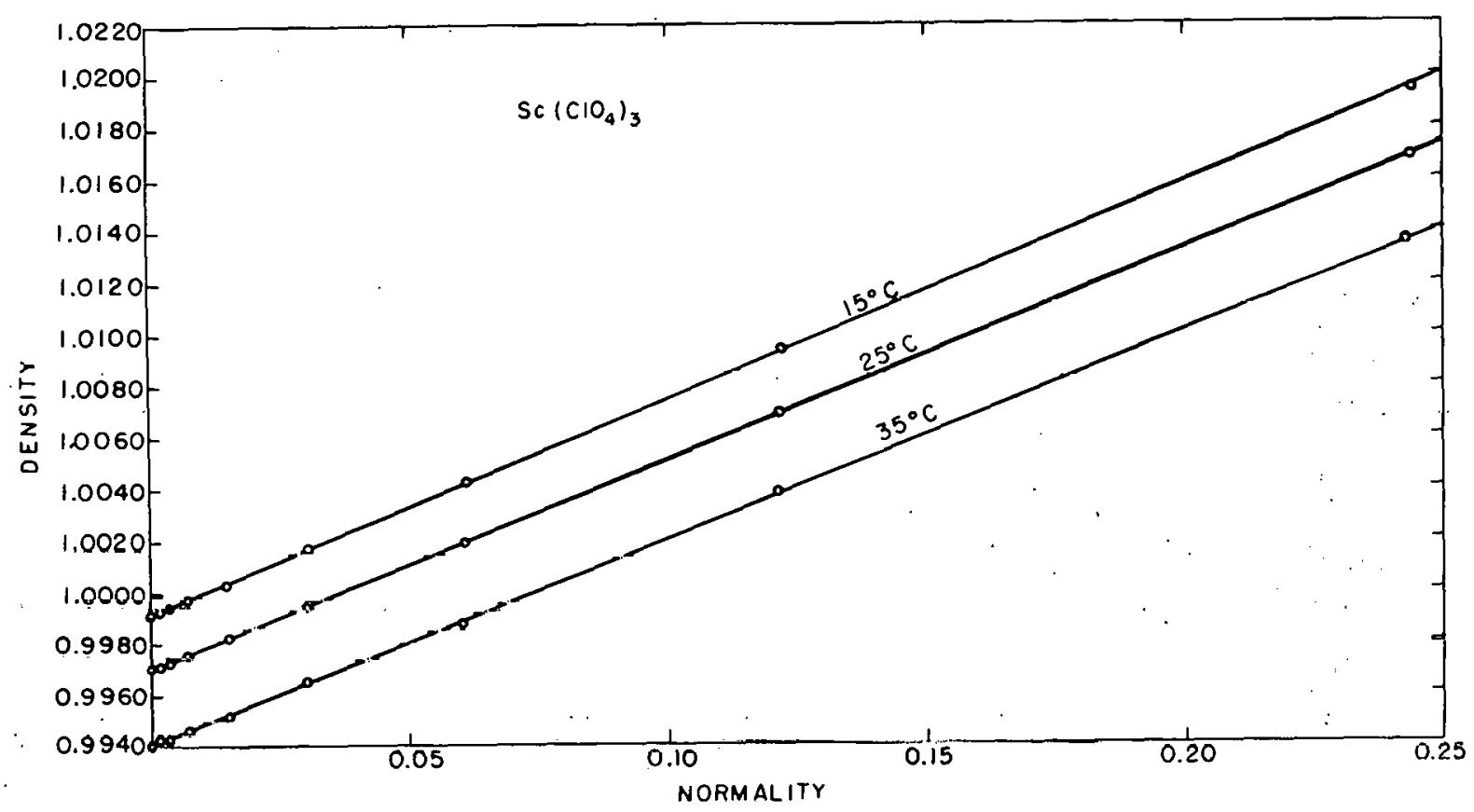

Fig. 16-Densities of aqueous scandium perchlorate solutions as a function of concentration.

In addition, partial molal volumes were calculated from the density data to be used in correcting the transference number data in the next section of this report. The molalities, needed in calculation of partial molal volumes were arrived at by the following reasoning. Since $\mathrm{m}=$ molality $=$ moles $/ 1000$ grams of water, $\mathrm{m} / 1000$ would be moles $/ \mathrm{gram}$ of water . If one now multiplies by grams of water/liter or 1000 times the density, the units moles/liter emerge which is the molarity. The molarity, normality, and molality of $3-1$ electrolytes are all interrelated by

$$
\mathrm{N}=\mathrm{M} / 3=\mathrm{mD} \mathrm{D}_{\mathrm{H}_{2} \mathrm{O}} / 3
$$

where $\mathrm{N}$ is the normality or equivalents per liter, $\mathrm{M}$ is the molarity or moles per liter, while $m$ is the molality or moles per 1000 grams of water.

The partial molal volumes were actually calculated from the apparent molal volumes, which, in turn, came from the densilies. tion by

The apparent molal volume, $\phi_{\mathrm{V}}$, is related to the molallty, un, alld deinsity, $d$, of a solu...

$$
\phi_{\mathrm{V}}=\frac{1000\left(\mathrm{~d}_{0}-\mathrm{d}\right)}{\operatorname{mad}_{0}}+\frac{\mathrm{M}_{2}}{\ddot{\mathrm{d}}}
$$

where $d_{0}$ is the density of the solvent and $M_{2}$ is the molecular weight of the solute. The values of $\phi_{\mathrm{V}}$ were then expressed in terms of a power series in terms of the molality by use of least squares methods. The partial molal volume, $\bar{v}$, is related to the apparent molal volume, $\phi_{\mathrm{V}}$, by

$$
\overline{\mathrm{V}}=\phi_{\mathrm{V}}+\mathrm{m} \frac{\partial \phi_{\mathrm{V}}}{\partial \mathrm{m}}
$$

where $\mathrm{m}$ is the molality. Resultant equations for $\phi_{\mathrm{V}}$ for scandium chloride are 


$$
\begin{aligned}
& \phi_{\mathrm{V}}=21.70-55.53 \mathrm{~m}+416.00 \mathrm{~m}^{2}-988.94 \mathrm{~m}^{3} \text { at } 15^{\circ} \mathrm{C} . \\
& \phi_{\mathrm{V}}=25.15-58.96 \mathrm{~m}+177.89 \mathrm{~m}^{2}+190.58 \mathrm{~m}^{3} \text { at } 25^{\circ} \mathrm{C} ., \text { and } \\
& \phi_{\mathrm{V}}=32.65-151.07 \mathrm{~m}+826.80 \mathrm{~m}^{2}-1410.9 \mathrm{~m}^{3} \text { at } 35^{\circ} \mathrm{C} .
\end{aligned}
$$

For scandium nitrate

$$
\begin{aligned}
& \phi_{\mathrm{V}}=65.60-28.78 \mathrm{~m}+124.14 \mathrm{~m}^{2}+768.76 \mathrm{~m}^{3} \text { at } 15^{\circ} \mathrm{C} . \\
& \phi_{\mathrm{V}}=66.47-9.80 \mathrm{~m}-11.54 \mathrm{~m}^{2}+30.35 \mathrm{~m}^{3} \text { at } 25^{\circ} \mathrm{C} ., \text { and } \\
& \phi_{\mathrm{V}}=69.61-9.02 \mathrm{~m}-15.39 \mathrm{~m}^{2}+2.00 \mathrm{~m}^{3} \text { at } 35^{\circ} \mathrm{C} .
\end{aligned}
$$

For scandium perchlorate

$$
\begin{aligned}
& \phi_{\mathrm{V}}=93.94-17.59 \mathrm{~m}-35.60 \mathrm{~m}^{2}-56.00 \mathrm{~m}^{3} \text { at } 15^{\circ} \mathrm{C} ., \\
& \phi_{\mathrm{V}}=100.96-17.59 \mathrm{~m}-47.51 \mathrm{~m}^{2}-37.82 \mathrm{~m}^{3} \text { at } 25^{\circ} \mathrm{C} . \text {, and } \\
& \phi_{\mathrm{V}}=104.23-18.56 \mathrm{~m}-41.18 \mathrm{~m}^{2}-24.91 \mathrm{~m}^{3} \text { at } 35^{\circ} \mathrm{C} \text {. }
\end{aligned}
$$

The chloride data are valid over the range 0 to $0.15 \mathrm{~m}$; the nitrate, 0 to $0.20 \mathrm{~m}$; the perchlorate, 0 to $0.1 \mathrm{~m}$.

The data with considerable curvature (chloride) was done on the IBM 650 computer while the data having almost straight line character (nitrates and perchlorates) was done by simple progressive curve-fitting.

\section{TRANSFERENCE NUMBERS}

Introduction

The transference number of an ion in solution is a measure of that portion of the total current which is carried hy that ion.

In an electric field, an ion will migrate through the solution with a velocity dependent upon its mobility. Since each ion has a characteristic mobility the different ions in solution will transport different amounts of current.

The transference number depends on the number of ions or equivalent concentration, $\mathbf{C}_{\mathbf{i}}$, the charge on the ion, $\mathrm{Z}_{\mathbf{i}}$, and its mobility, $\mathrm{U}_{\mathbf{i}}$. The transference number of the ith ion, $\mathrm{T}_{\mathbf{i}}$, is then the ratio of the current, $i$, carried by the ion to the total current, $i$, carried by the entire system.

$$
\mathrm{T}_{\mathrm{i}}=\frac{i}{\mathrm{I}}=\frac{\mathrm{C}_{\mathrm{i}} \mathrm{Z}_{\mathrm{i}} \mathrm{U}_{\mathrm{i}}}{\sum_{\mathrm{S}} \mathrm{C}_{\mathrm{S}} \mathrm{Z}_{\mathrm{S}} \mathrm{U}_{\mathrm{S}}}
$$

For the case of the binary electrolyte, $\mathrm{C}_{+} \dot{\mathrm{Z}}_{+}=\mathrm{C}_{-} \mathrm{Z}_{-}$and the expression reduces to

$$
\mathrm{T}_{+}=\frac{\mathrm{U}_{+}}{\mathrm{U}_{+}+\mathrm{U}_{-}}
$$

for the catiün. The mobllity, $U$, is related to the ionic equivalent conductance, $\lambda$, by

$$
\lambda_{+}=U_{+} F
$$

and

$$
\lambda_{-}=U_{-} \mathrm{F} \text {. }
$$

where $F$ is the Faraday. Then

$$
\mathrm{T}_{+}=\frac{\lambda_{+}}{\lambda_{+}+\lambda_{-}}=\frac{\dot{\lambda}_{+}}{\dot{\Lambda}}
$$

By use of this relationship, one can calculate individual ionic equivalent conductances from. total equivalent conductances and transference numbers. Thus, conductances and transference numbers have a close relationship. 
If one now uses the Onsager equation for the conductance of a binary electrolyte which was presented in the conductances results section, and substitutes the expression just given for $\mathrm{T}_{+}$one obtains

$$
T_{+}=T_{+}^{0}+S_{(T)} \Gamma^{1 / 2}
$$

where

$$
S_{(T)}=\frac{T_{+}^{0}\left(\left|Z_{+}\right|+\left|Z_{-}\right|\right)-\left|Z_{+}\right|}{\left(\left|Z_{+}\right|+\left|Z_{-}\right|\right) \Lambda_{0}}
$$

and

$$
\beta=\frac{28.98\left(\left|\mathrm{Z}_{+}\right|+\left|\mathrm{Z}_{-}\right|\right)^{3 / 2}}{\eta(\mathrm{DT})^{1 / 2}}
$$

Astually this equation gives the limiting slope of the transference number as a function of the square ront of the equivalent concentration and strictly applles unly lu lie case of 1 ulectrolytes in dilute solutions. The exlended Onsagcr cquation presenter hy hye (78) wives better agreement between theory and experiment but the mathematics are much more involved.

-.- - Transference numbers submit the Onsager theory to it mur rigorous tcot than do equivalent conductances since small differences in the individual ionic contributions to the conductivity are masked in the total equivalent conductance of the sall while the transference number is greatly effected.

Measurement of transference numbers can be carried out in three ways.

1. The Hittorf method which depends upon concentration changes in the solutions;

2. The electromotive force method; and

3. The moving boundary method.

The Hittorf method involves electrolyzing a solution of a solute in a three compartment cell. The cell is constructed with an anode compartment, a middle compartment, and a cathode compartment. Samples can be withdrawn from all three compartments and analyzed after the passage of a known amount of current. Before passage of current, the electrolyte concentration is the same in all three compartments.

Washburn (86, p. 276) developed a simple formula for the computation of transference numbers from Hittorf-type data. The number of equivalents of an $10 n, N_{f}$, left in a given weight of solvent, for example, in the anode compartment, after electrolysis must be equal to the number of equivalents, $\mathrm{N}_{\mathrm{O}}$, present before electrolysis plus the number of equivalents, $\mathrm{N}_{\mathrm{e}}$, introduced by the electrode reaction minus the number of equivalents; $\mathrm{N}_{\mathrm{e}} \mathrm{T}$, lost by ionic migration

$$
N_{f}=N_{o}+N_{e}-N_{e} T
$$

Solving for the transference number then gives

$$
T=\left(N_{0}-N_{f}+N_{\epsilon}\right) / N_{e}
$$

$\mathrm{N}_{\mathrm{e}}$ can be obtained from the known number of Faradays passed through the cell during the cr. periment and $\mathrm{N}_{\mathrm{o}}$ and $\mathrm{N}_{\mathrm{f}}$ are found by analysis of the compartment solutions before and after electrolysis. $\mathrm{N}_{e}$ is positive if the ion is added to the solvent by dissolution of the electrode and negative if the ion plates out on the electrode. The concentration of the middle compartmont must remain unchanged during electrolysis.

The emf method involves the use of concentration cells. The potentials of a cell will liquid junction and a cell without liquid junction (both having the same concentrations of solutes) are measured and compared. For a cell with liquid junction

$$
-\mathrm{FdE}_{\mathbf{l}}=\mathrm{Td} \mu
$$


where $F$ is the Faraday, $E_{t}$ is the potential of the cell with transference, and $\mu$ is the chemical potential. For a cell without liquid junction,

$$
-F d E=d \mu
$$

Therefore, solving for $\mathrm{T}$ one obtains

$$
\frac{d E_{t}}{d E}=T
$$

This method is the least accurate of the three and is, therefore, not often used.

The moving boundary method, which was used in this research, is the simplest to execute and affords the greatest accuracy. The solution to be measured is placed in a calibrated tube of uniform cross-section with a narrow bore. An indicator solution is placed above the solution to be measured and is mechanically separated from it. The cell is fitted with an anode in the indicator solution and a cathode in the solution to be measured. When a potential is applied across the cell leads and the solutions are allowed to come into intimate contact, the cations of the solution to be measured migrate towards the cathode with a characteristic velocity. The indicator cations follow the leading cations but will not pass them because the indicator cations have a slower mobility. An interface or boundary is formed between the leading and following solutions which moves with the velocity of the leading ions. If the.solutions have different colors of sufficient intensity or sufficiently. different indices of refraction, the boundary becomes visible.

The boundary remains sharp because of the potential gradients developed in the cell. These potentials are a function of the distance along the calibrated tube as shown in Figure 17. When the slower-moving following ions get ahead of the boundary at $\mathbf{b}$ in Figure 17, they are then in an environment having too small a potential gradient and are slowed down. Likewise, the leading ions find too great a potential gradient and are speeded up should they wander into the region behind the boundary.

The equation for calculation of the transference number from moving boundary data was derived by Miller (87).

Consider the cell initially loaded with two solutes, MA and NB, with a boundary between the two at $a-b$ as in Figure 18 (a). A potential difference is then applied across the cell by the electrodes $\mathrm{E}^{+}$and $\mathrm{E}^{-}$and the movement of the interface or boundary is followed. The anions, $\mathrm{A}^{-}$, of the compound $\mathrm{M}^{+} \mathrm{A}^{-}$cross $\mathrm{y}-\mathrm{y}$ to form the anion boundary a $-\mathrm{a}$ between solutions $\mathrm{N}^{+} \mathrm{B}^{-}$and $\mathrm{N}^{+} \mathrm{A}^{-}$. L Likewise, the cations will move toward the negative electrode, $\mathrm{E}^{-}$, crossing $\mathrm{y}-\mathrm{y}$, to form the boundary $\mathrm{c}-\mathrm{c}$ between the solutions $\mathrm{N}^{+} \mathrm{A}^{-}$and $\mathrm{M}^{+} \mathrm{A}^{-}$. For a solution of $C$ equivalents of a binary salt per liter, the volume swept out per Faraday of current passed is $1000 / \mathrm{C}$ milliliters. $T_{+} 1000 / \mathrm{C}$ milliliters of the total milliliters is due to the motion of the cations while $\mathrm{T}_{-} 1000 / \mathrm{C}$ is due to anion movement. If now $\mathrm{X}$ Faradays of current are passed through the solution, a different volume, $v_{+}$will be swept out by the cation boundary and $V_{-}$by the anion boundary. The following then holds:

$$
\frac{F}{T_{+} 1000 / C}=\frac{X}{V_{+}} \text {and } \frac{F}{T_{-} 1000 / C} \frac{X}{V_{-}}
$$

where $F$ is the raraday.

Solving for $\mathrm{T}_{+}$and $\mathrm{T}_{-}$gives

$$
\mathrm{T}_{+}=\frac{\mathrm{FV}_{+} \mathrm{C}}{1000 \mathrm{X}} \quad \text { and } \quad \mathrm{T}_{-}=\frac{\mathrm{FV} \_\mathrm{C}}{1000 \mathrm{X}} \quad \therefore \quad \therefore
$$

For a constant current of $I$ amperes flowing for $t$ seconds $X=I$ and when this is substituted the expressions for $T_{+}$and $T_{-}$become 


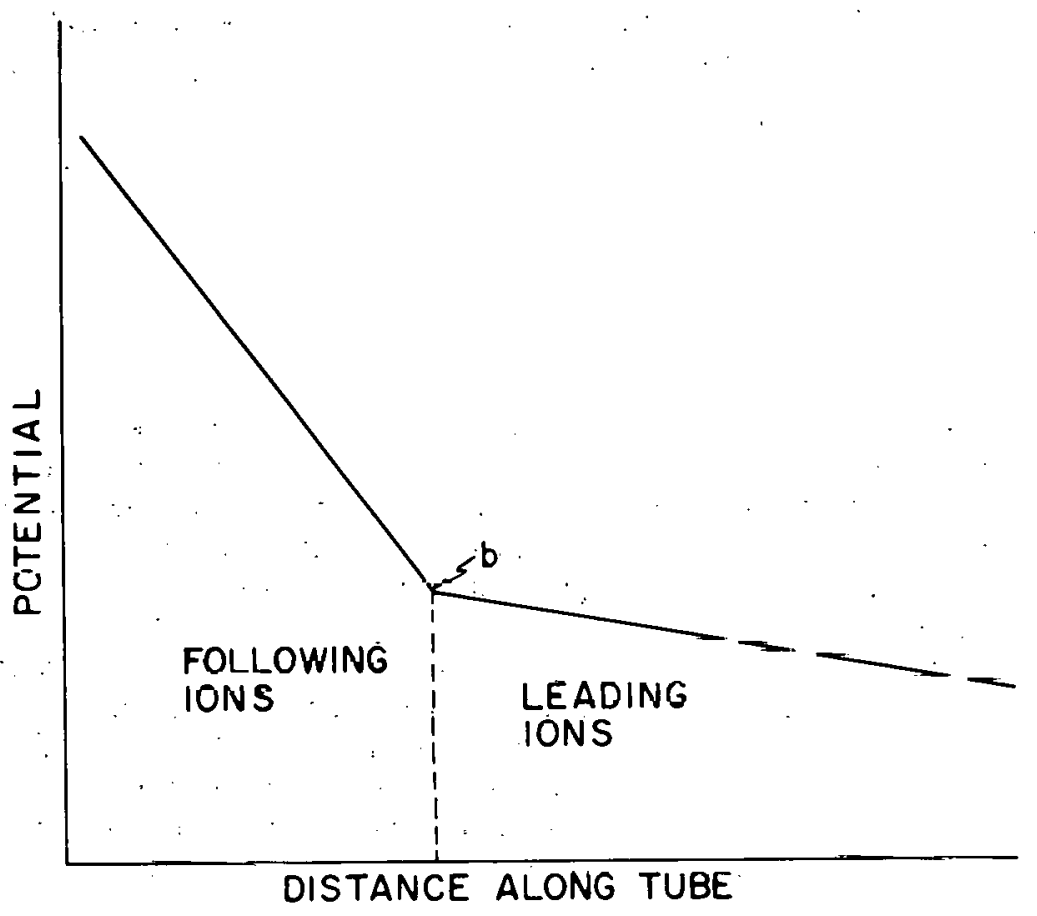

Fig. 17-Potential gradients along the: measuring tube during electrolysis.
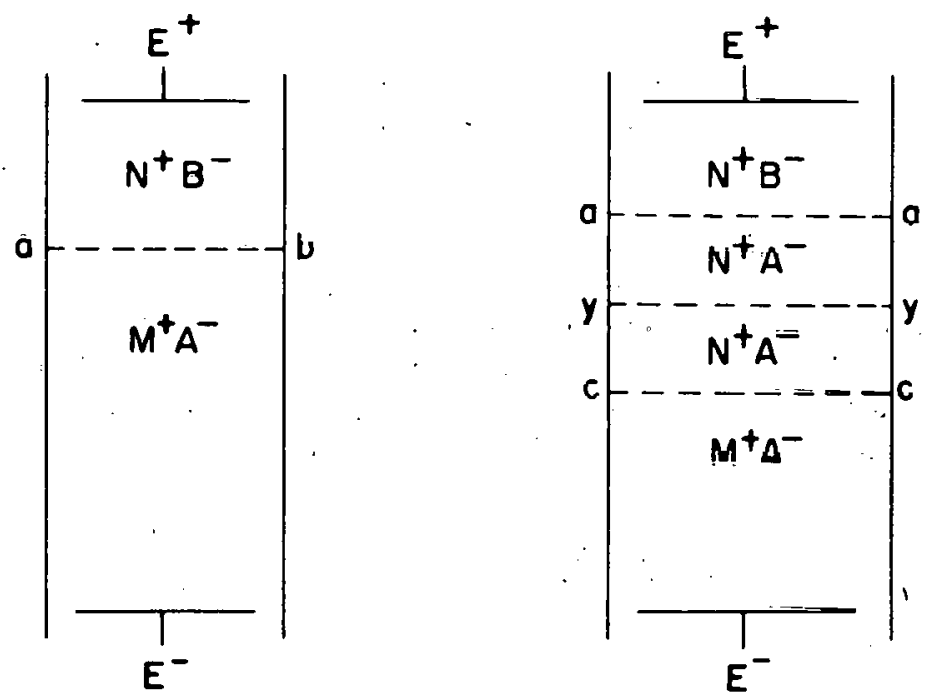

Flg. 18- Motion of the solutes.in the cell during electrolysis. 


$$
\mathrm{T}_{+}=\frac{\mathrm{FV}_{+} \mathrm{C}}{1000 \mathrm{It}} \quad \text { and } \quad \mathrm{T}_{-}=\frac{\mathrm{FV} \mathrm{C}_{-}}{1000 \mathrm{It}}
$$

In this expression, $\mathrm{V}_{+}$and $\mathrm{V}_{-}$are in milliliters, $\mathrm{C}$ is in equivalents per liter, $\mathrm{t}$ is in seconds, and $I$ is in amperes.

\section{History of Transference Number Measurements}

Two of the earliest investigators to discover that the positive and negative ions in solution do not transport the same amount of current were Daniell (88) and Hittorf (89). Daniell used a cell having three compartments separated by bladder-diaphragms. He observed unequal concentration changes in the cathode and anode compartments.

Hittorf's investigations in 1853-1903 confirmed Daniell's results and helped lead to Kohlrausch's independent migration theory in 1876 and Arrhenius' dissociation theory in 1884 .

Early measurements using the Hittorf method have been summarized by Noyes and Falk (90). More recent work by Jones and Dole (91), Jones and Bradshaw (92), and MacInnes and Dole (93) used improved methods. Nowadays, the Hittorf method is not often used because it is time-consuming.

The use of cells with and without transference was studied by MacInnes and Parker (94), MacInnes and Beattie (95), Hammer (96), and Jones and Dole (97).

The moving boundary method was originated by Lodge (98) who used a gelatin medium through which the ions migrated. He incorporated an indicator ion in the gel which formed either a precipitate or a colored complex with the ion being studied and measured the boundary velocity but erroneously assumed the potential gradient was constant throughout the gel.

Whetham (99) pointed out this error in 1893 and stated that the potential gradient depended on the conductivity of the ionic species and was not the same on both sides of the boundary.

Other advances in the field of transference number measurements by observation of mov ing boundaries were made by Steele (100) in 1901, and Denison and Steele (101) in 1906. Steele formed his boundaries by use of gelatin plugs. The boundaries were then allowed to move into a gelatin-free tube where they were observed. He conceived the idea of making use of the difference in refractive indices of uncolored solutions to follow the boundary movement. Denison and Steele then used a parchment cone to take the place of the gelatin plugs.

Methods for improving the boundary by other boundary-forming devices include those of MacInnes and Smith (102), Macinnes and Brighton (103), and Spedding, Porter, and Wright $(2,3)$. MacInnes and Brighton used a "shearing disk" and Spedding, Porter, and Wright introduced the use of a hollow-bore stopcock to produce the boundary initially.

In 1904 Franklin and Cady (104) used a boundary forming method which has come to be called the "autogenic boundary method". This consisted of a metal electrode such as mercury, copper, or cadmium acting as an anode in contact with the solution. The electrode reaction produced cations of the electrode metal which acted as the indicator ions and the concentration was automatically adjusted to the Kohlrausch ratio by the electric field action. In 192932 Longsworth (105) and Cady and Longsworth (106) again used this method.

In 1897, Kohlrausch (107) derived an important relation between the concentration changes and the movement of the concentration gradient at the boundary. For the passage of one Faraday of current,

$$
\mathrm{T}_{+}=\frac{\mathrm{FV}_{+} \mathrm{C}}{1000 \mathrm{It}}
$$

reriuces to

$$
\mathrm{T}_{+1}=\mathrm{C}_{1} \mathrm{~V}_{1}
$$

where $T_{+1}$ is the cation transference number of the leading solution, $V_{1}$ is the volume in liters swept out by the cations of the leading solutions, and $C$ is the concentration in equivalents per liter. If the cations of the indicator solution are to keep up to the houndary they must sweeps out the same volume as the leading ions so that 


$$
T_{+f}=C_{f} V_{f}
$$

where $T_{+f}$ is the cation transference number of the indicator solution, $C_{f}$ is the concentration of the following solution in equivalents per liter, and $V_{f}$ is the volume swept out by the cations of the following solution. Then since $V_{1}=V_{f}$, the two equations can be combined to give

$$
\mathrm{T}_{+1} / \mathrm{C}_{1}=\mathrm{T}_{+\mathrm{f}} / \mathrm{C}_{\mathrm{f}}
$$

This has come to be known as the "Kohlrausch ratio".' Recent work has shown that the range of concentrations over which this relation operates is about $3-5 \%$, contrary to Kohlrausch's belief that the concentration adjustment of the indicator electrolyte just behind the boundary of any system will take place automatically. There is no such effect on the leading solution by the boundary, however. Thus, the transference number of the leading solution can be quite accurately determined even if the indicator solution does not quite meet the "Kohlrausch ratio" requirements.

A study of this effect was made by Macinnes and Snillı (102). The obscrved transference number gave a cubic equation-lype curve when $T_{\text {obs. }}$ was plotted $v s . \widetilde{C}_{\mathrm{f}}$. The plateau corresponded to the correct value of the transference number su the following oolution concentra = tions were adjusted to operate within this plateau region. A representative curve fur llie scandium chloride system can be seen in Figure 23. The plateau region was found to be greater for small-bore tubes, dilute solutions, and rising buundasles. Ther mal mixing io larger for wide-bore tubes and concentrated solutions, and may cause the solutions to fail to adjust to the concentration given by the "Kohlrausch ratio" if the initial concentration is off hy more than $3-8 \%$.

Since the Hittorf method measures the transference number of an ion with reference to the water of the solution and the moving boundary method measures the motion relative to a fixed mark on the tube, correction must be made for the motion of the water relative to the tube. The partial molal volumes are used to make this correction. The idea of correcting the mov : ing boundary data so that it would then coincide with the Hittorf data obtained with the same solution was proposed by Miller (87) and later calculated quantitatively by Lewis (108). If one side of the cell is left open to the atmosphere and the other is closed, the volume correction calculation is simplified since then one needs to consider only the volume changes between the boundary and the closed side.

Longsworth (105) proposed an additional correction. He observed that in dilute solutions the sum of the cation and anion transference numbers was not exactly one. He reasoned that this was due to that small fraction of the total current which was carried'by impurities in the solvent. Therefore, he derived the following to correct for these impurities:

$$
\Delta \mathrm{T}_{+}=\mathrm{T}_{+}\left(\mathrm{L}_{\text {solvent }} / \mathrm{L}_{\text {solution }}\right)
$$

where $L_{\text {t }}$ is the respective specific conductances.

The complete equation used in calculating the corrected transference number is then

$$
\mathrm{T}_{+}=\frac{\mathrm{FCV}}{1000 \mathrm{It}}-\frac{\mathrm{C} \Delta \mathrm{V}}{1000}+\mathrm{T}_{+}\left(\mathrm{L}_{\text {solvent }} / \mathrm{L}_{\text {solution }}\right)
$$

The first correction term for the volume change during electrolysis is the mure lupuitant of the two in concentrated solutions while the second specific conductance correction term becomes most important in dilute solutions. This is because the specific conductivity of the solution becomes smaller with decreased concentration while the specific conductivity of the solvent remains rnnstant. More will be said of the volume correction for the scandium case in the following Experimental Procedure section. The validity of the volume correction was tested and confirmed by. Smith (109) and MacInnes and Longsworth (110).

Some of the necessary properties of the indicator solution are:

1. The indicator solute must not react with the ion undergoing measurement.

2. The transference number of the indicator ion must be less than that of the leading ion. 
3. The density of the following solution must be less than that of the leading solution for falling boundaries and greater than that of the leading solution for rising boundaries to prevent mixing.

4. There must be a sufficient difference in some property of the leading and following ions which will permit observation of the boundary. Examples of such properties are color and refractive index.

In 1923, MacInnes undertook a very extensive study of the moving boundary method; his work being summarized in a review article by MacInnes and Longsworth (110). Quite a few improvements were made in technique and equipment and they are discussed in the review * article.

LeRoy and Gordon (111) and Hartley and Donaldson (112) used an electronic current controller. Until this time the current often was kept constant manually.

A novel method of transference number measurement was employed by MacInnes (113) who measured the effect of gradients of centrifugal force on the emf of simple galvanic cells.

Transference numbers of the rare earths which share group III of the periodic table with scandium and yttrium have been measured by personnel of the Ames Laboratory $(3,5,6,8)$.

\section{EXPERIMENTAL}

\section{Materials}

The solutions of the chloride and perchlorate used in the conductance measurements were also used in the transference number measurements. Their preparation and the analysis of the oxide used is fully covered in the Experimental section under Conductances. The samples having concentrations between those samples which were used in conductance measurements were prepared by dilution of the conductance samples. Lithium chloride was used as the indicator solution. A stock solution was prepared from reagent grade lithium carbonate by the method of Scatchard and Prentiss (114). The lithium carbonate was treated with reagent grade hydrochloric acid and flushed with nitrogen until the $\mathrm{pH}$ was 6.6. The solution was analyzed by taking aliquots, evaporating to dryness in the presence of sulfuric acid, igniting at $800^{\circ} \mathrm{C}$., and weighing as the sulfate. Solutions to be used in measurements were then made from this stock solution by dilution with conductivity water.

\section{Apparatus}

The complete apparatus consisted of an electrolytic cell, two stop watches, a telescope for viewing the boundary, a constant current source with accompanying voltage measuring circuit, a light box on an elevator for illumination of the cell to make observation of the boundary possible, and a constant temperature bath. A block diagram of the apparatus is given in Figure 19. A picturlal representation of the entire set up is included as Figure 20.

The transference cell was patterned after MacInnes and Longsworth's cell (110) except that the boundary was sheared by a hollow bore stopcock $(2,3)$. Figure 21 is a drawing of the component parts of the cell. It was constructed entirely of pyrex, the calibrated tube being a 2 milliliter pyrcx measuring pipette, graduated in 0.1 milliliter intervals, which was sealed into the apparatus. The silver electrodes were purchased from the Klett Manufacturing Co., New York, New York, and consisted of a hollow silver tube threaded into a silver cylinder. The cylinder was compused uf allernate layers of that and corrugated plates of silver. The silver chloride was plated on by electrolysis in a $1 \mathrm{~N}$ hydrochloric acid solution at 0.45 amps for about 1 hour. The measuring tube was calibrated by previous workers of the Ames Laboratory by weighing the mercury delivered between the marks. This was done prior to incorporation of the measuring pipette into the cell. The anode was made by melting pure cadmium metal in a test tube under vacuum. When cool, a hole was drilled into the center, threaded, and the threaded copper lead screwed into it. The copper was shielded from the solution by a glass tube which extended into a well drilled in the cadmium for it and which was sealed in with Pyseal. The two glass electrode cups prevent any electrode reastion products from getting into the measuring tube. The entire cell was $50 \mathrm{~cm}$ high and $10 \mathrm{~cm}$ wide. 


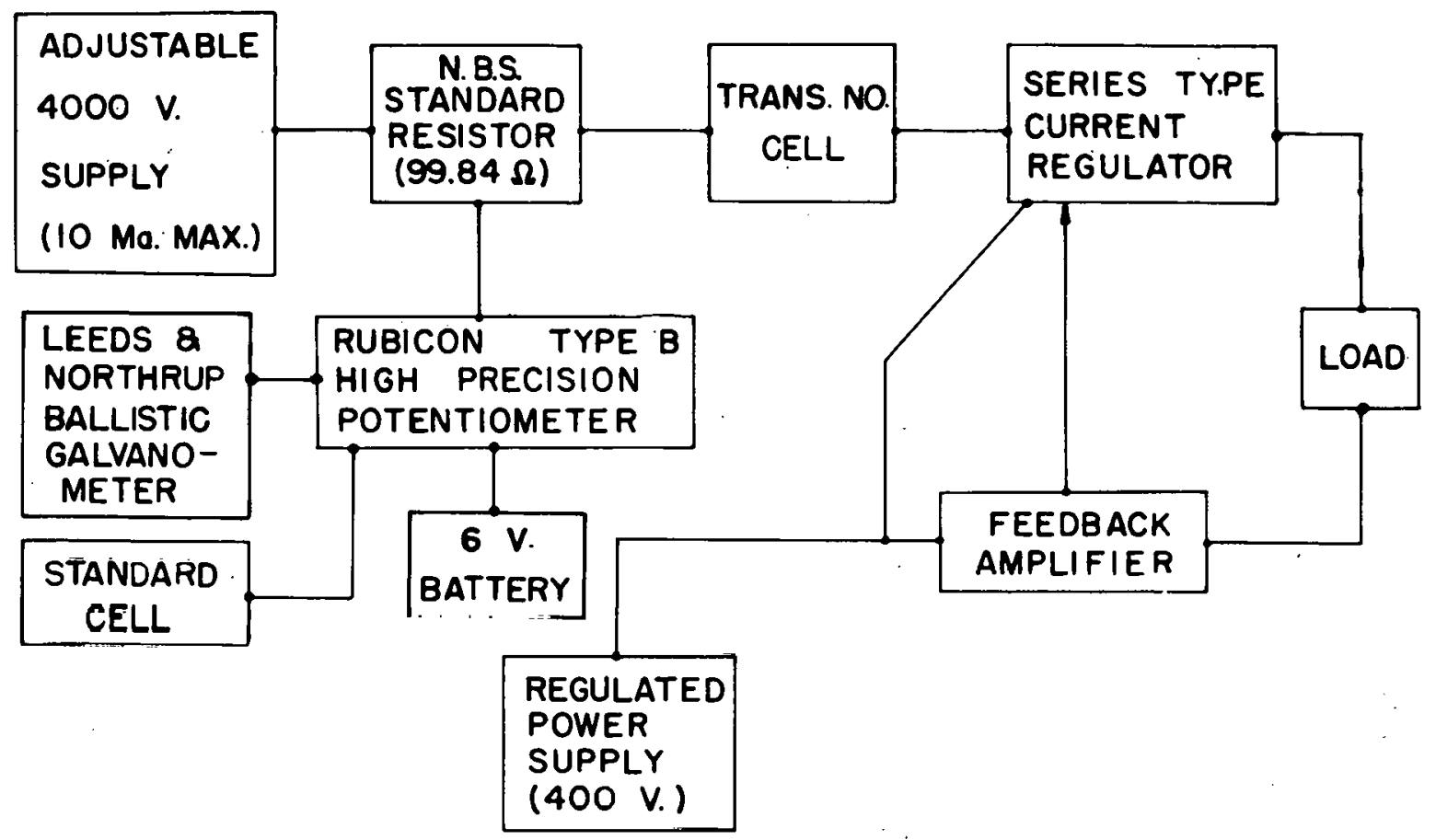

Fig. 10-Block diagram of the apparatus used in transference number determinatiuns.

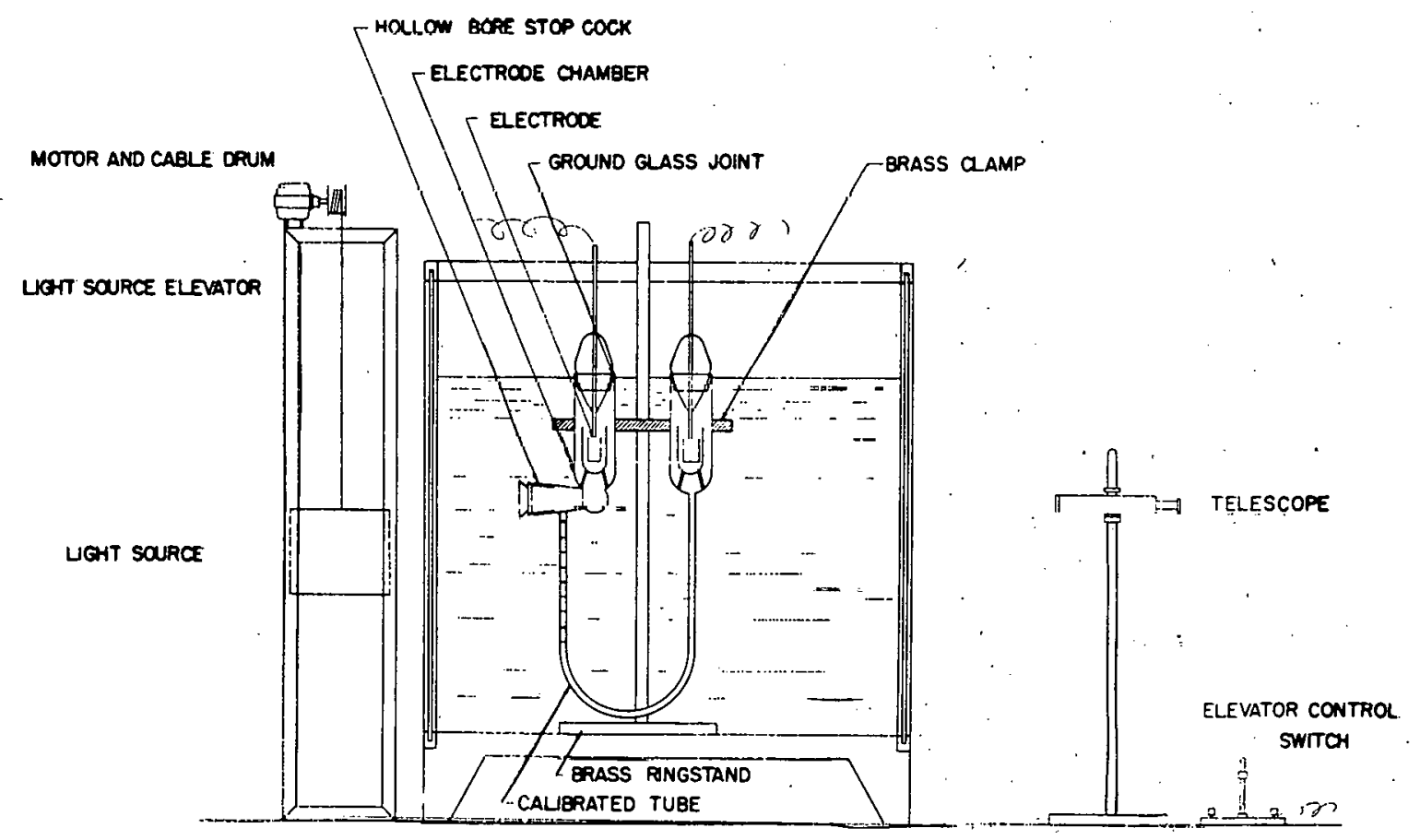

Fig. 20-Pictorial representation of the components of the transference number apparatus. 


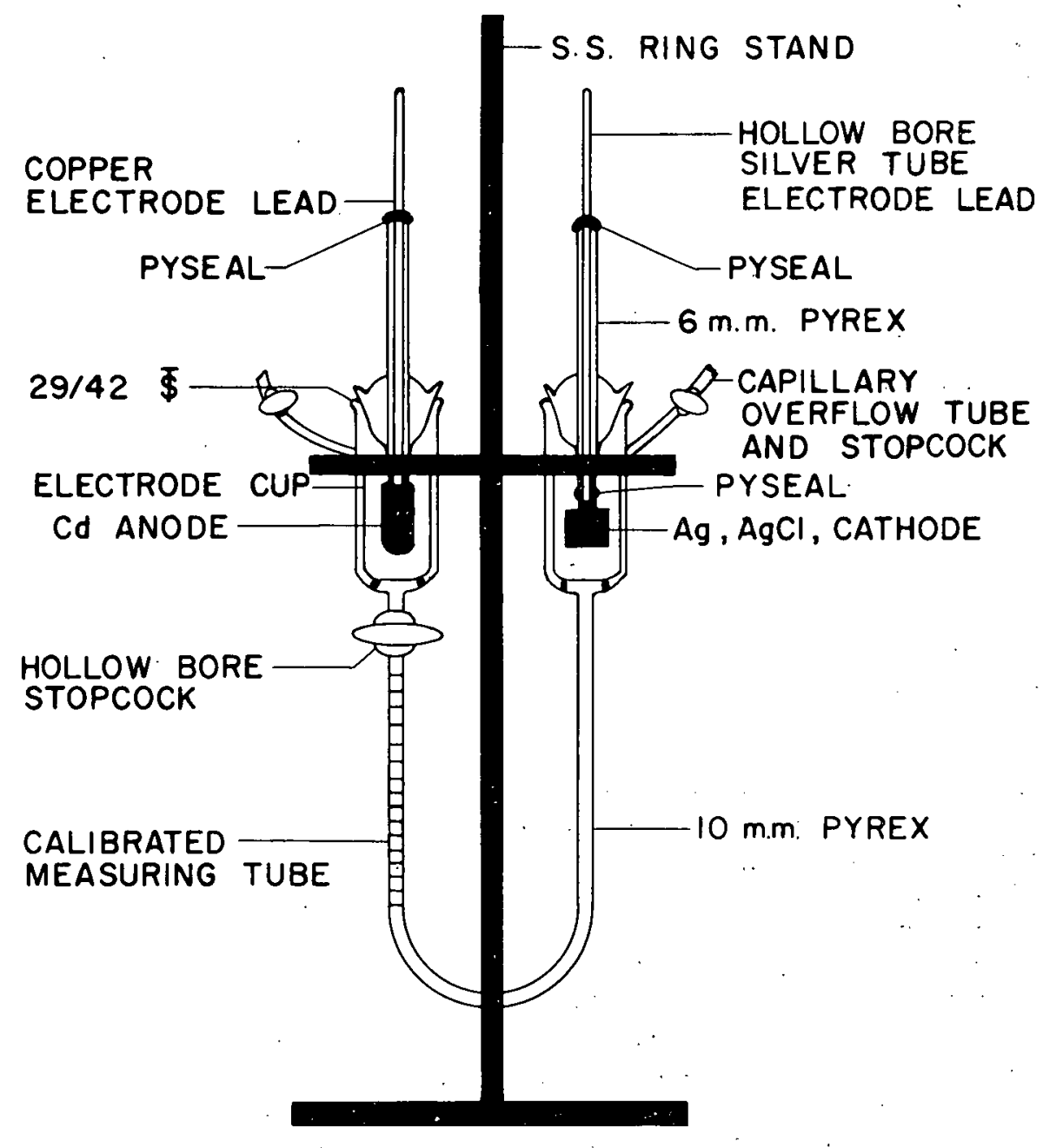

Fig. 21-Component parts of the transference number cell.

The time the boundary took to jass between the graduations on the measuring tube was measured by two stop watches. They had previously been checked on a Western Electric Time Rate Rernrier and shown to be accuratc to within $4-5$ secunds for a 24 hour period. The watches were mounted in a wooden frame which had a hinged lid resting on the crowns of the watches. When the hinged lid was depressed, the one watch was stopped and the other started. By resetting the watches after taking a reading, the cycle could be repeated. This then gave a method of taking continuous, consecutive, individual time readings between marks on the measuring tube.

The boundary was observed by making use of the differences in refractive indices of the leading and following solutions. A light was mounted in a box, connected to a reversible elevator so it could be raised and lowered, and having a frosted glass plate across a narrow slit in the box. When the light was placed on the side of the cell opposite the viewer and adjusted so that it passed through the tube at a critical angle for total reflection, the boundary appeared as a sharp line in the tube. A telescope cathetometer was used for viewing this boundary.

The electronic circuit of the constant current controller which was designed and constructed by the Electronics Shop of the Ames Laboratory is shown in Figure 22. This unit consisted of a high voltage rectifier and filter section which was adjustable to provide up to 4000 volts output at 10 milliamperes, a regulated 400 volt power supply which provided power for the curront regulator ainplifier, and a series type current regulator. The controller provided 


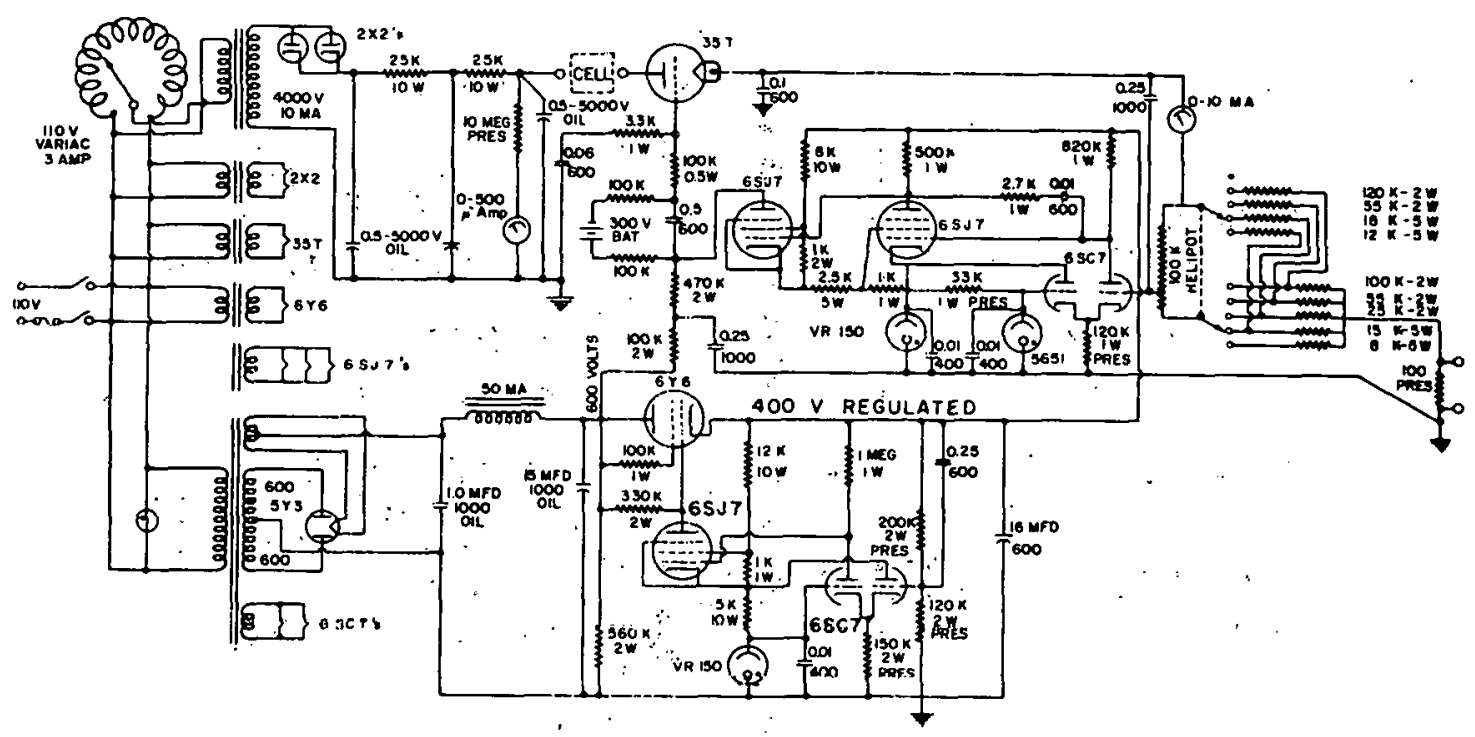

Fig. 22-Electronic circuit of the constant current controller and voltage source used in the transference number measurements.

current which was constant within $0.1 \%$ during a 45 minute period. A $100 \mathrm{ohm}$ standard resistor, calibrated by the National Bureau of Standards, was connected in series with the transference cell and the current regulator. The potential drop across this resistor was measured by a Rubicon Type B High Precision Potentiometer manufactured by the Rubicon Division of The Minneapolis Honeywell Co., Philadelphia, Pennsylvania. The current through the cell was then calculated by use of Ohm's law. Essentially, the cell was also in series with an electronic rheostat whose resistance was controlled by feedback. In turn, the feedback was controlled in such a manner as to tend to keep the current constant. The electronic rheostat was essentially a modification of a conventional voltage regulator. Because of the extremes of cell voltage' needed, the equipment was designed with the load in the plate circuit of the rheostat tube instead of the cathode circuit which is the usual arrangement for such current sources.

A large, glass-walled, aquarium-type, water bath filled with distilled water was used to control the temperature of the cell. The temperature was controlled at $25 \pm 0.05^{\circ} \mathrm{C}$. About 45 minutes were required for the cell to reach thermal equilibrium.

\section{Procedure}

The cathode compartment and the lower loop of the cell, up to the hollow-bore stopcock, was filled with the scandium solution to be measured and the cell assembled as in Figure 21 . The anode compartment was filled with lithium chloride solution which was made up to a concentration as dictated by the "Kohlrausch ratio". After rinsing the outside, the cell was placed in the bath and checked for current leaks with a vacuum-tube voltmeter. After allowing the cell to come to thermal equilibrium, the hollow-bore stopcock was opened, the anode compartment overflow stopcock closed, and the current impressed across the cell. The positive lead was connected to the cadmium anode and the negative lead to the silver-silver chloride cathode.

The first runs were made at constant scandium concentration with varying lithium concentration so the "Kohlrausch ratio" could be determined. This was done with both the chloride and perchlorate. Once the position of the plateau region was found, all following runs were made with lithium solutions of a concentration which would operate in the center of the plateau region. A representative curve for the chloride is included here as Figure 23. The "Kohlrausch $\mathrm{k}^{\prime \prime}$ is defined as

$$
\mathrm{k}=\frac{\text { concentration of lithium chloride }}{\text { concentration of scandium salt solution }}
$$




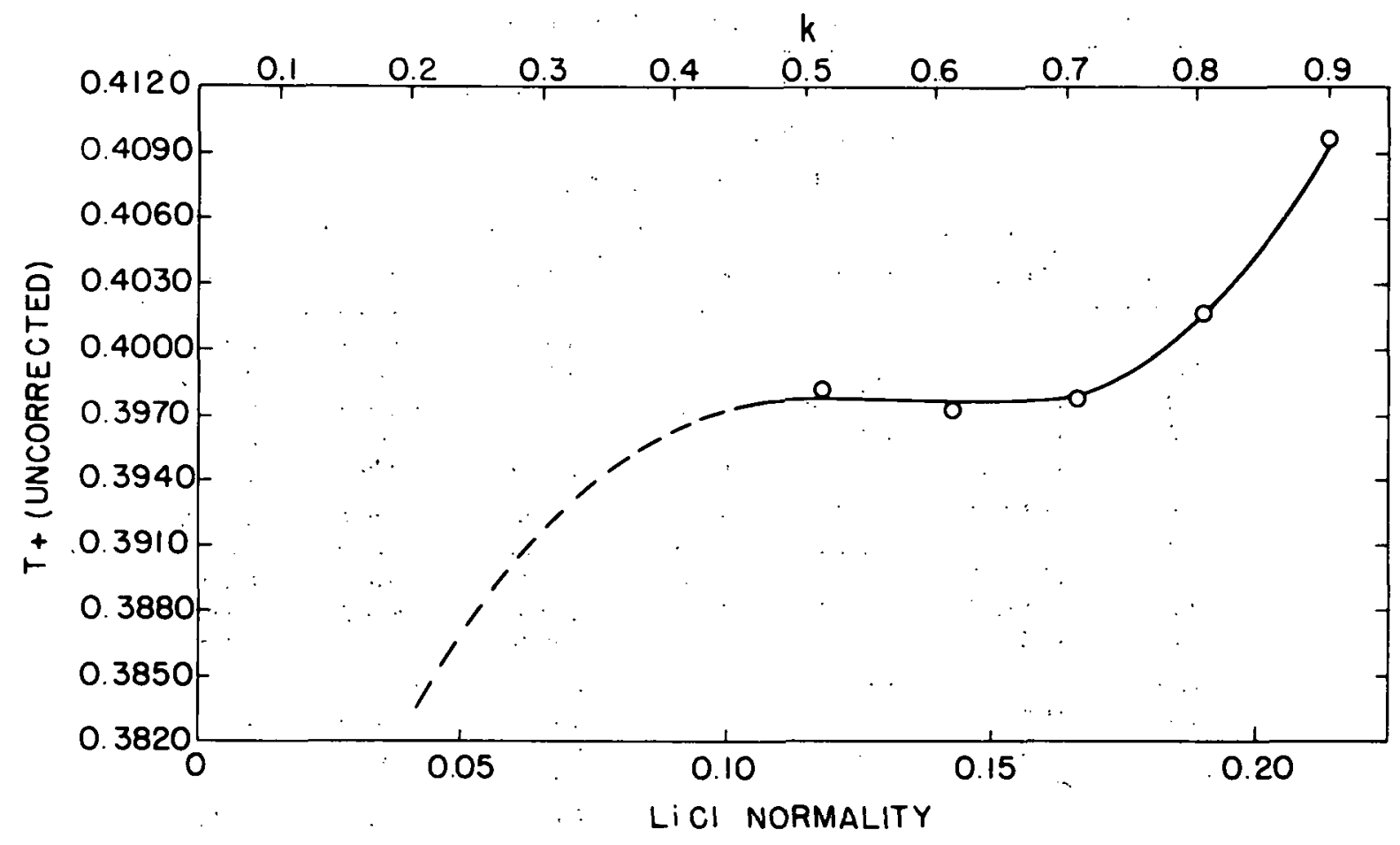

Fig. 23- Representative curve for the determination of the "Kohlrausch ratio" in the case of scandium chloride.

The value of $\mathrm{k}$ was found to be 0.6 for scandium while the people working with rare earths used 0.8. The boundary became too diffuse to observe at the lower end. However, the curve for $\mathrm{KCl}$ was found to follow the pattern portrayed by the dotted line $(40$, p.119).

The progress of the boundary as it moved down the tube was followed by keeping the light source slightly below the boundary and observing it with the cathetometer. The hairline was. lined up with the marks on the tube. As the boundary crossed the hairline, the stopwatch was started. The voltage was read each time the boundary passed a mark also.

Results

A typical set of data is shown in Table 14. The average current was computed from the series of voltage readings. The calibratcd volumes of the measuring tube and the corresponding times were grouped into sets to minimize errors. A transference number was then "calculated for each set and the observed transference number taken as the average over all the sets.

If the measured voltage is reasonably constant, the average value can be used in calculating the observed transference number. As has been shown before, since

$$
\mathrm{T}_{+}=\left[\frac{(\text { Conc. of soln:) } \mathrm{F} \mathrm{R}}{1000 \mathrm{~V}_{\text {measured }}}\right]\left[\frac{\text { volume }}{\text { time }}\right]
$$

then by grouping sets and using the average voltage

$$
\mathrm{T}=\left[\frac{(\text { Conc. of soln:) F R }}{1000 \mathrm{~V}_{\text {average }}}\right]\left[\frac{\Sigma \text { volume }}{\Sigma \text { time }}\right]
$$

where $\mathrm{K}$, as given in Table 14 , is the first term in the above expression. The solution concentration is in equivalents per liter, the volume in milliliters, and the time in seconds. R. has the value of 99.84 ohms as measuired by the National Bureau of Standards. 
Table 14-A Representative Set of Transference Number Data

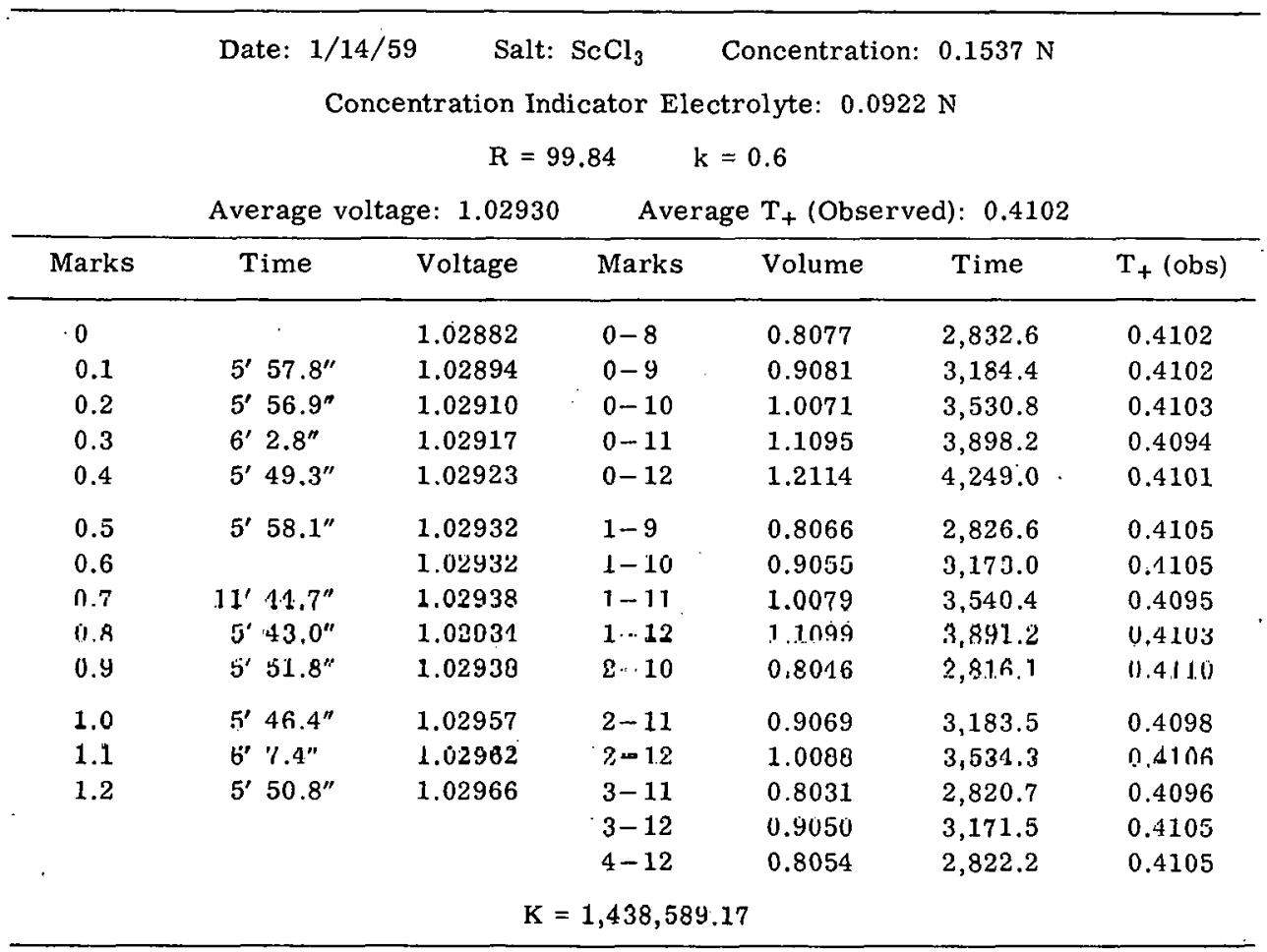

The volume change correction which was referred to in the transference number introduction section was determined using the following values: $\overline{\mathrm{V}}_{\mathrm{Cd}}=13.0 \mathrm{ml}$. (115); $\overline{\mathrm{V}}_{\mathrm{CdCl}_{2}}=24.339+$ $19.982 \mathrm{~m}-26.196 \mathrm{~m}^{2}(9, \mathrm{p} .97)$. The scandium solution partial molal volumes are to be found in the section of this report on Densities and Partial Molal Volumes. The molalities of the scandium solutions were calculated from their normalities by using the densities in the following manner:

$$
\mathrm{m}=\frac{100 \mathrm{~N} / \mathrm{s}}{1000 \mathrm{D}_{25^{\circ}-\mathrm{N}(\mathrm{G} . \mathrm{E} . \mathrm{W} .)}}
$$

where $\mathrm{N}$ is the normality (equivalents per liter), $\mathrm{D}_{25^{\circ}}$ is the density of the solution at $25^{\circ} \mathrm{C}$., and (G. E. W.) is the gram equivalent weight. The molality of the $\mathrm{CdCl}_{2}$ was calculated on the basis of the total charge passed through the cell during an experiment and was

$$
\mathrm{m}=\frac{(\mathrm{It} / \mathrm{F}) 1000}{\text { Total volume change swept out by the boundary }}
$$

The conditions in the cell both before and after electrolysis are pictured in Figure 24. A descending boundary was used. Before the passage of current the boundary is al $B$. Durring the passage of one Faraday of current, the observed rare-earth boundary moves from $\mathrm{B}$ to $\mathrm{C}-\mathrm{C}$ while if there had been no accompanying volume change, it would have been at $C^{\prime}-C^{\prime}$. Of interest then are the volume changes which occur between $\mathrm{A}-\mathrm{A}$ and $\mathrm{C}-\mathrm{C}$ during the passage of one Faraday of current. The losses and gains behind $\mathrm{C}-\mathrm{C}$ are:

For the passage of one Faraday through the cell,

1. There is a loss of $1 / 2$ mole of cadmium metal from the anode so $\Delta \overline{\mathrm{V}}_{1}=-\overline{\mathrm{V}}_{\mathrm{Cd}} / 2$;

2. There is a gain of $1 / 2$ mole of cadmium ions, $\mathrm{Cd}^{+2}$, in the form of $\mathrm{CdCl}_{2}$ so $\Delta \overline{\mathrm{V}}_{2}=$ $+\overline{\mathrm{v}} \mathrm{Cd}^{+2 / 2}$

3. There is a gain of 1 mole of chloride ions from $\mathrm{LiCl}$ to $\mathrm{CdCl}_{2}$ so $\Delta \overline{\mathrm{V}}_{3}=+\overline{\mathrm{V}}_{\mathrm{Cl}^{-}}$; 
4. There is a loss of one mole of chloride ion to $\mathrm{CdCl}_{2}$ from $\mathrm{LiCl}$ so $\Delta \overline{\mathrm{V}}_{4}=-\overline{\mathrm{V}}_{\mathrm{Cl}^{-}}$;

5. There is a gain of $T_{-}$mole of chloride ions into the lithium region due to migration of chloride ions toward the anode so $\Delta \overline{\mathrm{V}}_{5}=+\left(\mathrm{T}_{-}\right) \overline{\mathrm{V}}_{\mathrm{Cl}}{ }^{-}$;

6. There is a gain of $T_{+}$moles of chloride ions in the lithium region due to downward motion of the boundary so $\Delta \overline{\mathrm{V}}_{6}=+\left(\mathrm{T}_{+}\right) \overline{\mathrm{V}}_{\mathrm{Cl}^{-}}$;

7. There is a loss of $\mathrm{T}_{+} / 3$ moles of scandium ions from the scandium chloride region due to migration toward the cathode so $\Delta \overline{\mathrm{V}}_{7}=-\left(\mathrm{T}_{+} / 3\right) \overline{\mathrm{V}}_{\mathrm{Sc}^{+3}}$;

8. There is a loss of $T_{+}$moles of chloride ions from the scandium chloride region so $\Delta \overline{\mathrm{V}}_{8}=-\left(\mathrm{T}_{+}\right) \overline{\mathrm{V}}_{\mathrm{Cl}^{-}}$.

The net change in volume as calculated from the closed side of the cell is then

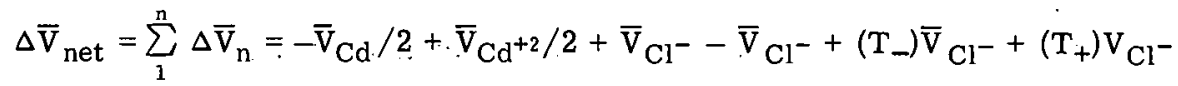

$$
\begin{aligned}
& -\left(\mathrm{T}_{+} / 3\right) \overline{\mathrm{V}}_{\mathrm{Sc}^{+3}}-\left(\mathrm{T}_{+}\right) \overline{\mathrm{V}}_{\mathrm{Cl}^{-}}
\end{aligned}
$$

Since $T_{+}+T_{-}=1$ by definition then

$$
\left(\mathrm{T}_{+}+\mathrm{T}_{-}\right) \overline{\mathrm{V}}_{\mathrm{Cl}^{-}}^{\prime}=\dot{\overline{\mathrm{V}}}_{\mathrm{Cl}^{-}}
$$

and the expression for $\overline{\mathrm{V}}_{\text {net }}$ can then be simplified to

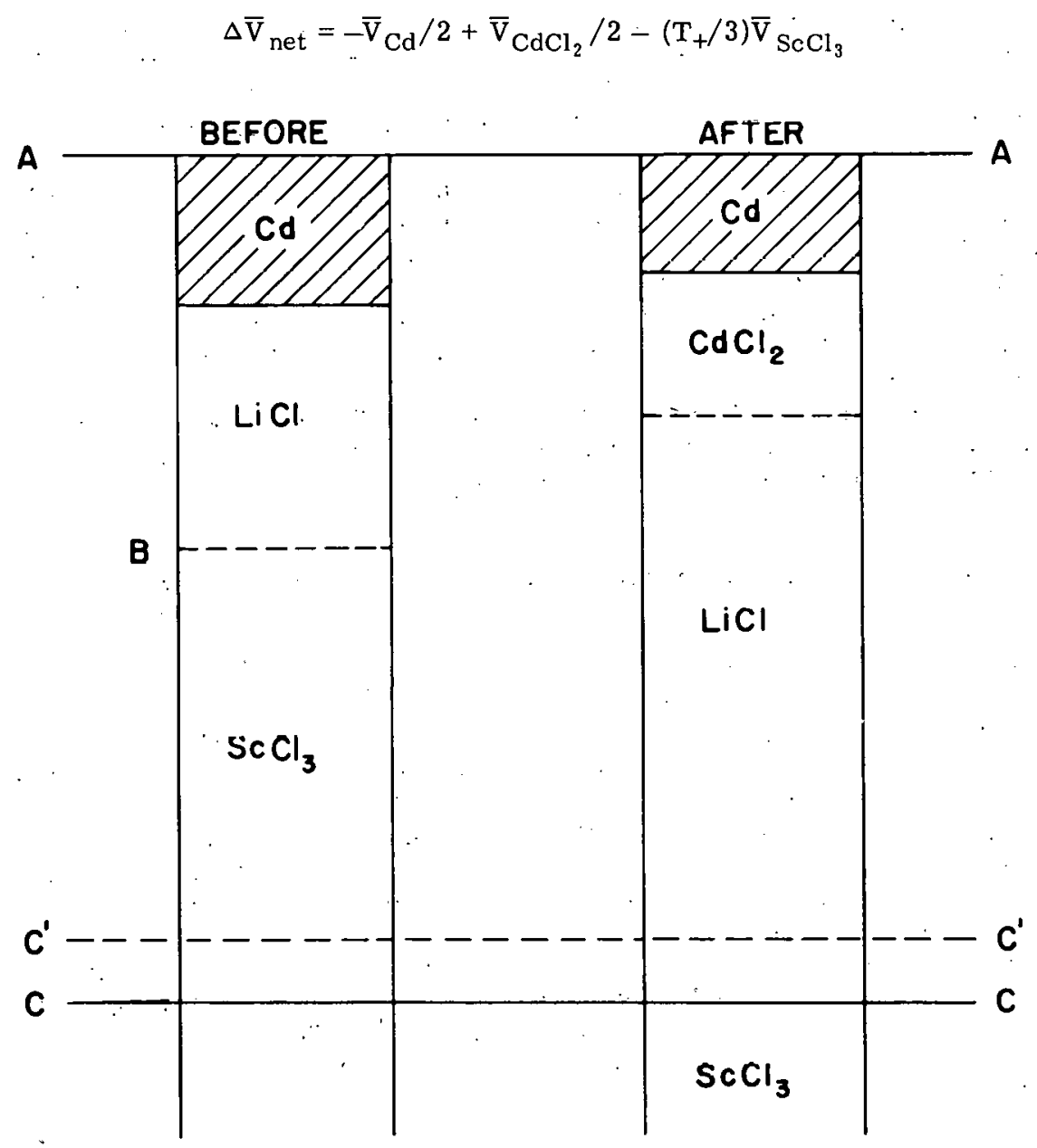

Fig. 24 - Condilions in the cell both before and after electrolysis for the case of the chloride. In the case of the pcrchlorate, an additional region of $\mathrm{LiClO}_{4}$ is built up between the $\mathrm{LiCl}$ and the $\mathrm{Sc}\left(\mathrm{ClO}_{4}\right)_{3}$. 
This was then used in

$$
\mathrm{T}_{+}=\mathrm{T}_{+}^{\prime}-\frac{\mathrm{C} \Delta \overline{\mathrm{V}}_{\text {net }}}{1000}
$$

where $T_{+}$is the volume-change corrected transference number and $T_{+}^{\prime}$ is the uncorrected or observed transference number.

For the perchlorate case, the situation is a little more complex since a $\mathrm{LiClO}_{4}$ region must also be considered. The expression is then

$$
\Delta \bar{V}_{n e t}=\sum_{1}^{n} \Delta \bar{V}_{n}=-\bar{V}_{\mathrm{Cd}} / 2+\bar{V}_{\mathrm{CdCl}_{2}} / 2-\overline{\mathrm{V}}_{\mathrm{Cl}^{-}}+\overline{\mathrm{V}}_{\mathrm{ClO}_{4}}-\left(\mathrm{T}_{+} / 3\right) \overline{\mathrm{V}}_{\mathrm{Sc}\left(\mathrm{ClO}_{4}\right)_{3}}
$$

Since individual ionic partial molal volumes cannot be measured, an approximation

$$
\overline{\mathrm{V}}_{\mathrm{ClO}_{4}}{ }^{--} \overline{\mathrm{V}}_{\mathrm{Cl}^{-}} \approx \overline{\mathrm{V}}_{\mathrm{LiClO}_{4}}-\overline{\mathrm{V}}_{\mathrm{LiCl}}=26.48(84, \text { p. } 115)
$$

was used.

In addition, the conductance correction was applied to the transference number data. The resultant corrected and uncorrected data are given in Tables is and 16 will thelr acculnpanying Figurès 25 and 26.

Table 1b-. Cation Iransference Ninulles a fỉ Dcandium Chlorido

\begin{tabular}{lccccc}
\hline Normality & Normality $^{1 / 2}$ & $\begin{array}{c}\mathrm{T}_{+} \\
\text {(obs.) }\end{array}$ & $\begin{array}{c}\text { Volume } \\
\text { correction }\end{array}$ & $\begin{array}{c}\text { Solvent } \\
\text { correction }\end{array}$ & $\begin{array}{c}\mathrm{T}_{+} \\
\text {(corr.) }\end{array}$ \\
\hline 0.2382 & 0.4880 & 0.3973 & -0.0010 & +0.0000 & 0.3963 \\
$0.1936^{\mathrm{a}}$ & 0.4400 & 0.4033 & -0.0009 & +0.0001 & 0.4025 \\
$0.1537^{\mathrm{a}}$ & 0.3920 & 0.4102 & -0.0007 & +0.0001 & 0.4096 \\
$0.1191^{\mathrm{a}}$ & 0.3151 & 0.4168 & -0.0005 & +0.0001 & 0.4164 \\
$0.0864^{\mathrm{a}}$ & 0.2940 & 0.4260 & -0.0003 & +0.0001 & 0.4258 \\
0.0596 & 0.2140 & 0.4368 & -0.0002 & +0.0002 & 0.4368 \\
\hline
\end{tabular}

${ }^{a}$ These samples were diluted from the original scandium chloride stock solution using the same conductivity water that was originally used in making up the series. The respective conductances were then read from Figure 4.

Table 16- Gation Transference Numhers for Scandium Perchlorate

\begin{tabular}{lccccc}
\hline Normality & Normality $^{1 / 2}$ & $\begin{array}{c}\mathrm{T}_{+} \\
\text {(obs.) }\end{array}$ & $\begin{array}{c}\text { Volume } \\
\text { correction }\end{array}$ & $\begin{array}{c}\text { Solvent } \\
\text { correction }\end{array}$ & $\begin{array}{c}\mathrm{T}_{+} \\
\text {(corr.) }\end{array}$ \\
\hline 0.2436 & 0.4936 & 0.4390 & -0.0038 & +0.0000 & 0.4352 \\
$0.1989^{\mathrm{a}}$ & 0.1160 & 0.4447 & -0.00 .38 & 10.0000 & 0.1409 \\
$0.1576^{\mathrm{a}}$ & 0.3970 & 0.4506 & -0.0029 & +0.0000 & 0.4478 \\
0.1218 & 0.3490 & 0.45154 & -0.0023 & +0.0001 & 0.4572 \\
$0.0901^{3}$ & 0.3001 & 0.4095 & 0.0016 & +0.0001 & 0.4680 \\
0.0609 & 0.2468 & 0.4778 & -0.0010 & +0.0001 & 0.4769 \\
\hline
\end{tabular}

aThese samples were diluted from the original scandium pcrchlorato ctools solution using the same conductivity water that was originally used in making up the series. The respective conductances were then read from Figure 8.

The concentration range could not be extended beyond the range shown here since at one extreme the boundary became too diffuse to follow (concentrated end) and at the other extreme, the boundary moved too fast to conveniently measure it (dilute end). 


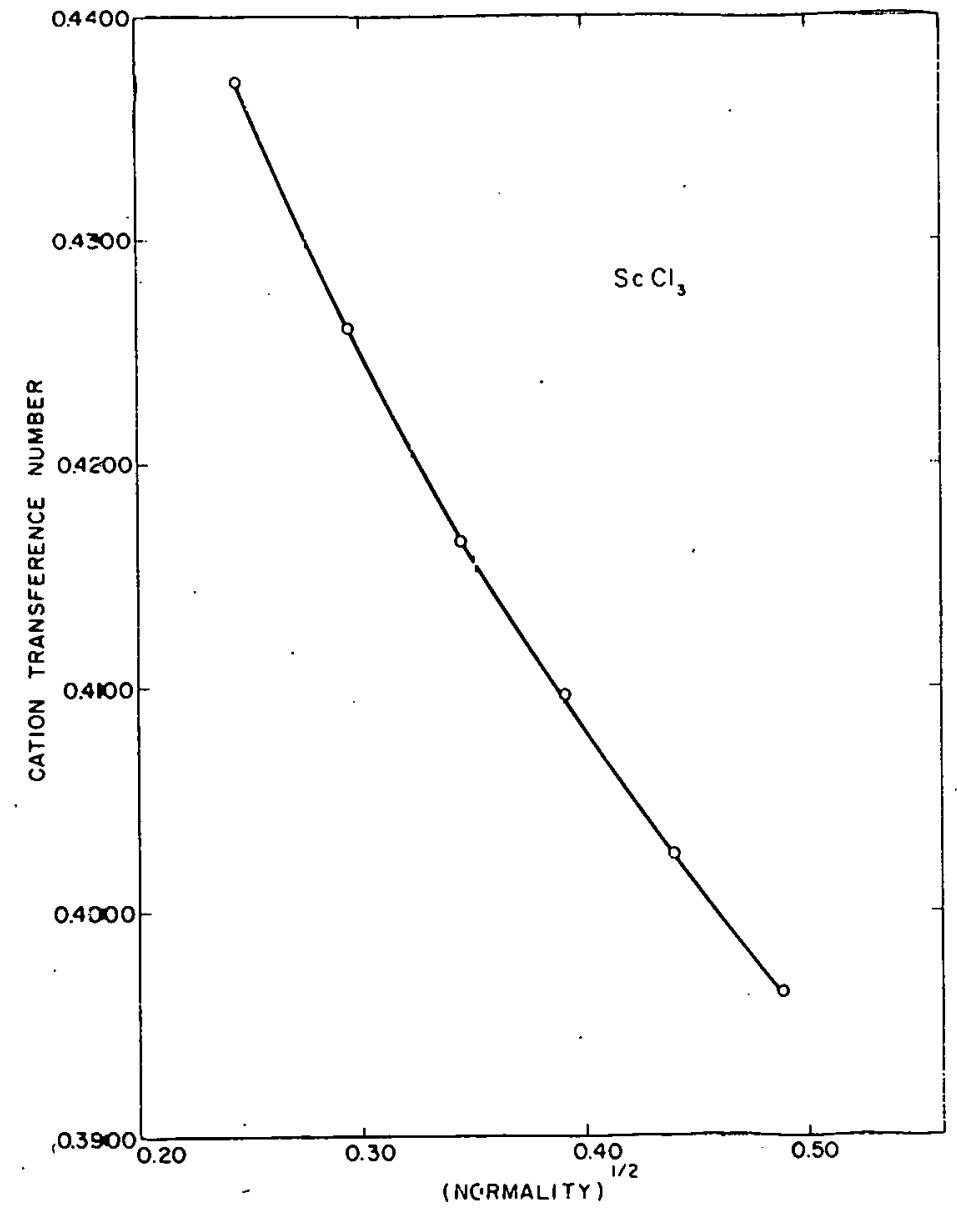

Fig. 25-Cation transference numbers for varying scandium chlcride concentrations.

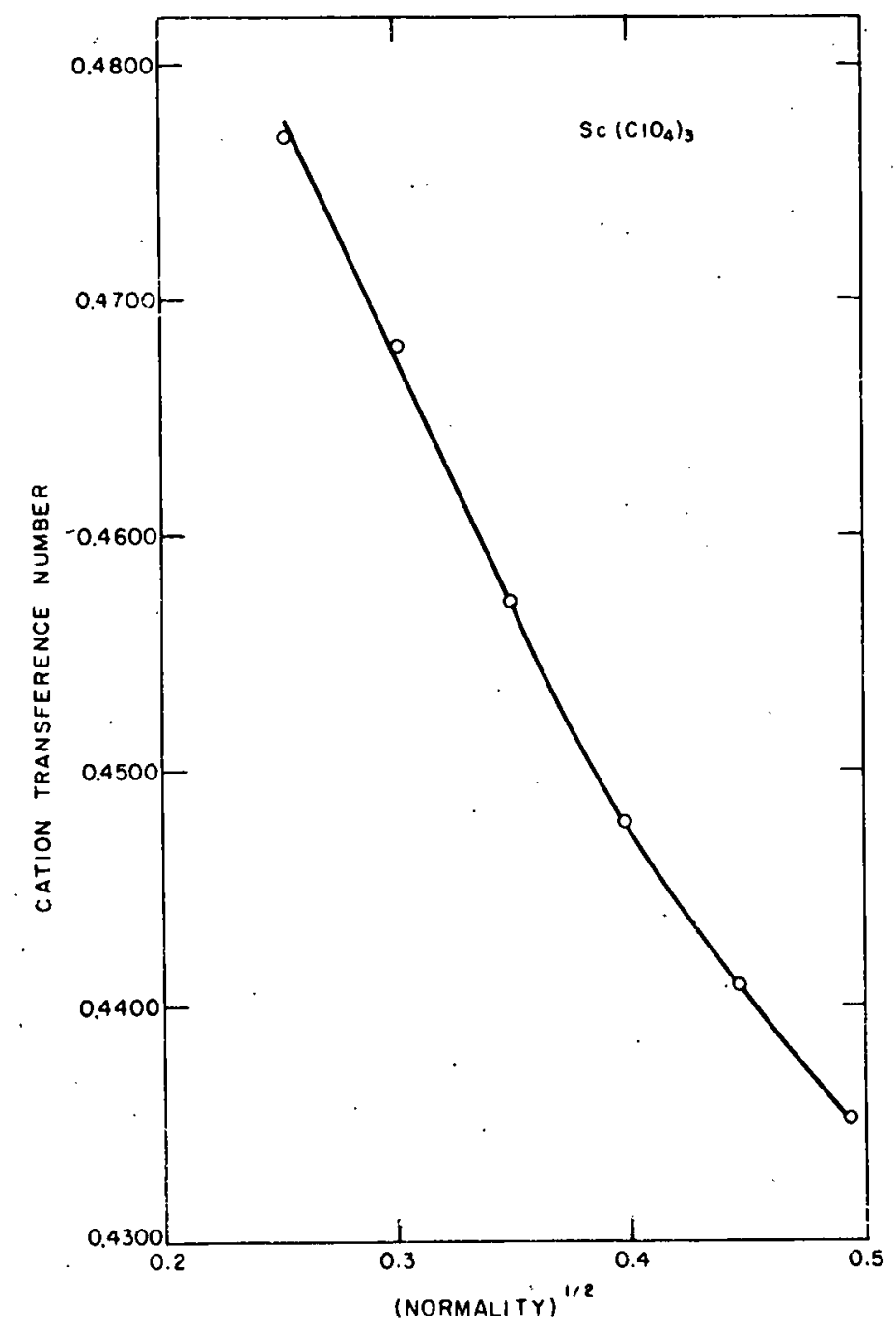

Fig. 26-Cation transference numbers for varying scandium perchlorate concentrations. 
The concentration of the solutions were known to $\pm 0.1 \%$. Since the accuracy of the measurements also depends on the measurement of the time it takes the boundary to travel between marks, the measurement of the current passing through the solution, and the volume of the tube between each set of marks, the total error could be as great as $0.3 \%$ for the uncorrected data and $0.2 \%$ for the corrected data.

The time required for the boundary to travel between marks was at least 120 seconds and the stopwatch could be read to 0.2 second or $0.17 \%$. The average voltage across the standard resistor in series with the cell was usually within $0.03 \%$ of any experimental readings. The volume calibrations were probably good to $0.05 \%$.

The transference numbers for the scandium salts compared with the corresponding rareearth salts were in all cases considerably larger than those for the rare earths.

As in the case of the conductance measurements, hydrolysis again plays a significant part but to a much lesser degree since the transference number runs made use of samples on the concentrated end of the series where the degree of hydrolysis is relatively small.

\section{SOLUBIITIES}

\section{Introduction}

Since baths were already available at $25^{\circ}$ and $60^{\circ} \mathrm{C}$. due to other solubility determinations being carried out and since data on solubilities for scandium salts is lacking in the handbooks, it was decided to do some solubilities as a side issue.

\section{EXPERIMENTAL}

\section{Apparatus}

An oil bath at $60^{\circ} \mathrm{C}$. and a water bath at $25^{\circ} \mathrm{C}$. both $\pm 0.1^{\circ} \mathrm{C}$. and regulated by micro-set thermoregulators was used. A motorized shaker was used in conjunction with the baths.

\section{Materials}

The chloride and perchlorate were prepared by dissolving the oxide in the appropriate acid and recrystallizing from solution. 'The $\mathrm{N}^{\prime}$-(hydroxyethyl)ethylenediamine $-\mathrm{N}, \mathbf{N}, \mathrm{N}^{\prime}$-triacetate was obtained from the eluate from a separation run. The solution was reduced in volume and the solid separated from the liquid. The solid was then dried at $80^{\circ} \mathrm{C}$. with no apparent decomposition. Spectrographic analysis showed the compound to contain no metal ions other than scandium. An attempt was made to prepare the hydrogen scandium ethylenediamine $N, N_{,} N^{\prime}, N^{\prime}-$ tetraacetate but the empirical formula of the compound which resulted was found to be $\mathrm{Sc}[\mathrm{Sc}(\mathrm{EDTA})]_{3} \cdot 6 \mathrm{H}_{2} \mathrm{O}$. Moss (116) found the same type of compounds for the rare earths.

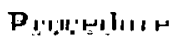

The solubilities were approached from both the saturated and unsaturated sides. After an equilibration time of 2 weeks for the chloride and perchlorate and 2 months for the chelate compound, samples of the solutions were removed and weighed. The solutions were then transferred to crucibles, taken to dryness with heat lamps, treated with nitric acid to avoid oxychloride formation, covered with recrystallized oxalic acid to prevent spattering, and gently. ignited to the oxides at $800^{\circ} \mathrm{C}$. The chelate was likewise destroyed with nitric acid to prevent the compound from swelling out of the crucible during ignition.

An analysis of the crystals in equilibrium with the solutions was made on the samples which were saturated at the start. In this way, the crystals which were analyzed were all grown at the temperature of the respective baths. The crystals were blotted as much as possible, between filter paper, transferred to a weighing vial, weighed, and then transferred to the crucibles for ignition. 
The.results of the solubility tests are given in Table 17. The analysis of the perchlorate crystals was difficult because of the extremely hygroscopic nature of the crystals. To completely resolye this difficulty, it would be necessary to do complete vapor pressure determinations over the crystals as well as perhaps crystal structures at different temperatures. Again, these would have to be done in a carefully controlled atmosphere.

Table 17 - Solubilities of Scandium Salts

\begin{tabular}{|c|c|c|c|}
\hline Salt & Temp., & $\begin{array}{c}\text { Grams/100 grams of water } \\
\text { on basis of empirical } \\
\text { formula shown }\end{array}$ & $\begin{array}{c}\text { Grams } / 100 \text { grams of } \\
\text { water on anhydrous } \\
\text { basis }\end{array}$ \\
\hline \multirow[t]{2}{*}{$\mathrm{ScCl}_{3}$} & 25 & $155.1-\mathrm{ScCl}_{3} \cdot 6 \mathrm{H}_{2} \mathrm{O}$ & $54.9 \dot{6}$ \\
\hline & 60 & $202.6-\mathrm{ScCl}_{3} \cdot 5 \mathrm{H}_{2} \mathrm{O}$ & 138.3 \\
\hline \multirow[t]{2}{*}{$\mathrm{Sc}\left(\mathrm{ClO}_{4}\right)_{3}$} & 25 & & 184.4 \\
\hline & 60 & $\cdot \cdot \cdot \cdot \cdot$ & 192.5 \\
\hline \multirow[t]{2}{*}{ Sc(HEDTA) } & 25 & $0.51-\mathrm{Sc}(\mathrm{HEDTA}) \cdot 6 \mathrm{H}_{2} \mathrm{O}^{2}$ & 0.37 \\
\hline & 60 & $3.32-\mathrm{Sc}(\mathrm{HEDTA}) \cdot 10 \mathrm{H}_{2} \mathrm{O}^{\mathrm{a}}$ & 2.10 \\
\hline
\end{tabular}

${ }^{a}$ The abbreviation, HEDTA, stands for $\mathrm{N}^{\prime}-\left(\right.$ hydroxethyl)-N,N, $\mathrm{N}^{\prime}$-triacetic acid.

\section{Discussion}

In his thesis, Pokras (117) states that the solubility of the perchlorate should be at least 310 grams per 100 grams of water at $25^{\circ} \mathrm{C}$. but that the solution upon which he based this estimate could not be made to recrystallize even when the container was set on dry ice. Indeed, if one calculates the data given in this thesis on the basis of $\mathrm{Sc}\left(\mathrm{ClO}_{4}\right)_{3} \cdot 6 \mathrm{H}_{2} \mathrm{O}$, one obtains a value of 578.0 grams of $\mathrm{Sc}\left(\mathrm{ClO}_{4}\right)_{3} \cdot 6 \mathrm{H}_{2} \mathrm{O}$ per 100 grams of water at $25^{\circ} \mathrm{C}$.

Pokras also measured the vapor pressure over his salt at $25^{\circ} \mathrm{C}$. by isopiestic methods. He assumed he had the hexahydrate. The salt was found to gain weight in the presence of a solution of sulfuric acid and water having the composition of 2.8 moles of water per mole of sulfuric acid and the salt lost weight in a 2.40:1 mixture. Since the vapor pressure of a 2.80:1 mixture is $1.75 \mathrm{~mm}$. at $24^{\circ} \mathrm{C}$. and $1.90 \mathrm{~mm}$ at $26^{\circ} \mathrm{C}$. while a $2.40: 1$ mixture is 2.48 at $24^{\circ} \mathrm{C}$. and 2.70 at $26^{\circ} \mathrm{C}$., the scandium perchlorate had a vapor pressure of $2-3 \mathrm{~mm}$. at $25^{\circ} \mathrm{C}$. Calcium chloride in a saturated solution has a vapor pressure of $4-5 \mathrm{~mm}$. so the perchlorate is a much better desiccant than calcium chloridc. This is the cause of the difficulty in trying to determine accurately the empirical formula of the crystals in equilibrium with the saturated solutions. For mulas having from 5 to 7 waters were obtained with the perchlorate at from $25^{\circ} \mathrm{C}$. to $60^{\circ} \mathrm{C}$. For this reason, no data are given for the perchlorate in Table 17 for other than the anhydrous salt.

\section{STABILITY CONSTANTS}

\section{Introduction}

Until recently, the rare earths and yttrium have been in short supply because of the lack of a good purification method. The work performed at the Ames Laboratory $(118,119,120)$ on the separation of macroscopic quanlities of rare earths paved the way to an abundant supply of pure rare earths for research and industrial applications. The method involved the use of ionexchange resins in conjunction with chelating agents. Stability constants are of interest to workers in the ficld of ion-exchange separations since they allow an estimation of the separation possible as well as the distance of elution required. Powell (121) has reviewed the possible application of several chelating agents to the ion-exchange separation of the rare-earth element.s. 
Wheelwright (122) measured the stability constants for the rare-earth series with ethylenediamine-N,N, $N^{\prime}, N^{\prime}$ - tetraacetic acid (hereafter referred to as EDTA) and $\mathrm{N}^{\prime}$-(hydroxyethyl) ethylenediamine-N,N, $\mathrm{N}^{\prime}$-triacetic acid (hereafter referred to as HEDTA).

It has been found that EDTA separates all the members of the rare-earth series but requires a retaining ion while HEDTA gives a very good separation with all but $\mathrm{Sm}, \mathrm{Eu}, \mathrm{Gd}, \mathrm{Tb}$, Dy, Ho, and Er. On the other hand HEDTA requires no retaining ion other than $\mathrm{H}^{+}$and does a remarkable job of separating several of the common ions from the rare earths (121). Thus, it appears that each chelating agent has its advantages and drawbacks. Ion-exchange workers are continually searching for new chelating agents to use in separation processes.

This research was intended to measure the stability constants of two new chelating agents; 1,2-bis-[2-di(carboxymethyl)-aminoethoxy] ethane (hercafter referred to as DE since it has a diether linkage in the central carbon chain, and 2,2'-bis-[di(carboxymethyl)-amino] diethyl ether (hereafter referred to as ME because it has a monoether linkage) as well as to extend the measurements with EDTA, HEDTA, 1,2-diaminocyclohexane-N,N, $\mathbf{N}^{\prime}, \mathrm{N}^{\prime}$-tetraacetic acid (hereafter referred to as DCTA), and carboxymethyl-bis-[2-di(carboxymethyl)-aminoethyl] amine (hereafter referred to as DE'I'PA) to include scandium.

The otruotural formılae for the chelating agents just mentioned are given in Figure 27.

The stability constants of half uf lle rare-earth ocrios have heen measured for DCTA (123) and all of the rare-earth series for DETPA (124).

An clectron donor, combined with a metal ion, constitutes what is commonly known as a complex or coordination compound. When the substaite which combines with the metid lun cuintains two or more donor groups, structural rings are formed and the resulting complex is more
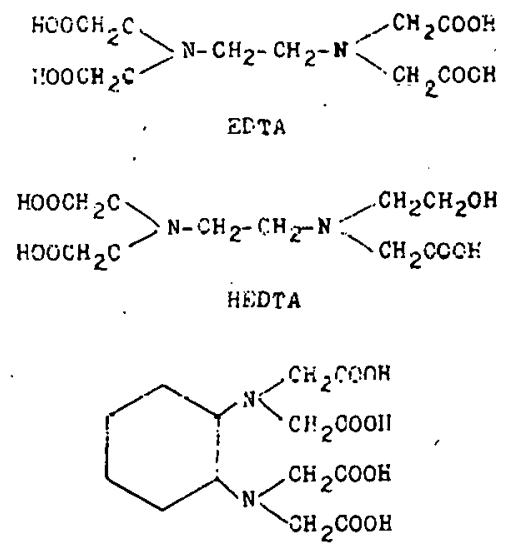

DĆTA<smiles>O=C(O)CN(CCO)CCN(CCO)CCO</smiles>

DETPA

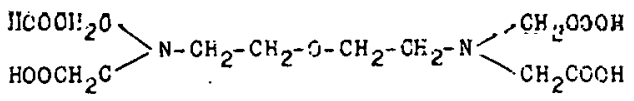

ME

${ }_{\mathrm{HOOCH}} \mathrm{COOCH}_{2} \mathrm{C}>\mathrm{N}-\mathrm{CH}_{2}-\mathrm{CH}_{2}-\mathrm{O}-\mathrm{CH}_{2} \mathrm{OHi}_{2}-\mathrm{CH}_{2}-\mathrm{CH}_{2}-\mathrm{N}>\mathrm{CH}_{2} \mathrm{COOH}$

DE

Fig. 27-Structural formulas of the chelating agents used in this research. 
properly known as a chelate. Both ionic and covalent types of complexes and chelates have been realized, depending upon the particular metal used and the nature of the complexing or chelating agent.

Chelates can be detected by several means among which are:

1. Preparation, isolation, purification, and analysis of prepared compounds;

2. Alteration of normal chemical behavior of a metal ion such as failure of a rare-earth chelate solution to precipitate rare-earth hydroxide when treated witl base;

3. Intensification of color, an example of which is the deepening of the blue copper solution 'color;

4. Conductometric titrations;

5. Measurement of peak shifts in the absorption spectra; and

6. Polarographic analysis in which the half-wave voltage is shifted to more negative values by chelation.

It is an established fact that EDTA can act as a tetra-, penta, or hexadentate chelating agent depending on the metal ion involved and the conditions of the solution such as $\mathrm{pH}$. The hexadentate structure may be visualized as utilizing all four groups as well as the two nitrogen atoms. In the case of DETPA and DE an octadentate chelate structure is possible, utilizing the carboxyls, nitrogens, and oxygens and, in the case of $\mathrm{ME}$, a heptadentate structure is possible. As will be seen later, this complicates the measurement of the stability constants by allowing the formation of bimetallic chelate species with copper.

Several methods of measuring the stability constants of metal chelates have been developed. Schwarzenbach, Willi, and Bach (125) and Schwarzenbach and Ackerman (126) determined the stability constants of the alkaline earth-EDTA complexes by titration of EDTA with standard potassium hydroxide in the presence of a fifteen-fold excess of the metal ion. The titrations were done with silver-silver chloride and hydrogen electrodes in $0.1 \mathrm{M}$ potassium chloride. The results were explained by postulating

$$
\mathrm{M}^{+2}+\mathrm{H}_{2} \mathrm{Ch}^{-2} \rightleftharpoons \mathrm{MHCh}^{-}+\mathrm{H}^{+}
$$

and

$$
\mathrm{M}^{+2}+\mathrm{HCh}^{-3} \rightleftharpoons \mathrm{MCh}^{-2}+\mathrm{H}^{+}
$$

Schwarzenbach used a-graphical procedure to calculate the constants for the above chelates and Martell and Calvin (127) proposed an algebraic method for accomplishing the same task. For complexes of low or intermediate stability, this method was applicable but, with the rare earths, the equilibria were too far to the right to permit accurate calculations.

In order to render it applicable to measurements of stability constants of very stable complexes, the original pH method was modified by Ackerman and Schwarzenbach (128), and Schwarzenbach and Freitag (129). Two chelating agents were used which competed with each other for bonding with a heavy metal ion. A second metal was introduced which formed a very stable complex with one of the chelating agents and no complex with the other chelating agent. To measure the rare-earth constants, Wheelwright (122) used copper and $\beta, \beta^{\prime}, \beta^{\prime \prime}$-triaminotriethylamine (tren) in the reaction

$$
\mathrm{CuCh}^{-2}+\mathrm{H}_{3} \operatorname{tren}^{+3}+\mathrm{M}^{+3} \rightleftharpoons \mathrm{MCh}^{-}+\mathrm{Cu} \operatorname{tren}^{+2}+3 \mathrm{H}^{+}
$$

Partial neutralizalion of the released hydrogen ion with standard sodium hydroxide and subsequent measurement of the $\mathrm{pH}$ enabled him to calculate the rare-earth stability constants.

Two non-pH potentiometric methods have also been applied to stability constant determinations. Schwarzenbach and Heller (130) used a gold electrode to follow the titration of iron(II) sulfate with iodine in the presence of an excess of EDTA. Measurements were done in $0.1 \mathrm{M}$ potassium chloride at $20^{\circ} \mathrm{C}$. By use of a complicated graphic and algebraic treatment of the data, they were able to calculate stability constants for the iron(II) and iron(III) complexes, $\mathrm{FeCh}^{-2}$ and $\mathrm{FeCh}^{-}$, as well as constants for the various hydroxy-complexes formed from the above species. Carini and Martell (131) devised a method for meacurement of the true thermo- 
dynamic equilibrium constants for the alkaline earth-EDTA reactions. Experimentally, the emf of the cell

$$
\text { Pt }-\mathrm{H}_{2}, \mathrm{~K}^{+}\left(\mathrm{m}_{1}\right), \mathrm{M}^{+2}\left(\mathrm{~m}_{2}\right), \mathrm{Cl}^{-}\left(\mathrm{m}_{3}\right), \mathrm{H}_{\mathrm{n}} \mathrm{Ch}^{\mathrm{n}-4}\left(\mathrm{~m}_{4}\right), \mathrm{AgCl}-\mathrm{Ag}
$$

was measured at various temperatures and concentrations $\left(m_{1}, m_{2}, m_{3}, m_{4}\right)$ for $n$ 's of 0 to 2 . The standard free energy change was calculated at each temperature for the reaction

$$
\mathrm{M}^{+2}(\mathrm{aq})+\mathrm{Ch}^{-4}(\mathrm{aq})=\mathrm{MCh}^{-2}(\mathrm{aq})
$$

The iron(III) complex with EDTA has been measured by Kolthoff and Auerbach (132) using spectrophotometric means. The measurements were done in 0.6 to 1 molar perchloric acid to suppress the ionization of the acid-EDTA species and to prevent $100 \%$ formation of iron chelate. This was necessary since iron has such a large stability constant. The concentration of uncomplexed iron was determined by difference from the known total iron content and the spectrophotometric value of the $\mathrm{FeCh}^{-}$content. The $\mathrm{Ch}^{-4}$. concentration was gotten from the four arid dissociation constants and the $\mathrm{pH}$. The iron(III) constant was then determined from

$$
\mathrm{K}_{\mathrm{FeCh}^{-}}=\frac{\left[\mathrm{FoCh}^{-}\right]}{\left[\mathrm{Fe}^{+3}\right]\left[\mathrm{Ch}^{-4}\right]}
$$

Martell and Plumb (133) and Plumb, Martell, and Bersworth (134) employed a competition reaction utilizing two metal cations reacting with half the theoretical amount of chelating agent rcquired to completely chelate both cations. Adjustment of the $\mathrm{pH}$ caused the uncomplexed material to precipitate. Because of the solid phase present, scveral weeks of equilibration, with shaking, was necessary. The individual phases were analyzed spectrophotometrically. Rather large errors were experienced since no correction for possible complexes between free cations and buffer components was made and because the solid phase introduced complications. Only stability constant ratios could be obtained by this method so an independent determination was necessary to obtain absolute values.

Radioactive exchange offers another means of measurement leading to stability constant values. Cook and Long (136) used the method to determine the nickcl-EDTA constant. Nickel(II) ions were added to a radioactive nickel-EDTA chelate solution which was prepared from $\mathrm{Ni}^{63}$. The exchango

$$
\stackrel{\mathrm{NiCh}^{-2}}{*} \mathrm{Ni}^{+2} \rightleftharpoons \mathrm{NiCh}^{-2}+\mathrm{Ni}^{*}+2
$$

took place where the asterisks stand for the radioactive ion. Timed aliquots were treated with hydroxide to precipitate the uncomplexed ions from the mixture, measurement of the activity and $\mathrm{pH}$ then gave stability constants.

The use of ion-exchange techniques for determining stability constants is based on the fact that, in a system consisting of the metal catlun lo be measured, the chelating agent, and the ion-exchange resin, the amount of cations picked up by a definite amount of resin is proportional to the amount of free cations over a wide concentration range. It is necessary to determine the exchange constant in the presence of the chelating agent, $\alpha$, as well as the exchange constant in the absence of the chelating agent, $\alpha_{0}$. Ionic strengths of both sululiuns must match. The stability constant is then

$$
\dot{K}=\frac{\frac{\alpha_{0}}{\alpha}-1}{\mathrm{Ch}^{-n}}
$$

The theory of the method is developed fully in publications by Fronaeus (136) dealing with the copper acetate, nickel acetate; and nickel thiocyanate complexes. The method is best applied to complexes of low stability. 
Conductivity methods (137) can be used to obtain stability constants but are applicable only when the complex is uncharged as with oxalates and malonates of bivalent metals.

Distribution of a metal ion between two immiscible solvents $(138,139,140,141)$ amounts to determining the concentration of the uncharged complex, and consequently this method is limited to systems where an uncharged complex is formed.

The last method which will be discussed here is the polarographic measurement of the concentration of free cations released from the chelated form upon exchange for a second metal ion. Two general approaches have been used. The first depends on the determination of the shift in half-wave potential for the metal ion upon chelation. The shift of the potential as a function of concentration of the chelating ion gives information as to the composition and stability of the complex. Koryta and Kössler (142) measured the nitrilotriacetate complexes of cadmium, lead, and zinc and Matyska and Kössler (143) measured the formation constants for the mercury-EDTA complexes, $\mathrm{HgCh}^{-2}, \mathrm{HgHCh}^{-}$, and $\mathrm{HgOHCh}^{-3}$ using this basic procedure.

The second general polarographic method is the one used in the research for this report. It depends on the fact that each ionic species is reduced at the dropping mercury electrode at a characteristic potential. Individual waves are thus produced provided their half-wave potentials differ by at least 0.2 of a volt. Ackerman and Schwarzenbach (144) studied the reaction between copper(II) and the cadmium-EDTA complex using this method. Titanium-EDTA complexes were studied by Blumer and Kolthoff (145) and Pecsok and Maverick (146).

Bril and Krumholz (147) evaluated a series of stability constant ratios for copper-EDTA with nickel, cadmium, and zinc; cadmium-EDTA with zinc; and lead-EDTA with zinc. The reaction was essentially

1

$$
\mathrm{M}^{+2}+\mathrm{NCh}^{-2} \rightleftharpoons \mathrm{MCh}^{-2}+\mathrm{N}^{+2}
$$

and the equilibrium constant is the ratio of the two metal-chelate stability constants.

Schwarzenbach, Gut, and Anderegg (149) have measured a large number of yarious metal chelate stability constants by use of this method.

\section{EXPERIMENTAL}

\section{Materials}

The rare-earth oxides used in this research were produced by ion-exchange techniques utilizing the methods perfected in the Ames Laboratory $(118,119,120,121)$. All were equal to or greater than $99.9 \%$ pure. Nitrate stock solutions were prepared by dissolving an excess of oxide in reagent-gradc nitric acid and filtering off the excess oxide. The solutions were analyzed gravimetrically for rare-earth content. Hundredth-molar solutions were prepared from these stock solutions.

The chelating agents (EDTA, HEDTA, DCTA, DETPA, ME, and DE) were obtained from Geigy Industrial Chemicals, a division of Geigy Chemical ronporation, Aı dsley, New York.

Standard, carboinale-free potassium hydroxide was prepared by the method of Powell and Hiller (73) for use in standardizing and preparing the 0.0100 molar potassium chelates.

Hundredth-molar scandium nitrate was prepared by dilution of the stock solution prepared for use in conductance measurements.

All other chemicals used in this research were reagent-grade chemicals. One molar potassium nitrate was used to adjust the ionic strength; 0.1000 molar sodium acetate-acetic acid buffer to hold the $\mathrm{pH}$ at 4.65 ; and 0.0100 molar cadmium and copper nitrate for standards.

\section{Apparatus}

A Sargent model XXI polarugraph sold by Sargent and Company, Chicago, Illinois was used in this research. The cell was fashioned from a 100 milliliter beaker. The saturated calomel electrode was connected to the cell by a potassium nitrate-agar bridgc. The cell was immersed in a constant temperature bath. 


\section{Procedure}

The samples were prepared by combining:

1. Ten milililiters of 0.0100 molar cadmium or copper nitrate,

2. Ten milliliters of 0.1000 molar buffer,

3. Ten milliliters of rare-earth or scandium nitrate,

4. Ten milliliters of 0.0100 molar tri-, tetra-, or penta-potassium chelate depending on which chelating agent was being used,

5. Enough potassium nitrate to adjust the ionic strength to 0.1 (taking into account the potassium nitrate formed in the reaction of the potassium chelates with the rare-earth and scandium nitrates).

The mixtures were then diluted to a total volume of 100 milliliters.

The completely complexed reference solutions contained the same concentrations of copper or cadmium, chelate, and buffer with an ionic strength of 0.1 while the free-metal reference solutions contained the same concentrations of copper or cadmium and buffer with an ionic strength of 0.1 . The europium runs were done by replacing cadmium with europium.

Two drops of $0.2 \%$ basic fuchsin were ddded to the aliquots introduced to the cell in the case of rnpper. This effcctivoly sulpresscd the maxima. No suppressant was necessary with llit cadmium or enrophunt.

Helium or argon was bubbled through the cell prlur lu inalking a measuremenl to remove oxygen.

The diffusion currents of the samples and attendant standards were used to calculate the percentage of released cation.

Derivation of the necessary equations procceds as follows:

When equal molar amounts of the potassium metal chelate and rare-earth nitrate equilibrate, the rare earth competes with the motal ion for the chelate,

$$
\mathrm{MCh}^{-2}+\mathrm{R}^{+3} \rightleftharpoons \mathrm{RCh}^{-}+\mathrm{M}^{+2}
$$

where $\mathbf{M}$ is copper or cadmium, $\mathbf{R}$ is the rare earth or scandium, and $\mathrm{Ch}$ stands for, a tetrabasic chelate. The reduction waves which were measured for this research were

$$
\begin{aligned}
& 2 \mathrm{e}^{-}+\mathrm{Cu}^{+2} \rightleftharpoons \mathrm{Cu}, \mathrm{E}_{1 / 2} \approx-0.05 \\
& 2 \mathrm{c}^{-}+\mathrm{Cd}^{+2} \rightleftharpoons \mathrm{rd}, \mathrm{E}_{1 / 2} \approx-0.60
\end{aligned}
$$

and

$$
\mathrm{e}^{-}+\mathrm{Eu}^{+3} \rightleftharpoons \mathrm{Eu}^{+2}, \mathrm{E}_{1 / 2} \approx-0.68
$$

The diffusion current is proportional lu llie concentration of the species producing the pular ugraphic wave. The percentage of uncomplexed copper was calculatcd: from the ratio of the diffusion currents of each of the rare-earth runs to thuse of thc two referenice solutions. Since the metal-chelate waves were lar cnough remned from the free metal waves in all: cases, no correction for cunli ibution by the rnmpletely complexed reference solution was necessary.

Since the rcactants were originally present in equimolar quantities, the following cxpressions hold at equilibrium: $[\mathrm{RCh}]=[\mathrm{M}]$ and $[\mathrm{MCh}]-[\mathrm{R}] \equiv \mathrm{C}$. [M]: wherr. $\mathrm{C}$ is the initial concentration of both reactants. The equilibrium constant for the exchange reaction is

$$
\mathrm{K}_{\mathrm{eq}:}=\frac{[\mathrm{M}][\mathrm{RCh}]}{[\mathrm{MCh}][\mathrm{R}]}
$$

If one writes the equations for the complexing of the rare earth and cadmium and their accompanying constants, 


$$
\mathrm{R}_{\cdot}^{+3}+\mathrm{Ch}^{-4} \rightleftharpoons \mathrm{RCh}^{-}, \quad \mathrm{K}_{\mathrm{RCh}}=\frac{[\mathrm{RCh}]}{[\mathrm{R}][\mathrm{Ch}]}
$$

and

$$
\mathrm{M}^{+2}+\mathrm{Ch}^{-4} \rightleftharpoons \mathrm{MCh}^{-2}, \quad \mathrm{~K}_{\mathrm{MCh}}^{\prime}=\frac{[\mathrm{MCh}]}{[\mathrm{M}][\mathrm{Ch}]}
$$

it is evident that

$$
\mathrm{K}_{\mathrm{eq} .}=\frac{\mathrm{K}_{\mathrm{RCh}}}{\mathrm{K}_{\mathrm{MCh}}}=\frac{[\mathrm{M}][\mathrm{RCh}]}{[\mathrm{MCh}][\mathrm{R}]}=\frac{[\mathrm{M}]^{2}}{(\mathrm{C}-[\mathrm{M}])^{2}}
$$

Therefore,

$$
\mathrm{K}_{\mathrm{RCh}}=\mathrm{K}_{\mathrm{MCh}} \frac{(\% \mathrm{M})^{2}}{(100-\% \mathrm{M})^{2}}
$$

or

$$
2 \log \frac{\% \mathrm{M}}{100-\% \mathrm{M}}=\log \mathrm{K}_{\mathrm{RCh}}-\log \mathrm{K}_{\mathrm{MCh}}
$$

The values of $\log \mathrm{K}_{\mathrm{MCh}}$ for copper and cadmium which were used to compute the rare earth and scandium constants are given in Table 18.

Table 18-Copper-Chelate and Cadmium-Chelate Stability Constants Uscd in Calculating the Rare-Earth and Scandium-Chelate Constants

\begin{tabular}{lccc}
\hline $\begin{array}{c}\text { Chelating } \\
\text { agent }\end{array}$ & $\begin{array}{c}\text { Copper } \\
\text { constant }\end{array}$ & $\begin{array}{c}\text { Cadmium } \\
\text { constant }\end{array}$ & $\begin{array}{c}\text { Temperature } \\
{ }^{\circ} \mathrm{C} .\end{array}$ \\
\hline EDTA & $18.80^{\mathrm{a}}$ & $16.62^{\mathrm{b}}$ & 20 \\
HEDT A & $17.4^{\mathrm{c}}$ & $13.0^{\mathrm{c}}$ & 29.6 \\
DCTA & $21.30^{\mathrm{d}}$ & $19.23^{\mathrm{d}}$ & 20 \\
DETPA & & $18.93^{\mathrm{e}}$ & 20 \\
DE & & $16.73^{\mathrm{b}}$ & 20 \\
ME & & $16.27^{\mathrm{b}}$ & 20 \\
\hline
\end{tabular}

\footnotetext{
${ }^{a}$ Reference, 123 , p. 76.

${ }^{b}$ Reference 150.

${ }^{c}$ Referènce 123, p. 78 .

dReference 123, p. 89.

Reference 151 .
}

When stability constants for EDTA, HEDTA and DCTA with scandium were measured against copper no extraneous waves were noted in the polarograms. Data for these measurements are presented in Table 24. Figure 28 is the HEDTA-Sc-Cu curve which illustrates the general appearance of the measurable polarographic curves. In the c:ase of DETPA, ME, and $\mathrm{DE}$, however, it was impussible to use copper as the standard because curves such as shown in Figure 29 resulted. The waves labeled $A, B$, and $C$ on curve number 2 were due to copper ion, di-copper chelate, and copper chelate species, respectively. Since it was known that cadmiumDETPA gave a single break when titrated with base, indicating complete dissociation of the hydrogen-cadmium chelate, and also exhibited no tendency to form a di-cadmium species, as indicated by titration curves and polarographic studies, it was decided to use carmium as a 


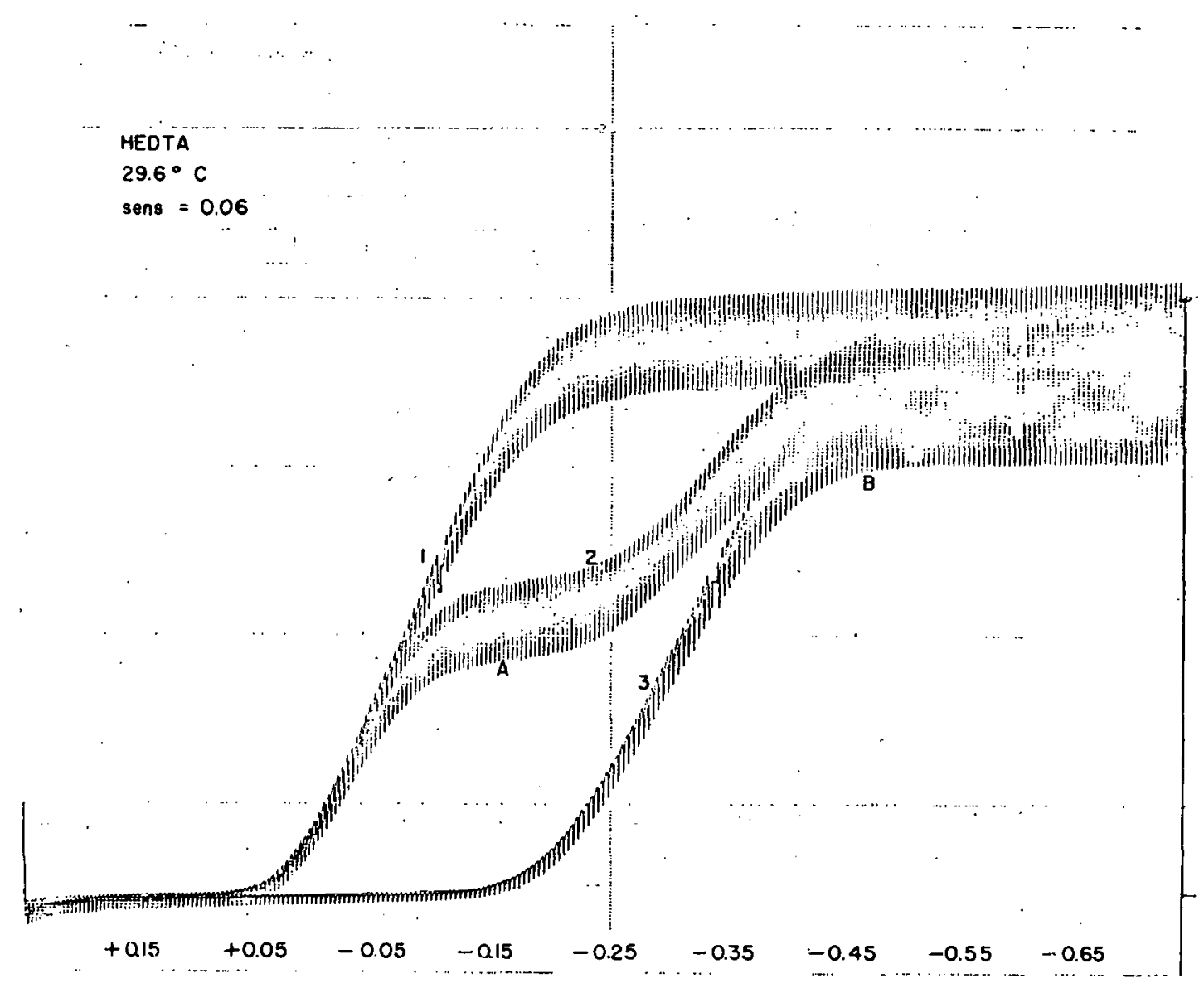

Fig. 28-Polarographic curves obtained for the HEDTA-scandium-copper case.

standard for the scandium and rare-earth chelate measurements. However, it was soon dis covered that the cadmium-chelate stability constants were so much smaller than the scandiumchelate constants that almost $100 \%$ of the cadmium was released in every case. As a consequence large errors resulted.

The method used in measuring the diffusion currents for all of the polarographic determinations is shown in Figure 30. The lines are drawn in order from $A-A^{\prime}$ to $H-H^{\prime} . J-J^{\prime}$ is then drawn through the intersection of $\mathrm{C}-\mathrm{C}^{\prime}$ and $\mathrm{H}-\mathrm{H}^{\prime}$. The diffusion current is measured as the length trom lie intcrcoction of $B-B^{\prime}$ with $J-J^{\prime}$ to the interscetion of $A-A^{\prime}$ with $J-J^{\prime}$. The halfwave potential is the ratio of the length $R-L$ to the voltagc per unit length.

Because ot the failure of the rarmium to give measurable answers with scandium, a standard was needed which had a much larger stability constant. Eulupium mot this requirement and sulseciucntly, all the srandium chelates were done against europium and the $\mathrm{ME}-$ rart-earth and DE-rare-earth constants were measured dydinst both carminm and europium. The europium constants are given in Table $1 \mathrm{l}$.

The trend in the polarographic waves for the DE-rare-earth case is shown in Figure 31 and the data obtained from all the polarographic runs on DE and ME are presented in Tables 20-23 with accompanying Figures $32-35$ while the scandium results are to be found in Table 24.

All runs were done at an ionic strength of 0.1 with potassium nitrate as the supporting electrolyte. The voltage limits used in measurements on copper were +0.25 to -0.75 , those for cadmium were -0.30 to -1.30 , and those for europium were -0.40 to -1.1 . 


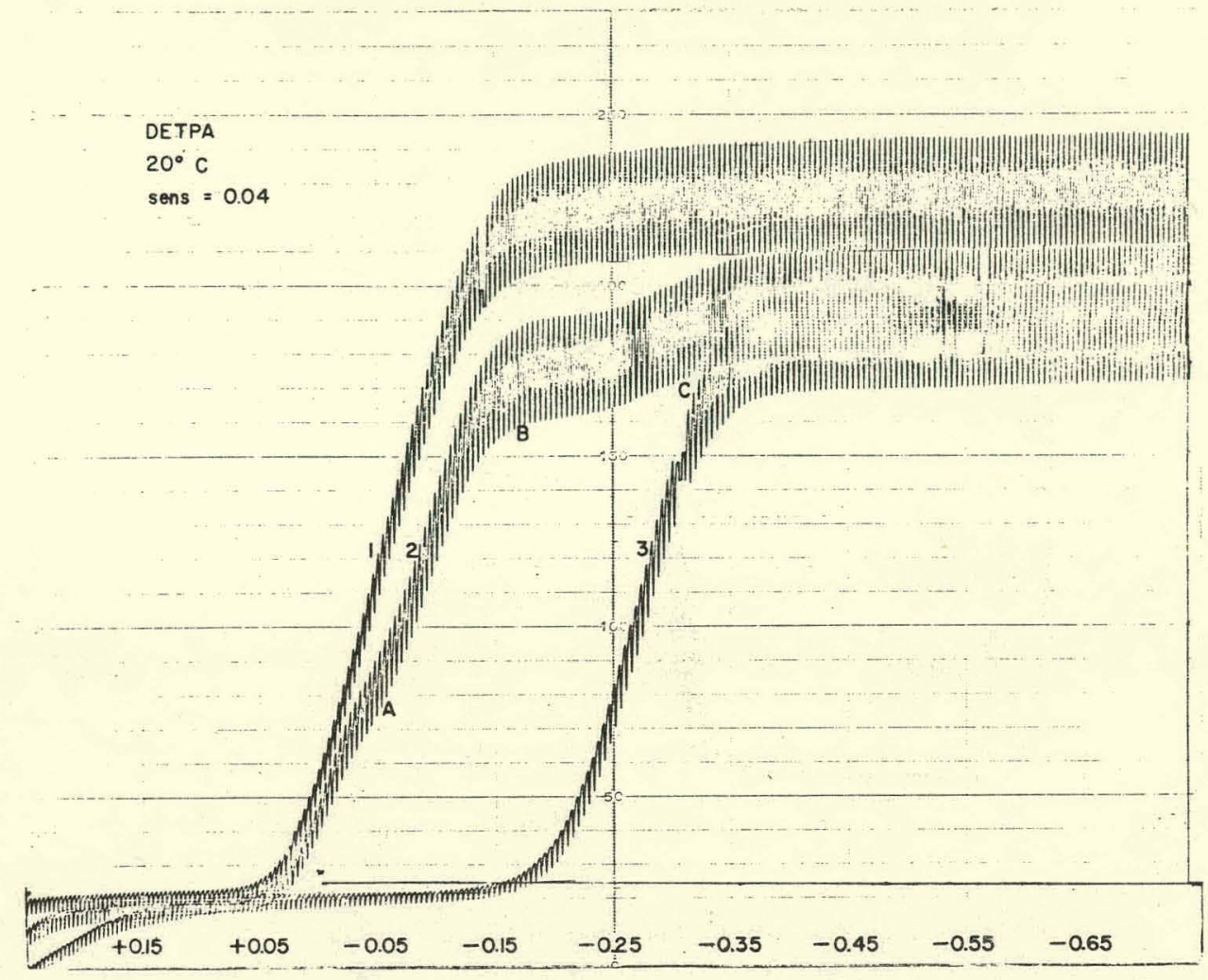

Fig. 29-Polarographic curves obiained for the DETPA-scandium-copper case. Curve 1 is due to the free copper ion; curve 2 is the equilibrium mixture; and curve 3 is the completely chelated copper. The letters on each curve mark the individual waves observed in that curve.

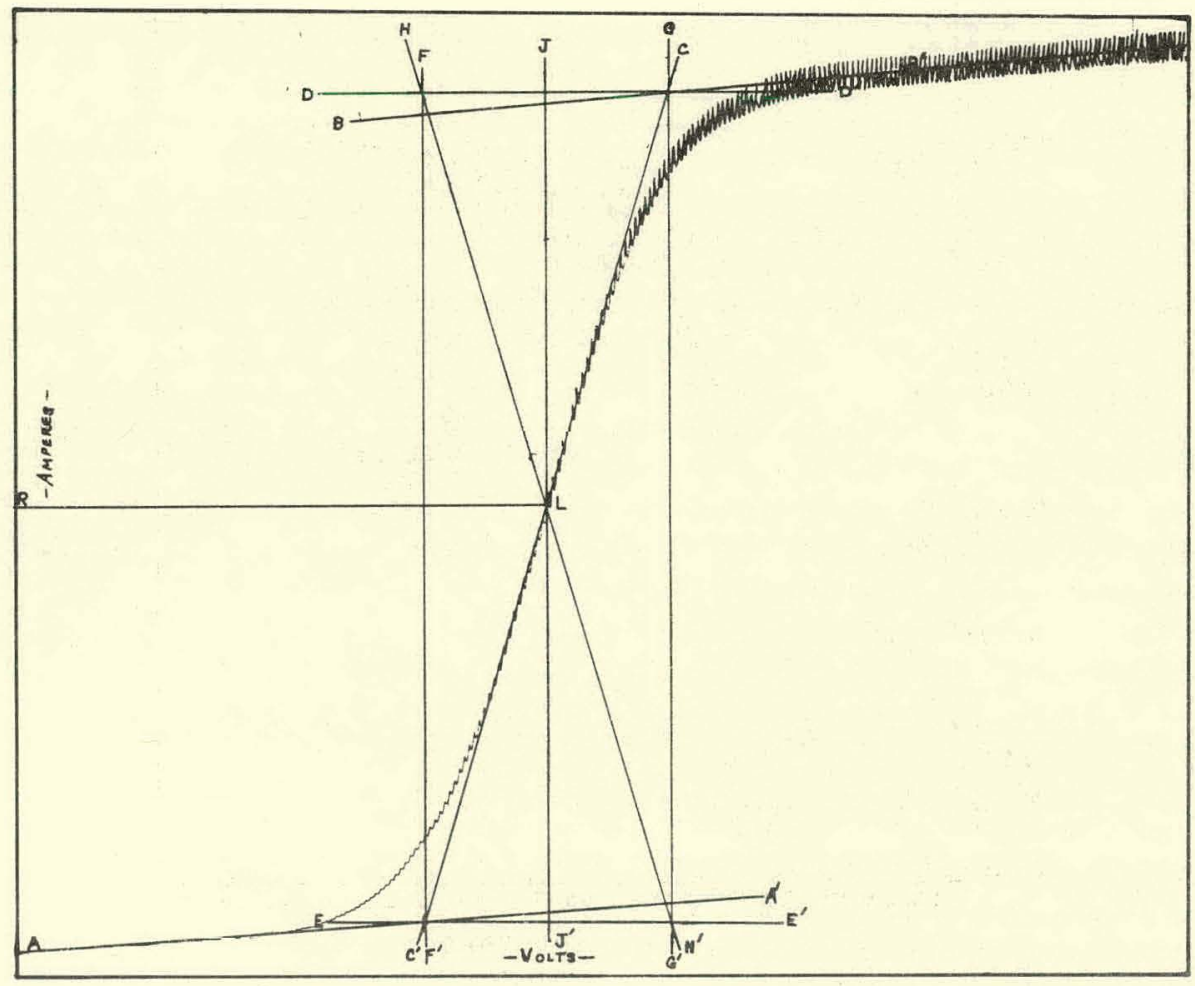

Fig. 30-Construction of lines for determining the diffusion current from the polarographic curves. 


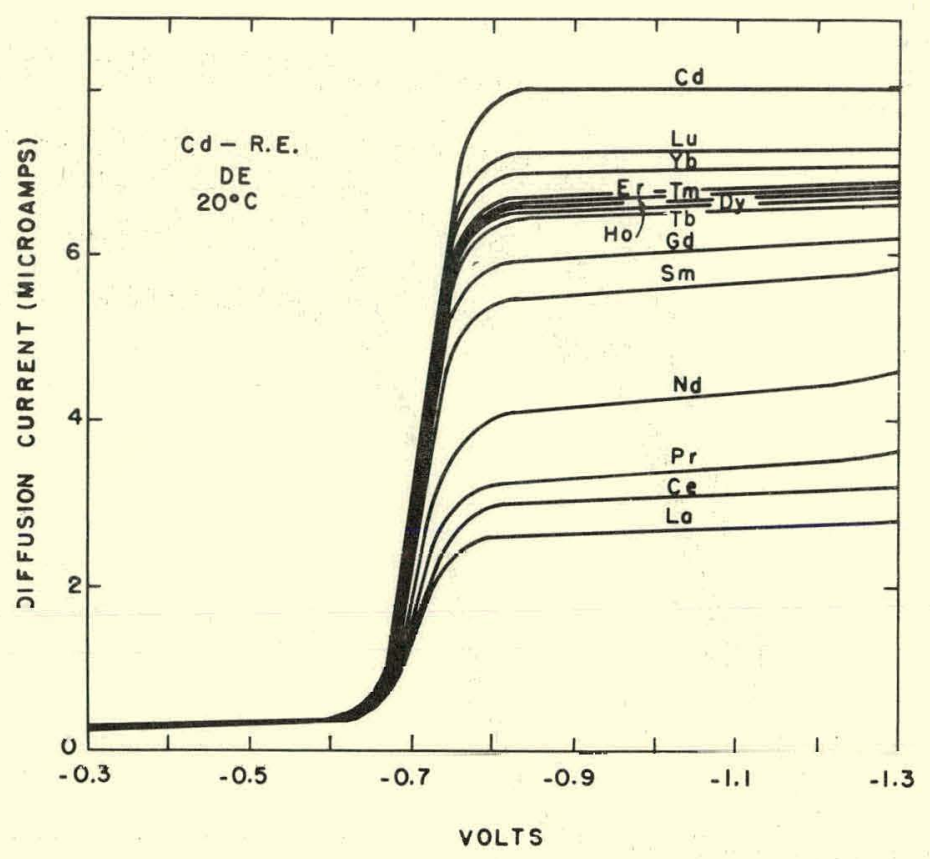

Fig. 31-Progressive trends in the polarographic curves for the DErare-earth system using cadmium as the standard. The general character of the ME curves was identical.

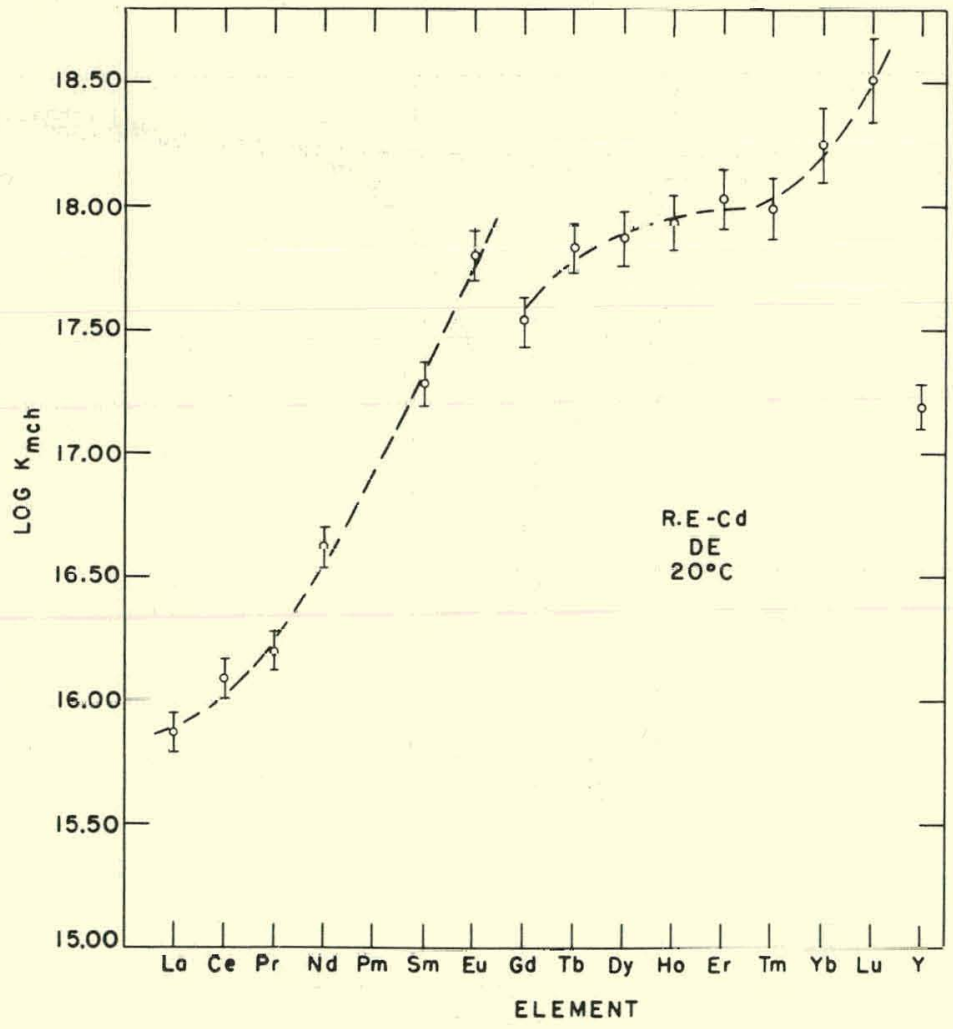

Fig. $32-$ Rare-earth-DE-stability constants at $20.00 \pm 0.02^{\circ}$ C., based on cadmium, and showing the uncertainty range. 


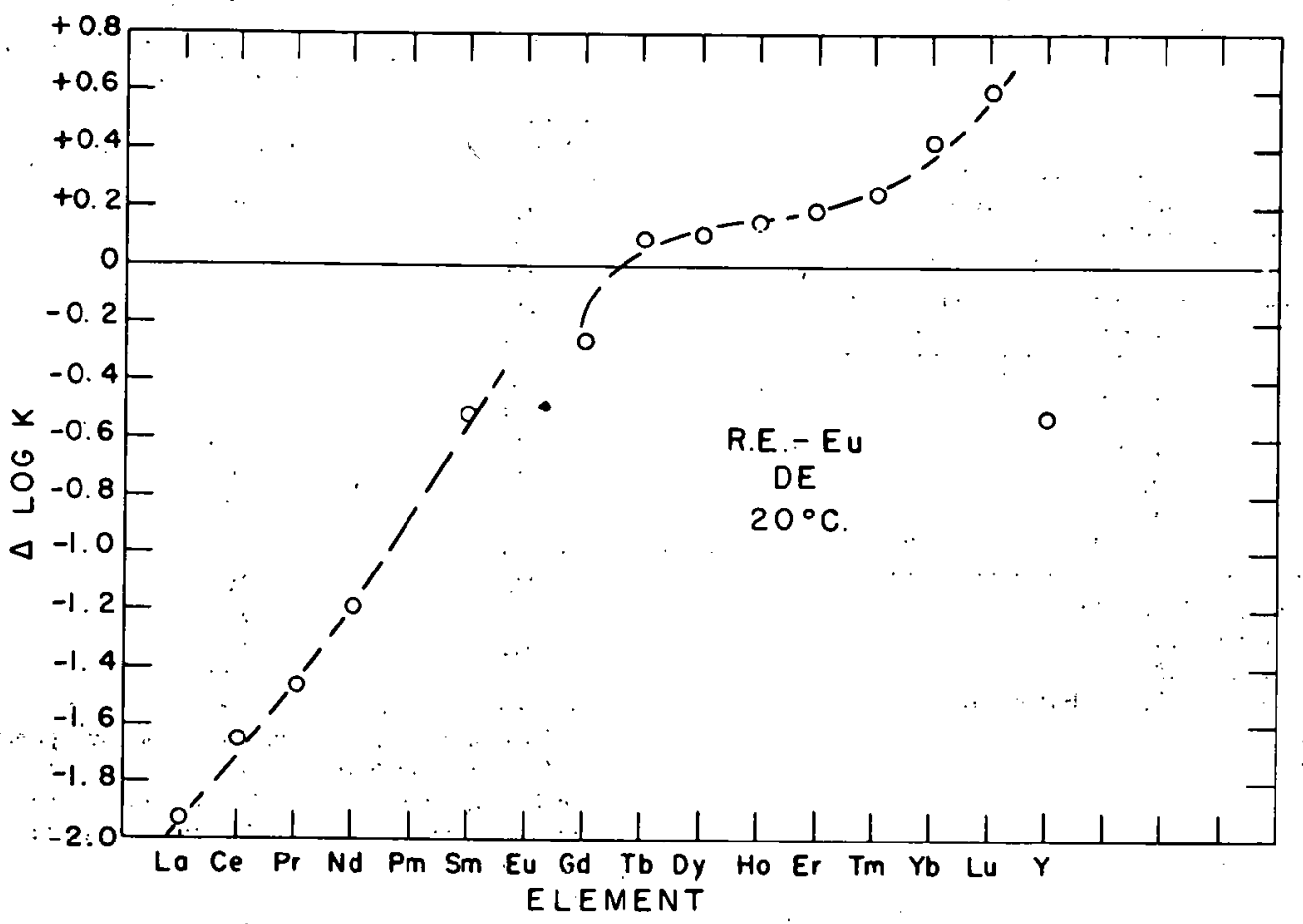

Fig. 33- Rare-earth-DE-stability constants at $20.00 \pm 0.02^{\circ} \mathrm{C}$., based on europium.

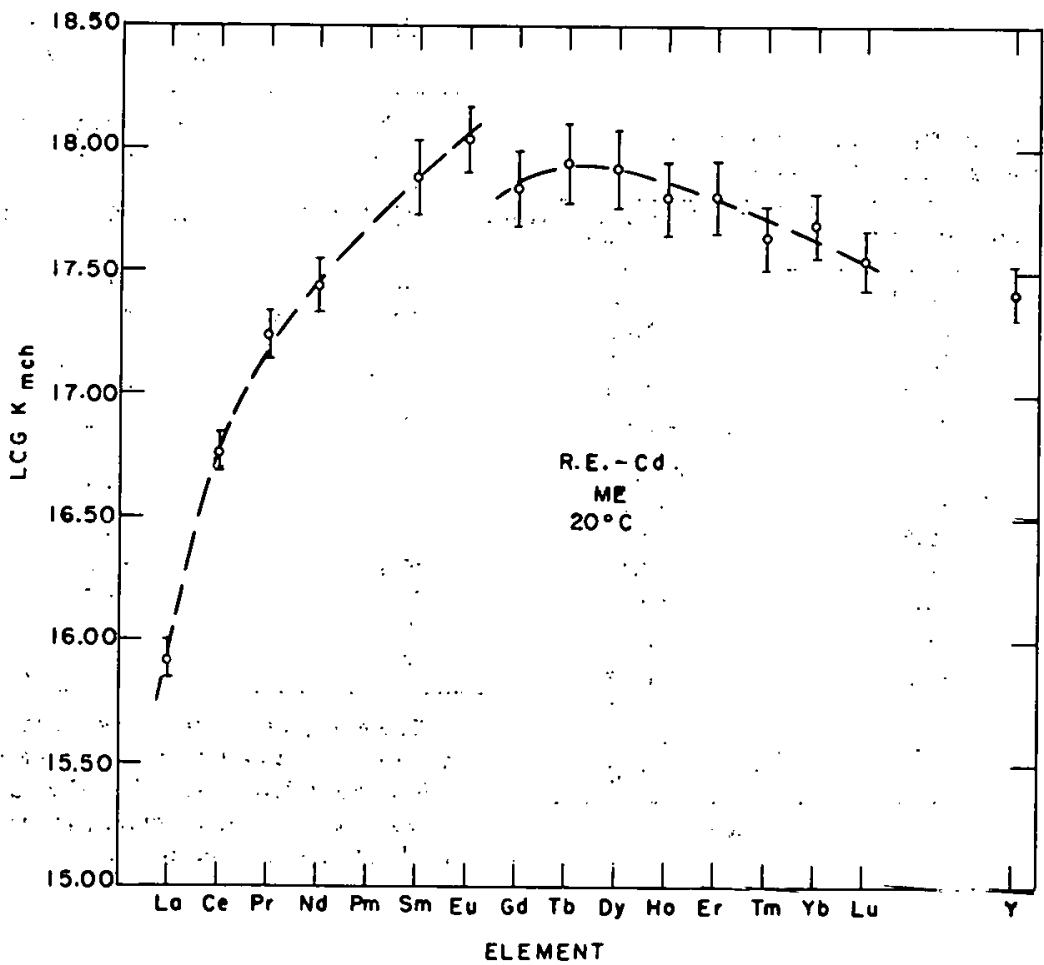

Fig. 34-Rare-earth-ME stability constants at $20.00 \pm 0.02^{\circ} \mathrm{C}$, , based on cadmium, and showing the uncertainty range. 
Table 19-Europium-Chelate Stability Constants Used in Calculating the Scandium-Chelate Constants

\begin{tabular}{lcc}
$\begin{array}{c}\text { Chelating } \\
\text { agent }\end{array}$ & $\begin{array}{c}\text { Europium } \\
\text { constant }\end{array}$ & $\begin{array}{c}\text { Temperature } \\
{ }^{\circ} \mathrm{C} .\end{array}$ \\
\hline EDTA & $17.35^{\mathrm{a}}$ & 20 \\
HEDTA & $15.21^{\mathrm{b}}$ & 25 \\
DCTA & $18.62^{\mathrm{c}}$ & 20 \\
DETPA & $22.91^{\mathrm{d}}$ & 25 \\
DE & $17.80^{\mathrm{e}}$ & 20 \\
ME & $17.72^{\mathrm{e}}$ & 20 \\
\hline
\end{tabular}

${ }^{a}$ Reference 123 , p. 76.

${ }^{b}$ Reference 122.

'Reference 123, $\mathrm{n}$ 89.

u Unpublished data of Hardor aud Chidberek.

This research.
Table 20-Rare-earth-DE Stability Constants at $20.00 \pm 0.02^{\circ} \mathrm{C}$. vs. Cadmium

\begin{tabular}{ccc}
\hline Rare earth & \% Uncomplexed cadmium & Log $_{\text {MCh }}$ \\
\hline La & 27.1 & 15.87 \\
Ce & 32.5 & 16.09 \\
Pr & 35.2 & 16.20 \\
Nd & 46.8 & 16.62 \\
Sm & 65.4 & 17.28 \\
Eu $^{2}$ & & 17.80 \\
"Gd & 71.6 & 17.53 \\
Tb & 77.9 & 17.83 \\
Dy & 78.9 & 17.87 \\
Ho & 80.0 & 17.93 \\
Er & 81.8 & 18.03 \\
Tm & 80.8 & 17.99 \\
Yb & 85.3 & 18.25 \\
Lu & 88.6 & 18.51 \\
Y & 63.2 & 17.19 \\
\hline
\end{tabular}

"The eurnpium oould anl be méasured against cadmium since the half-wave potentials for europium and cadmium arr too cluse. 'l'he value given here was obtained by cumparing europium to neodymium, gadolinium, and dysprosium.

Table 22-Rare-earth- $\dot{\mathrm{ME}}$ Stability Constants at $20.00 \pm 0.02^{\circ} \mathrm{C}$. ve. Cadınium

Table 21-Rare-earth-DE Stability Constants at $80.00 \pm U .02^{\circ}$ C. vs. Europium

\begin{tabular}{ccc}
\hline Rare earth & \% Uncomplexed europium & Log $\mathrm{K}_{\mathrm{MCl}}$ \\
\hline $\mathrm{La}$ & 9.81 & -1.93 \\
$\mathrm{Ce}$ & 13.0 & $\cdots-1.05$ \\
$\mathrm{Pr}$ & 15.6 & -1.17 \\
$\mathrm{Nd}$ & 20.3 & -1.10 \\
$\mathrm{Sm}$ & 35.2 & -0.52 \\
$\mathrm{Eu}$ & & Standard \\
$\mathrm{Gd}$ & 42.3 & -0.27 \\
$\mathrm{~Tb}$ & 52.2 & +0.08 \\
$\mathrm{Dy}$ & 52.8 & +0.10 \\
$\mathrm{Ho}$ & 54.4 & +0.15 \\
$\mathrm{Er}$ & 55.4 & +0.19 \\
$\mathrm{Tm}$ & 57.0 & +0.25 \\
$\mathrm{Yb}$ & 61.0 & +0.42 \\
$\mathrm{Lu}$ & 67.2 & $+0 . \mathrm{fr}_{0}$ \\
$\mathrm{Y}$ & 35.1 & -0.53 \\
\hline
\end{tabular}

\begin{tabular}{lll} 
& \% Uncomplexed cadmium & T.gg $_{M C h}$ \\
\hline La & 40.2 & 15.99 \\
Ce & 83.8 & 16.76 \\
Pr & 75.3 & 17.24 \\
Nd & 79.3 & 17.44 \\
Sn & 86.4 & 17.88 \\
Eu ${ }^{a}$ & & 18.04 \\
Gd & & 17.84 \\
Tb & 85.9 & 17.94 \\
Dy & 87.2 & 17.92 \\
Ho & 87.0 & 17.80 \\
Er & 85.4 & 17.81 \\
Tm & 85.5 & 17.64 \\
Yb & 82.8 & 17.69 \\
Lu & 83.7 & 17.55 \\
Y & 81.4 & 17.42 \\
\hline
\end{tabular}

${ }^{a}$ Tlir: ruropium cuuld not be measured against cadmium since the half-wave potentials for europium and cadmium are too close. The value given here was ohtained by comparing europium against neodymium. gadolinium, and dysprosium. 


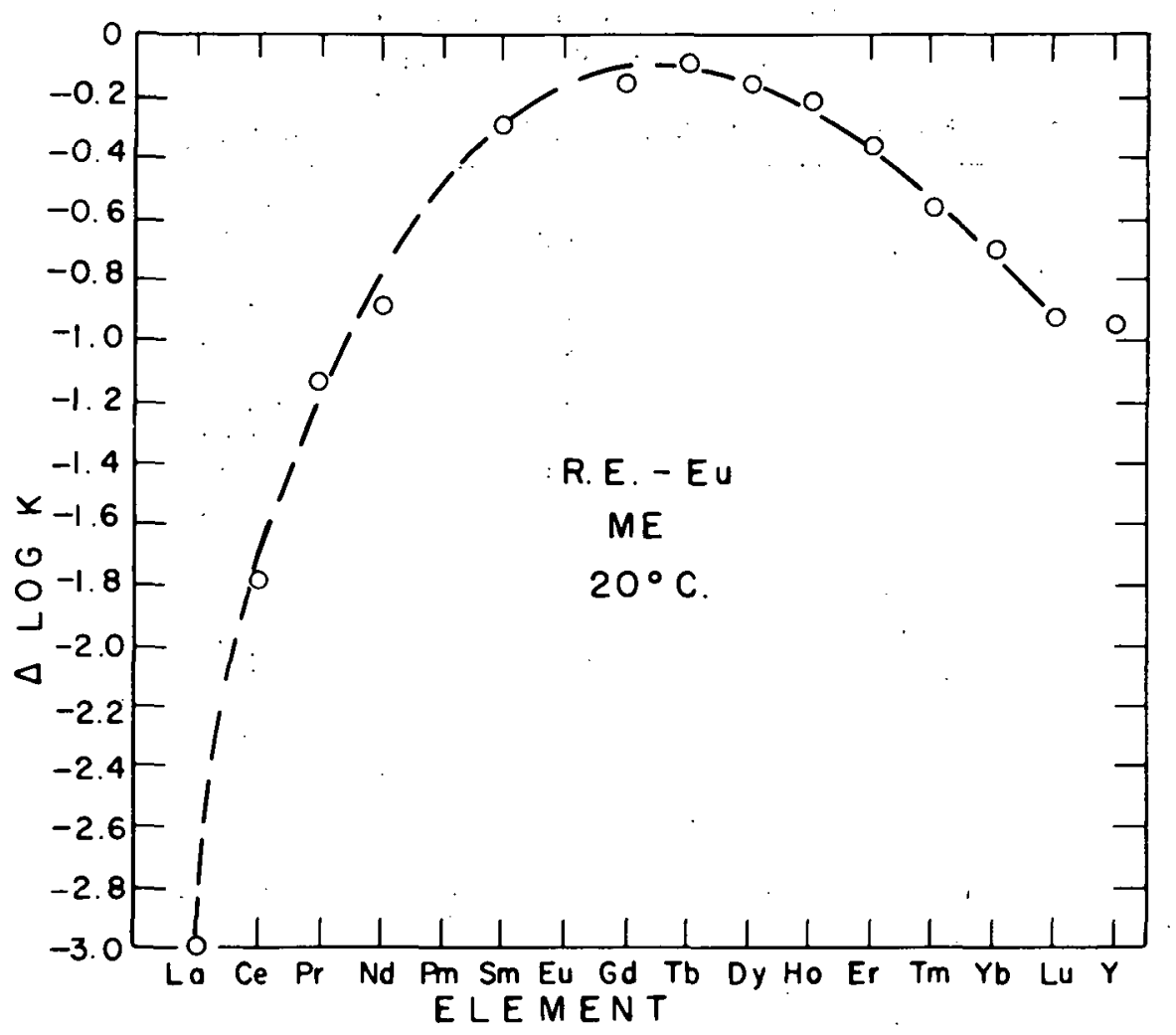

Fig. 35-Rare-earth-ME stability constants at $20.00 \pm 0.02^{\circ} \mathrm{C}$, , based on europium.

\section{Discussion}

The error made in the determination of the per cent uncomplexed metal ion amounts to about $\pm 2 \%$ and should be constant for all the determinations. The errors range from \pm 0.08 to \pm 0.17 lor the rare-earth DE and ME cases.

The determinations made with europium as a standard give an independent means of determining the absolute stability constants for the rare-earth $M E$ and $D E$ series if the europium constant is determined independently in the future.

Two values for the scandium-EDTA constant can be found in the literature. Schwarzenbach, liut and Anderegg (14y) give 23.1 and Schwarzenbach in another publication (152) gives 21.3. The discrepancy was not clarified by Schwarzenbach in reply to a letter from the author. The value obtained in this research supports the value of 21.3. In view of the results obtained by the author in separating lutetium and scandium (153), it would seem the value of 21.3 is more nearly correct since veller separations should have resulted if the value were 23.1.

In considering the mixtures used in determining the stability constants polarographically, it was seen that perhaps hydrogen metal chelate species and metal acetate complexes should be considered.

To facilitate the discussion and derivations, from here on, the equations will be numbered, a practice not deemcd necessary until now.

If we consider the reaction

$$
\mathrm{CdCh}^{-2}+\mathrm{R}^{+3} \rightleftharpoons \mathrm{RCh}^{-}+\mathrm{Cd}^{+2}
$$

which is the basic process being measured, an "exchange constant", $\mathrm{K}_{\mathrm{ex}}$, can be written,

$$
\mathrm{K}_{\mathrm{ex}}=\frac{\left[\mathrm{RCh}^{-}\right]\left[\mathrm{Cd}^{+2}\right]}{\left[\mathrm{CdCh}^{-2}\right]\left[\mathrm{R}^{+3}\right]}
$$


Table 23-Rare-earth-ME Stability Constants at $20.00 \pm 0.02^{\circ}$ C. vs. Europium

\begin{tabular}{lcc}
\hline Rare earth & \% Uncomplexed europium & Log $\mathrm{K}_{\mathrm{MCh}}$ \\
\hline $\mathrm{La}$ & 3.05 & -3.00 \\
$\mathrm{Ce}$ & 11.3 & -1.79 \\
$\mathrm{Pr}$ & 21.4 & -1.13 \\
$\mathrm{Nd}$ & 26.4 & -0.89 \\
$\mathrm{Sm}$ & 41.7 & -0.29 \\
$\mathrm{Gd}$ & 45.4 & -0.16 \\
$\mathrm{Eu}$ & & Standard \\
$\mathrm{Tb}$ & 46.9 & -0.11 \\
$\mathrm{Dy}$ & 45.5 & -0.16 \\
$\mathrm{Ho}$ & 43.8 & -0.22 \\
$\mathrm{Er}$ & 39.8 & -0.36 \\
Tm & 34.5 & $-\dot{0} .56$ \\
Yb & 31.0 & -0.70 \\
Lu & 25.7 & -0.92 \\
Y & 25.4 & -0.94 \\
& &
\end{tabular}

Taple 24 - Scandium-Chelate Stability Constants as Measured . Against Europium and Copper

\begin{tabular}{|c|c|c|c|c|c|}
\hline \multirow{2}{*}{$\begin{array}{l}\text { Chelating } \\
\text { agent }\end{array}$} & \multicolumn{2}{|c|}{$\begin{array}{l}\text { \% Uncomplexed } \\
\text { metal ion }\end{array}$} & \multirow{2}{*}{$\begin{array}{c}\text { Temperature } \\
\pm 0.02^{\circ} \mathrm{C} .\end{array}$} & \multicolumn{2}{|c|}{$\log \mathbf{K}_{\mathrm{ScCh}}$} \\
\hline & $\mathrm{Eu}$ & $\mathrm{Cu}$ & & From Eu & $\therefore$ From Cu \\
\hline EDTA & $\underline{\mathbf{a}}$ & 92.5 & 20 & ${ }^{\mathrm{a}}$ & $20.98+0.90$ \\
\hline HEDTA & 85.9 & 47.2 & 25 & $16.78 \pm 0.15$ & $17.30 \pm 0.07$ \\
\hline DCTA & $\underline{\mathbf{a}}$ & 90.0 & 20 & $\begin{array}{c}\mathrm{a} \\
\end{array}$ & $23.21 \pm 0.23$ \\
\hline DETPA & 84.5 & & 25 & $24.38 \pm 0.14$ & \\
\hline $\mathrm{DE}$ & $\therefore 90.6$ & & 20 & $19.80 \pm 0.23$ & \\
\hline$M D$ & 40.6 & & so & $10.13 \perp 0.07$ & \\
\hline
\end{tabular}

"The europium-chelate stability constants in these cases were so much smaller. than the scandium-chelate constants that it was impossible to obtain accurate , values of the scandium chelate stability constants by this route.

where $\mathrm{R}$ stands for rare earth.

Material balance equations which can be written are;

$$
\begin{aligned}
& \text { total chelate }=\mathrm{ChT}=\mathrm{RCh}^{-}+\mathrm{HRCh}+\mathrm{CdCh}^{-2}+\mathrm{HCdCh}^{-}+\mathrm{H}_{4} \mathrm{Ch}+\mathrm{H}_{3} \mathrm{Ch}^{-}+\mathrm{H}_{2} \mathrm{Ch}^{-2}+ \\
& \mathrm{HCh}^{-3}+\mathrm{Ch}^{-4}
\end{aligned}
$$

$$
\begin{aligned}
& \text { total rare earth }=\mathrm{R}_{\mathrm{T}}=\mathrm{R}^{+3}+\mathrm{RC}^{-}+\mathrm{HRCh}+\mathrm{RAc}^{+2}+\mathrm{RAC}_{2}^{+}+\mathrm{RAC}_{3} \\
& \text { total cadmium }=\mathrm{Cd}_{\mathrm{T}}=\mathrm{Cd}^{+2}+\mathrm{CdCh}^{-2}+\mathrm{HCdCh}^{-}+\mathrm{CdAc}^{+}+\mathrm{CdAc}_{3}+\mathrm{CdAc}_{3}^{-}
\end{aligned}
$$

and, since in the case of the research reported here, the cadmium, rare-earth, and chelate concentrations are equal;

$$
C d_{\mathrm{T}}=\mathrm{R}_{\mathrm{T}}=\mathrm{Ch}_{\mathrm{T}} .
$$


The equations and their accompanying ionization constants for the free-acid chelate species are:

$$
\begin{gathered}
\mathrm{H}_{4} \mathrm{Ch} \rightleftharpoons \mathrm{H}_{3} \mathrm{Ch}^{-}+\mathrm{H}^{+}, \quad \mathrm{K}_{1}=\frac{\left[\mathrm{H}_{3} \mathrm{Ch}^{-}\right]\left[\mathrm{H}^{+}\right]}{\left[\mathrm{H}_{4} \mathrm{Ch}\right]} \\
\mathrm{H}_{3} \mathrm{Ch}^{-} \rightleftharpoons \mathrm{H}_{2} \mathrm{Ch}^{-2}+\mathrm{H}^{+}, \quad \mathrm{K}_{2}=\frac{\left[\mathrm{H}_{2} \mathrm{Ch}^{-2}\right]\left[\mathrm{H}^{+}\right]}{\left[\mathrm{H}_{3} \mathrm{Ch}^{-}\right]} \\
\mathrm{H}_{2} \mathrm{Ch}^{-2} \rightleftharpoons \mathrm{HCh}^{-3}+\mathrm{H}^{+}, \quad \mathrm{K}_{3}=\frac{\left[\mathrm{HCh}^{-3}\right]\left[\mathrm{H}^{+}\right]}{\left[\mathrm{H}_{2} \mathrm{Ch}^{-2}\right]}
\end{gathered}
$$

and

$$
\mathrm{HCh}^{-3} \rightleftharpoons \mathrm{Ch}^{-4}+\mathrm{H}^{+}, \quad \mathrm{K}_{4}=\frac{\left[\mathrm{Ch}^{-4}\right]\left[\mathrm{H}^{+}\right]}{\left[\mathrm{HCh}^{-3}\right]}
$$

where, for the EDTA case, $\bar{K}_{1}=10^{-1.99}, K_{2}=10^{-2.67}, K_{3}=10^{-6.16}$, and $K_{4}=10^{-10.26}$ at $20^{\circ} \mathrm{C}$.

(118, p. 76).

By combination of Eqs. 7-10, one obtains

$$
\begin{aligned}
& {\left[\mathrm{H}_{4} \mathrm{Ch}\right]=\frac{\left[\mathrm{H}^{+}\right]^{4}\left[\mathrm{Ch}^{-4}\right]}{\mathrm{K}_{1} \mathrm{~K}_{2} \mathrm{~K}_{3} \mathrm{~K}_{4}}} \\
& {\left[\mathrm{H}_{3} \mathrm{Ch}^{-}\right]=\frac{\left[\mathrm{H}^{+}\right]^{3}\left[\mathrm{Ch}^{-4}\right]}{\mathrm{K}_{2} \mathrm{~K}_{3} \mathrm{~K}_{4}}} \\
& \therefore \\
& {\left[\mathrm{H}_{2} \mathrm{Ch}^{-2}\right]=\frac{\left[\mathrm{H}^{+}\right]^{2} \mathrm{Ch}^{-4}}{\mathrm{~K}_{3} \mathrm{~K}_{4}}}
\end{aligned}
$$

and

$$
\left[\mathrm{HCh}^{-3}\right]=\frac{\left[\mathrm{H}^{+}\right]\left[\mathrm{Ch}^{-4}\right]}{\mathrm{K}_{4}}
$$

In addition, several other formation constants are needed; these are

$$
\begin{gathered}
\mathrm{R}^{+3}+\mathrm{Ch}^{-4}=\mathrm{RCh}^{-}, \quad \mathrm{K}_{\mathrm{RCh}^{-}}=\frac{\left[\mathrm{RCh}^{-}\right]}{\left[\mathrm{R}^{+3}\right]\left[\mathrm{Ch}^{-4}\right]} \\
\mathrm{RCh}^{-}+\mathrm{H}^{+} \rightleftharpoons \mathrm{HRCh}, \quad \mathrm{K}_{\mathrm{HRCh}}=\frac{\left[\mathrm{HRCh}^{-}\right.}{\left[\mathrm{RCh}^{-}\right]\left[\mathrm{H}^{+}\right]} \\
\mathrm{Cd}^{+2}+\mathrm{Ch}^{-4} \rightleftharpoons \mathrm{CdCh}^{-2}, \quad \mathrm{~K}_{\mathrm{CdCh}}=\frac{\left[\mathrm{CdCh}^{-2}\right]}{\left[\mathrm{Cd}^{+2}\right]\left[\mathrm{Ch}^{-4}\right]}
\end{gathered}
$$

and

$$
\mathrm{CdCh}^{-2}+\mathrm{H}^{+} \rightleftharpoons \mathrm{HCdCh}^{-}, \quad \mathrm{K}_{\mathrm{HCdCh}^{-}}=\frac{\left[\mathrm{HCdCh}^{-}\right]}{\left[\mathrm{ChCh}^{-2}\right]\left[\mathrm{H}^{+}\right]}
$$

By solving Eq. 15 for $\left[\mathrm{RCh}^{-}\right]$, Eq. 16 for [HRCh], Eq. 17 for $\left[\mathrm{CdCh}^{-2}\right]$, Eq. 18 for $\left[\mathrm{HCdCh}^{-}\right]$, and substituting these in Eq. 3 along with the values of $\left[\mathrm{H}_{4} \mathrm{Ch}\right],\left[\mathrm{H}_{3} \mathrm{Ch}^{-}\right],\left[\mathrm{H}_{2} \mathrm{Ch}^{-2}\right]$, and $\left[\mathrm{HCh}^{-3}\right]$ from Eqs. 11-14, respectively, one obtains 


$$
\begin{aligned}
& \mathrm{Ch}_{\mathrm{T}}=\mathrm{K}_{\mathrm{RCh}}{ }^{-}\left[\mathrm{R}^{+3}\right]+\mathrm{K}_{\mathrm{HRCh}} \mathrm{K}_{\mathrm{RCh}^{-}}\left[\mathrm{H}^{+}\right]\left[\mathrm{R}^{+3}\right]+\mathrm{K}_{\mathrm{CdCh}^{-2}} \cdot\left[\mathrm{Cd}^{+2}\right]
\end{aligned}
$$

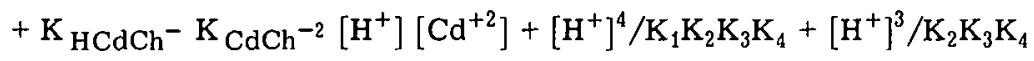

$$
\begin{aligned}
& +\left[\mathrm{H}^{+}\right]^{2} / \mathrm{K}_{3} \mathrm{~K}_{4}+\left[\mathrm{H}^{+}\right] / \mathrm{K}_{4}+1\left[\mathrm{Ch}^{-4}\right]
\end{aligned}
$$

The $\mathrm{H}_{2} \mathrm{CdCh}$ species was neglected since at the $\mathrm{pH}$ of the buffer (4.65) the $\mathrm{HCdCh}^{-}$or $\mathrm{CdCh}^{-2}$ would be expected to be predominant.

We can make some substitutions in Eq. 19 for the EDTA case which will show the hydrogen-metal-chelate species to be unimportant compared to the $\mathrm{RCh}^{-}$and $\mathrm{CdCh}^{-2}$ species.

If we use the average value of $10^{16}$ for $\mathrm{K}_{\mathrm{RCh}}{ }^{-}$and $10^{16.5}$ for $\mathrm{CdCh}^{-2}$ as given by Bjerrum, Schwarzenbach, and Sillén (123, p. 76), $10^{2}$ for $\mathrm{K}_{\mathrm{HRCh}}$ according to Hagiwara (154), and $10^{2.5}$ for $\mathrm{K}_{\mathrm{HCdCh}}{ }^{-}$as given by Powell, Fritz, and James (155), then at a pH of 4.5 the $\left[\mathrm{H}^{+}\right]$is $10^{-4.5}$ and at $50 \%$ complexing $\left[\mathrm{Cd}^{+2}\right]$ is $10^{-3.3}$ and $\left[\mathrm{R}^{+3}\right]$ is $10^{-3.3}$. Substituting these values into Eq. 19 shows that all terms except those relating to the $\mathrm{RCh}^{-}$and $\mathrm{CdCh}^{-2}$ species are negligible in the case of EDTA at a pH of 4.5.

Likcwice, one can write

$$
\begin{aligned}
\mathrm{R}^{+3}+\mathrm{Ac}^{-} & \rightleftharpoons \mathrm{RAc}^{+2}, \quad \mathrm{~K}_{\mathrm{a}}=\frac{\left[\mathrm{RAc}^{+2}\right]}{\left[\mathrm{R}^{+3}\right]\left[\mathrm{Ac}^{-}\right]} \\
\mathrm{RAc}^{+2}+\mathrm{Ac}^{-} & \rightleftharpoons \mathrm{RAC}_{2}^{+}, \quad \mathrm{K}_{\mathrm{b}}=\frac{\left[\mathrm{RAc}_{2}^{+}\right]}{\left[\mathrm{RAc}^{+2}\right]\left[\mathrm{Ac}^{-}\right]}
\end{aligned}
$$

and

$$
\mathrm{RAc}_{2}^{+}+\mathrm{Ac}^{-} \rightleftharpoons \mathrm{RAC}_{3}, \quad \mathrm{~K}_{\mathrm{c}}=\frac{\left[\mathrm{RAc}_{3}\right]}{\left[\mathrm{RAc}_{2}^{+}\right]\left[\mathrm{Ac}^{-}\right]}
$$

for the rare-earth species and

$$
\begin{aligned}
\mathrm{Cd}^{+2}+\mathrm{Ac}^{-} \rightleftharpoons \mathrm{CdAc}^{+}, & \mathrm{K}_{\mathrm{d}}=\frac{\left[\mathrm{CdAc}^{+}\right]}{\left[\mathrm{Cd}^{+2}\right]\left[\mathrm{Ac}^{-}\right]} \\
\mathrm{CdAc}^{+}+\mathrm{Ac}^{-} \rightleftharpoons \mathrm{CdAc}_{2}, & \mathrm{~K}_{\mathrm{e}}=\frac{\left[\mathrm{CdAc}_{2}\right]}{\left[\mathrm{CdAc}^{+}\right]\left[\mathrm{Ac}^{-}\right]}
\end{aligned}
$$

and

$$
\mathrm{CdAC}_{2}+\mathrm{Ar}^{-}=\mathrm{CdAc}_{3}^{-}, \quad \mathrm{K}_{\mathrm{f}}=\frac{\left[\mathrm{CdAc}_{3}^{-}\right]}{\left[\mathrm{CAAC}_{2}\right]\left[\mathrm{Ac}^{-}\right]}
$$

for the cadmium species.

Combination of Eqs. $20-25$ with Eqs. 4 and 5 give

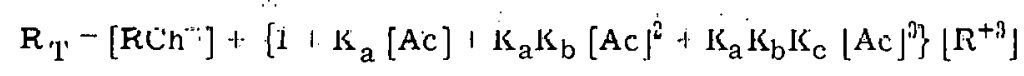

and

$$
\mathrm{Cd}_{\mathrm{T}}=\left[\mathrm{CdCh}^{-2}\right]+\left\{1+\mathrm{K}_{\mathrm{d}}[\mathrm{Ac}]+\mathrm{K}_{\mathrm{d}} \mathrm{K}_{\mathrm{e}}[\mathrm{Ac}]^{2}+\mathrm{K}_{\mathrm{d}} \mathrm{K}_{\mathrm{e}} \mathrm{K}_{\mathrm{f}}[\mathrm{Ac}]^{3}\right\}\left[\mathrm{R}^{+3}\right]
$$

Now from Eqs. 26 and 27,

$$
\left[\mathrm{R}^{+3}\right]=\frac{\mathrm{R}_{\mathrm{T}}-\left[\mathrm{RCh}^{-}\right]}{\mathrm{F}(\mathrm{Ac})}
$$


and

$$
\left[\mathrm{Cd}^{+2}\right]=\frac{\mathrm{Cd}_{\mathrm{T}}-\left[\mathrm{CdCh}^{-2}\right]}{\cdot \mathrm{f}(\mathrm{Ac})}
$$

where $F(A c)$ and $f(A c)$ are functions of the acetate concentration as expressed by the bracketed terms in Eqs. 26 and 27.

Substitution of Eqs. 28 and 29 in Eq. 2 then gives

$$
\mathrm{K}_{\mathrm{ex}}=\frac{\mathrm{K}_{\mathrm{RCh}^{-}}}{\mathrm{K}_{\mathrm{CdCh}^{-2}}}=\frac{\left[\mathrm{RCh}^{-}\right]\left[\mathrm{Cd}_{\mathrm{T}}-\mathrm{CdCh}^{-2}\right] \mathrm{F}(\mathrm{Ac})}{\left[\mathrm{CdCh}^{-2}\right]\left[\mathrm{R}_{\mathrm{T}}-\mathrm{RCh}^{-}\right] \mathrm{f}(\mathrm{Ac})}
$$

In the mixtures which were used in this research, Eq. 19 was shown to reduce to

$$
\mathrm{Ch}_{\mathrm{T}}=\left[\mathrm{RCh}^{-}\right]^{\prime}+\left[\mathrm{CdCh}^{-2}\right]
$$

Then, by virtue of Eq. 6,

$$
\left[\mathrm{RCh}^{-}\right]=\mathrm{Ch}_{\mathrm{T}}-\left[\mathrm{CdCh}^{-2}\right]=\mathrm{R}_{\mathrm{T}}-\left[\mathrm{CdCh}^{-2}\right]=\mathrm{Cd}_{\mathrm{T}}-\left[\mathrm{CdCh}^{-2}\right]
$$

Thus Eq. 30 can be further revised to give

$$
\mathrm{K}_{\mathrm{ex}}=\frac{\left[\mathrm{Ch}_{\mathrm{T}}-\mathrm{CdCh}^{-2}\right]^{2} \mathrm{~F}(\mathrm{Ac})}{\left[\mathrm{CdCh}{ }^{-2}\right]^{2} \mathrm{f}(\mathrm{Ac})}
$$

The $F(A c)$ and $f(A c)$ effectively cancel for the case of rare earth vs. europium, copper or cadmium sincc $\mathrm{K}_{\mathrm{a}} \approx \mathrm{K}_{\mathrm{d}}, \mathrm{K}_{\mathrm{b}} \approx \mathrm{K}_{\mathrm{e}}$, and $\mathrm{K}_{\mathrm{c}} \approx \mathrm{K}_{\mathrm{f}}(123, \mathrm{p}, 3)$. This leaves an expression for $\mathrm{K}_{\mathrm{ex}}$ which is identical with the original constant that was to be measured polarographically (Eq. 2).

The acetate and hydrogen-chelate stability constants should be determined in the future at an ionic strength of 0.1 to make sure that the above assumptions are valid for chelating agents other than EDTA. The polarograms obtained with the lighter rare earths in the case of both ME and DE showed a small wave which was attributed to the presence of a small concentration of hydrogen metal chelate species (HCdCh or HEuCh). No correction was made for this since the values of $\mathrm{K}_{\mathrm{HCdCh}}$ and $\mathrm{K}_{\mathrm{HEuCh}}$ were not known for the case of ME and DE.

\section{LITERATURE CITED}

1. Debye, P. and Hückel, E., Physik. Z., 24, 185(1923).

2. Spedding, F. H., Porter, P. E., and Wright, J. M., J. Am. Chem. Soc., 74, 2055(1952).

3.

4. $\longrightarrow$, and $\longrightarrow$ J. Am. Chem. Soc., $\overline{74}, 2781(1952)$.

5. and Yaffe, I. S., J. Am. Chem. Soc., 74, 4 $\overline{75} 1(1952)$.

6. and Dye, J. L., J. Am. Chem. Soc., 76, 879(1954).

7. and Jaffe, S., J. Am. Chem. Soc., 76, 882(1954).

8. and , J. Am. Chem. Soc., 76, 884(1954).

9. Heiser, D. J., "A Study of Thermodynamic Properties of Electrolytic Solutions of Rare Earths", Unpublished Ph.D. Thesis, Iowa State College Library, Ames, Iowa (1958).

10. Saeger, V. W., Ames, Iowa. Measurement of conductivities of concentrated rare earth solutions. Private communication (1959).

11. Ayers, B. O., "Apparent and Partial Molal Volumes of Some Rare-Earth Salts in Aqueous Solution", Unpublished Ph.D. Thesis, Iowa State College Library, Ames, Iowa (1954).

12. Atkinson, G., "Compressibilities of Some Rare-Earth Nitrates and Chlorides in Aqueous Solution", Unpublished Ph.D. Thesis, Iowa State College Library, Ames, Iowa (1956).

13. Spedding, F. H. and Miller, C. F., J. Am. Chem. Soc., 74, 3158(1952).

11. and , J. Am. Chem. Soc, 74, 4195(1952). 
15.

16. and Flynn, J. P., J. Am. Chem. Soc., 76, 1474(1954).

and , J. Am. Chem. Soc., 76, 1477(1954).

17. Naumann, A. W., "Heats of Dilution and Related Thermodynamic Properties of Aqueous Neodymium Chloride and Erbium Chloride Solutions", Unpublished Ph.D. Thesis, Iowa State College Library, Ames, Iowa (1956).

18. Eberts, R. E., "Relative Apparent Molal Heat Contents of Some Rare-Earth Chlorides and Nitrates in Aqueous Solutions", Unpublished Ph.D. Thesis, Iowa State College Library, Ames, Iowa (1957).

19. Spedding, F. H., Powell, J. E., Daane, A. H., Hiller, M. A., and Adams, W. H., J. Electrochem. Soc., 105, 683(1958).

20. Arrhenius; S., Z. physik. Chem,, 1, 631(1887).

21. van't Hoff, J. H., Z. physik. Chem., 1, 481(1887).

22. Van Laar, J. J., Z. physik. Chem., $18,245(1895)$.

23. Noyes, A. A., Congress Arts Sci., 4, 311(1904).

24. Sutherland, W., Phil. Mag., Ser. 6, 14, 1(1907).

25. Hertz, P., Ann. Physik, 4, 37, 1(1917).

26. Ghosh, I. C., J. Chem. Soc., 113, 449, 627, 707, 790(1918).

27. Milner, S. R., Phil. Mag., Ser. 6, 23, 551(1912); ibid., Sor, 6, 35, 742(1310).

28. Bjerrum, N., Seventh Int. Cong. Pure and Applied Chen. Proc., 1909, Pt. 6, Sec. 10, 58.

29. Kramers, H. A., Proc. Sect. Sci. Amsterdam, 30, 145(1927).

30. Fowler, R. H., Trans. Faraday Soc., 23, 434(1927).

31. and Guggenheim, E. A., "Statistical Thermodynamics", The University Press, Cambridge, England (1952).

32. Onsager, L., Physik. Z., 28, 277(1927); Chem. Rev., 13, 73(1933).

33. Kirkwood, J. G., J. Chem. Phys., 2, 767(1934).

34. Halpern, O., J. Chem. Phys., 2, $8 \overline{5}(1934)$.

35. Glasstone, S., "Textbook of Physical Chemistry", D. Van Nostrand Co., Inc., New York (1940).

36. Harned, H. S. and Owen, B. B., "The Physical Chemistry of Electrolytic Solutions", Reinhold Publishing Corporation, New York (1958).

37. Onsager, L., Physik. Z., 28, 277(1927).

38. Davies, C. W., "The Conductivities of Solutions", Chapman and Hall, London (1930).

39. Reilly, J., Rae, W. N., and Wheeler, T. S., "Physico-Chemical Methods", D. Van Nostrand, New York (1925).

40. Glasstone, S,. "Introdurtion tn F.lęstrochomistry", D. Van Nús(d'dul, New Ynrk (1942).

41. Kuhlrausch, F'. and Nippoldt, W. A., Ann. Physik, 138, 280(1869); ibid., 138, 370(1869).

42. Horsford, E. N., Ann. Physik, 70, 238(1847).

43. Wiedemann, G., Ann. Physik, 99, 177(1856).

44. Schmidt, W., Ann. Physik, 107, 539(1859).

45. Kohlrausch, F., Ann. Physik, 49, 225(1893).

46. , Pogg. Ann., 148, 143(1873).

47. , Ann. Physik, 56, 182(1805).

48. - Ann. Physik, 58, 514(1896); ibid., 60, 315(1897).

49. Koh!rausch, F. and Holborn, L., "Leitvermögen der Electrolyte", Teubner, Leipzig (1898).

50.

61. and Gı uliall, O., Ann. Phỹs 1k, 154, 1(1875); ibid., 154, 215(1875).

52. Washburn, E. W, and Bell, .J. F., J. Am. Chem. Soc., 35, 177(1913).

53. ,J. Am. Chem. Soc., 38, 2431(1916); ibid., 39, 235(1917).

54. Taylor, W. A. and Acree, S. F., J. Am. Chem. Soc., 38, 2396(1916).

55. Hall, R. E. and Adams, L. H., J. Am. Chem. Soc., 41, 1515(1919).

56. Jones, G. and Josephs, R. C., J. Am. Chem. Soc., 50, 1049(1928).

57. and Bollinger, G. M., J. Am. Chcm. Soc., 51, 2407(1929).

58. and

59. and , J. Am. Chem. Soc., 53, 1207(1931); ibid., 53, 411(1931).

60 . Shedlovsky, T.,

61. J. J. Am. Chem. Soc., 54, 1411(1932). 
62. Jones, G. and Christian, S. M., J. Am. Chem. Soc., 57, 272(1935).

63. Dike, P. H., Rev. Sci. Instruments, 2, 379(1931).

64. Washburn, E. W. and Parker, K., J. Am. Chem. Soc., 39, 235(1917).

65. Parker, H. C. and Parker, E. W., J. Am. Chem. Soc., $\overline{46}, 312(1924)$.

66. Jones, G. and Bradshaw, B. C., J. Am. Chem. Soc., 55, 1780(1933).

67. and Prendergast, M. J., J. Am. Chem. Soc., $\overline{59}, 731(1937)$ :

68. Parker, H. C., J. Am. Chem. Soc., 45, 1366(1923); ibid., 45, 2017(1923).

69. Shedlovsky, T., J. Am. Chem. Soc., 52, 1806(1930).

70. Spedding, F..H., Powell, J. E., Daane, A. H., Hiller, M. A., and Adams, W. H., J. Electrochem. Soc., 105, No. 11, 683(1958).

71. Fischer, W. and Bock, R., Z. anorg. Chem., 249, 146(1942).

72. Powell, J. E. and Hiller, M. A., J. Inorg. and Nucl. Chem., 9 , 100(1959).

73. and Hiller; M. A., J. Chem. Ed., 34, 330(1957).

74. Pinching, G. D. and Bates, R. G., J. Research, Natl. Bur. Standards, 37, 311(1946).

75. Lange, N. A., "Handbook of Chemistry", 7th ed., Handbook Publishers, Inc., Sandusky, Ohio (1949).

76. Robinson, R. A. and Stokes; R. H., "Electrolyte Solutions", Academic Press, New York (1955).

77. Jones, J. H., J. Am. Chem. Soc., 67, 855(1945).

78. Dye, J. L., "Conductances, Transference Numbers, and Activity Coefficients of Some Rare Earth Chlorides in Aqueous Solution", Unpublished Ph.D. Thesis, Iowa State College Library, Ames, Iowa (1953).

79. MacInnes, D. A., Shedlovsky, T., and Longsworth, L. G., J. Am. Chem. Soc., 54, 2758 (1932).

80. Bodlander, E., Dissertation, Berlin (1915) (Original not available for examination, reported in Int. Crit. Tables, $\underline{6}, 233(1929)$.

81. Shedlovsky, T., J. Am. Chem. Soc., 54, 1405(1932).

82. Kilpatrick, M. and Pokras, L., J. Electrochem. Suc., 100, 85(1953); J. Electrochem. Soc., 101, 39(1954).

83. Biedermann, G., Kilpatrick, M., Pokras, L., and Sillén, L. G., Acta Chem. Scand., 10, 1327(1.956).

84. Jaffe, S., "Conductances and Transference Numbers of Some Rare Earth Perchlorates, Sulfates and Nitrates in Aqueous Solution", Unpublished Ph.D. Thesis, Iowa State College Library, Ames, Iowa (1953).

85. Bauer, N., "Determination of Density", In Weissberger, A., ed. "Physical Methods of Organic Chemistry”, 2nd ed., Vol. I, p. 263, Interscience Publishers, Inc., New York (1949).

86. Washburn, E. W., "Principles of Physical Chemistry", McGraw-Hill Book Co., New York (1921).

87. Miller, W. L., Z. physik. Chem., 69, 436(1909).

88. Dunlell, J. F., Phil. Trans., 12y, 乌்(183y); ibid., 130, 209(1840).

89. Hittorf, W., Pogg. Annal:, 89, 117(1853); ibid., 98, 1(1856); ibid., 103, 1(1858); ibid., 106,

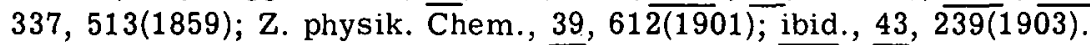

90. Noyes, A. A. and Falk, K. G., J. Am. Chem. Soc., 33, $1436(1911)$.

91. Jones, G. and Dole, M., J. Am. Chem. Soc., 51, 1073(1929).

92. and Bradshaw; B. C., J. Am. Chem. Soc., 54, 138(1932).

93. MacInnes, D. A. and Dole, M., J. Am. Chem. Soc., 53, 1357(1931).

01. and Farker, K,, J. Am. Chem. Süc., 37, 1445(1915).

95. . and Beattie, J. A., J. Am. Chem. Soc., 42, 1117(1920).

96. Hammer, W. J., J. Am. Chem. Soo., 57, 662(1025).

97. Jones, G. and Dole, M., J. Am. Chem. Soc., 51, 1073(1929).

98. Lodge, O., Brit. Assn. Advancement Sci. ,Rep.,1886, 389.

99. Whetham, W. C. D., Phil. Trans., 184A, 337(1893); Z.: physik. Chem., 11, 220(1893).

100. Steele, B. D., J. Chem: Soc., 79, $4 \overline{14(1901)}$; Phil: Trans., 198A, 105(1902).

101. Denison, R. B. and Steele, B. D., Phil. Trans., 205A, 449(1906).

102. MacInnes, D. A. and Smith, E. R., J. Am. Chem. Soc., 45, 2246(1923). 
103. and Brighton, T. B., J. Am. Chem. Soc., 47, 994(1925).

104. Franklin, E. C. and Cady, H. P., J. Am. Chem. Soc., 26, 499(1904).

105. Longsworth, L. G., J. Am. Chem. Soc., 54, 2741(1932).

106. Cady, H. P. and Longsworth, L. G., J. Am. Chem. Soc., 51, 1656(1929).

107. Kohlrausch, F., Ann. Physik, 62, 209(1897).

108. Lewis, G. N., J. Am. Chem. Soc., 32, 862(1910).

109. Smith, E. R., J. Research Natl. Bur. Standards, 8, 457(1932).

110. Macinnes, D. A. and Longsworth, L. G., Chem. Rev., 11, 171(1932).

111. LeRoy, D. J. and Gordon, A. R., J. Chem. Phys., 6, 398(1938); ibid., 7, 314(1939).

112. Hartley, G. S. and Donaldson, G. W., Trans. Faraday Soc., $33, \overline{457}(1 \overline{3} \overline{7})$.

113. MacInnes, D. A., Ann. New York Acad. Sci., $\underline{43}$, 243(1942).

114. Scatchard, G. and Prentiss, S. S., J. Am. Chem. Soc., 55, 4355(1933).

115. Longsworth, L. G. and MacInnes, D. A., J. Am. Chem. Soc., 60, 3070(1938).

116. Moss, F. A. J., "Observations on the Rare Earths: Some Studies on Ethylenediaminetetraacetic Acid Complexes", Unpublished Ph.D. Thesis, University of Illinois Library, Urbana, Illinois (1952).

117. Pokras, L., "The Chemistry of Scandium", Unpublished Ph.D. Thesis, Ill. Inst. of Technology Library, Chicago, lllinois (1ybz).

118. Spedding, F. H. and Powell, J. E., Chem. Engr. Prog. Symposium Ser., 50, No. 14 (1954). 119. and , "Basic Principles Involved in the Macro-Separation of Adjacent Rare E'arths from E'ach Uther by means of lon Exchange", U. S. Atomic Enèrgi C'ómmission Report, ISC-857 [Iowa State College] (1959).

120. , and Wheelwright, E. J., J. Am. Chem. Soc., 76, 2557(1954).

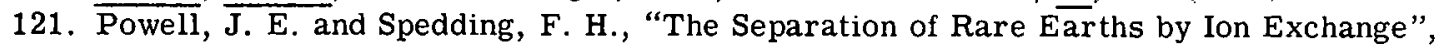
U. S. Atomic Energy Commission Report ISC-981 [Iowa State College] (1959).

122. Wheelwright, E. J., "The Use of Chelating Agents in the Separation of the Rare Earth Elements by Ion-Exchange Methods", Unpublished Ph.D. Thesis, Iowa State College Library, Ames, Iowa (1955).

123. Bjerrum, J., Schwarzenbach, G., and Sillén, L. G., "Stability Constants, Part 1: Organic Ligands", The Chemical Society, London (1957).

124. Hansen, R. D. and Chaberek, S., Abstr. of Papers, Am. Chem. Soc., 133, 35L(1958).

125. Schwarzenbach,.G., Willi, A., and Bach, R. O., Helv. Chim. Acta, 34, 576(1951).

126. and Ackerman, H., Helv. Chim. Acta, 30, 1798(1947).

127. Martell, A. E. and Calvin, M., "Chemistry of the Metal Chelate Compounds", PrenticeHall, Ncw York (1852).

128. Ackerman, H. and Schwarzenbach, G., Helv. Chim. Acta, 32, 1543(1949).

129. S̈chwarzenbach, G. and Freitag, E., Helv. Chim. Acta, 34, T492, 1503(1951).

130. and Heller, J., Helv. Chim. Acta, 34, 576(1951).

131. Carini, F. F. and Martell, A. E., J. Am. Chem. Soc., 75, 4810, 5745(1953); ibid., 76, 2153 (1954).

132. Kolthoff, I. M. and Auerbach, C., J. Am. Chem. Soc., 74, 1452(1952).

133. Martell, A. E. and Plumb, R. C., J. Phys. Chem., 56, 993(1952).

134. Plumb, R. C., Martell, A. E., and Bersworth, F. C., J. Phys. and Colloid Chem., 54, 1208 (1950).

135. Cook, C. M. and Long, R. A., J. Am. Chem. Soc. 73, 4119(1951).

136. Fronaeus, S., Acta Chem. Scand., 5, 859(1951); ibid., 6, 1200(1952); ibid., 7, 21, 46y(1953);

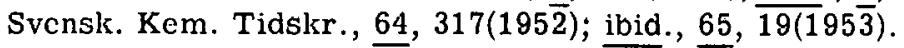

137. Money, R. M. and Davies, C. W., Trans. Faraday Soc., 28, 609(1932).

138. Rydberg, J. Acta Chem. Scand., ㄴ, 1503(1950); Arkiv Kemi, $\underline{8}, 101,113(1955)$; ibid., 9 , 81(1955); Svensk. Kem. Tidskr., 67, 499(1955).

139. Dyrssen, D., Svensk. Kem. Tidskr., 68, 212(1956).

140. and Eillén, L. G., Acta Chem. Ecand., 7, 663(1063).

141. Irving, H., Rossotti, F. J. C., and Williams, R. J. P., J. Chem. Soc., 1955, 1906.

142. Koryta, J. and Kössler, I., Coll. Czech. Chem. Comm., 15, 241(1950).

143. Matyska, B. and Kössler, I., Coll. Czech. Chem. Comm., 16, 221(1951).

144. Ackerman, H. and Schwarzenbach, G., Helv. Chim. Acta, $\overline{35}$, 485(1952). 
145. Blumer, M. and Kolthoff, I. M., Experimentia, $\underline{8}$, 138(1952).

146. Pecsok, R. L. and Maverick, E. F., J. Am. Chem. Soc., 76, 358(1954).

147. Bril, K. and Krumholz, P., J. Phys. Chem., 57, 874(1953).

148. Schwarzenbach, G. and Sandera, J., Helv. Chim. Acta, 36, 1089(1953).

149. , Gut, R. and Anderegg, G., Helv. Chim. Acta, 37, 937(1954).

150. - Senn, H. and Anderegg, G., Helv. Chim. Acta, 40, 1886(1957).

151. Ryskiewich, D. P., Unpublished data. (Original not available for examination; reported in the Geigy Chemical Co., Technical Bulletin, Chel 330, Geigy Chemical Co., Ardsley, New York. ca, 1957).

152. Schwarzenbach, G., Analyst, $80,713(1955)$.

153. Hiller, M. A., "Isolation and Purification of Scandium Oxide", Unpublished M.S. Thesis, Iowa State College Library, Ames, Iowa (1957).

154. Hagiwara, Z., Ames, Iowa. Data from titration studies. Private communication (1959).

155. Powell, J. E., Fritz, J. S., and James, D. B., "A Primary Standard for Alkalimetry and Chelometry", Submitted to Anal. Chem. to be published [ca, 1959]. 